\title{
ELETROCATÁLISE DA REAÇÃO DE REDUÇÃO DE OXIGÊNIO EM MEIO ÁCIDO EM LIGAS DE PLATINA DISPERSA EM CARBONO
}

\author{
Luís Gustavo Ribeiro de Amorim Santos
}

Tese apresentada ao Instituto de Química de São Carlos, da Universidade de São Paulo, para obtenção do título de Doutor em Ciências (em Físico-Química)

Orientador: Prof. Dr. Edson Antonio Ticianelli

São Carlos 


\section{DEDICATÓRIA}

Aos membros da minha família, José Luiz, Valdete Barbosa e Fábio L. Augusto, pelo apoio e incentivo em todas as etapas de minha vida e por me proporcionar uma formação sólida e de qualidade, fundamental para o meu desenvolvimento técnico e pessoal. 


\section{AGRADECIMENTOS}

Desejo registrar meus sinceros e profundos agradecimentos a todas as pessoas que contribuíram para possibilitar a realização desta obra e o engrandecimento da mesma.

Ao Prof. Dr. Edson A. Ticianelli inestimável orientador e professor, exemplo de conduta profissional e pessoal.

Ao Prof. Dr. Fábio H. B. Lima pelas valiosas discussões sobre RRO.

Aos técnicos do IQSC, Jonas, Valdecir, Janete, Maristela e Carlos Bento, ao do IFSC José Augusto e a todos os demais, que direta ou indiretamente colaboraram para o andamento deste trabalho.

Aos colegas de laboratório que com certeza contribuíram para a minha formação científica: Messias, Camilo, Janaína, Eduardo, Luciano, Daniela, Kênia, Márcia, Flávio Nikkei, Flávio Vargas, Roberto, Bruno, Robson, Felipe, Daniel Cantane.

Ao Instituto de Química de São Carlos - USP, pelo apoio institucional e as facilidades oferecidas.

Ao Laboratório Nacional de Luz Síncrotron, LNLS, pela utilização da linha de absorção de raios $\mathrm{X}$.

A FAPESP e ao CNPq pela bolsa concedida.

Ao suporte dado neste período de doutorado pelas amigas(os): Daiane, Rafaela Basso, Lidiane Andrade, Fabrizia, Priscila K., Fernado K. e João.

A todos que moraram comigo ao longo deste período, com destaque aos que passaram pela CCCPepui; Tarzan, Koxo e cia, especialmente aos crocodilospepui Nego Lee, Jaspion, Dan e Shunai, que contribuíram enormemente para que esta jornada fosse mais leve, divertida e marcante. Vida longa ao MarioKart! 


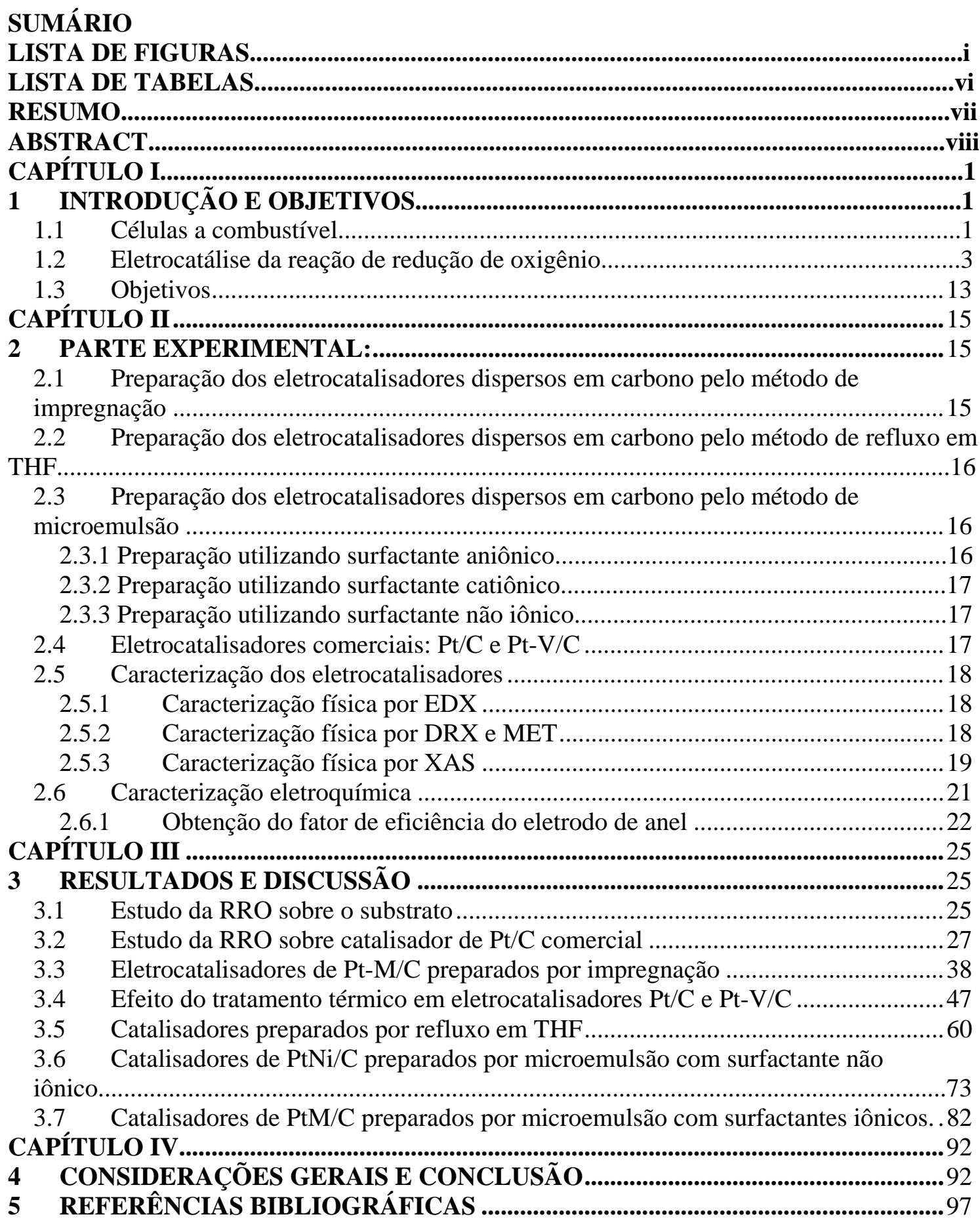





\section{LISTA DE FIGURAS}

Figura 1: Possíveis rotas reacionais para a RRO.....

Figura 2: Possíveis formas de adsorção da molécula de $\mathrm{O}_{2}$ (a) e possíveis rotas reacionais da reação de redução de oxigênio em meio ácido (b).

Figura 3: Voltamograma cíclico do $\mathrm{K}_{3} \mathrm{Fe}(\mathrm{CN})_{6} 10 \mathrm{mM}$ em $\mathrm{H}_{2} \mathrm{SO}_{4} \quad 0,5 \mathrm{M}$ saturado com $\mathrm{N}_{2}$. Velocidade de varredura de $50 \mathrm{mV} / \mathrm{s}$.

Figura 4: Varredura linear para o sistema $\mathrm{Fe}(\mathrm{CN})_{6}{ }^{3-} 10 \mathrm{mM}^{-} \mathrm{em}_{2} \mathrm{SO}_{4} 0,5 \mathrm{M}$, velocidade de varredura de $20 \mathrm{mV} / \mathrm{s}$. $E_{d}=1,55 \mathrm{~V}$. a) eletrodo de disco e b) eletrodo de anel.

Figura 5: Voltamograma cíclico para o eletrodo de carbono pirolítico e para o eletrodo de camada ultrafina de carbono Vulcan XC-72 em $\mathrm{H}_{2} \mathrm{SO}_{4}$ 0,5 M saturado com $\mathrm{N}_{2}$ em 50 $\mathrm{mV} / \mathrm{s}$.

Figura 6: Curvas de polarização de estado estacionário, obtidos ponto a ponto para a redução de $\mathrm{O}_{2}$ sobre diferentes substrato em $\mathrm{H}_{2} \mathrm{SO}_{4}$ 0,5 M a $1600 \mathrm{rpm}$. A) eletrodo de disco e B) eletrodo de anel.

Figura 7: Difratograma para Pt/C comercial (E-tek).

Figura 8: Espectro de XANES na borda $\mathrm{L}_{3}$ Pt para o eletrocatalisador de $\mathrm{Pt} / \mathrm{C}$ em diferentes potenciais do eletrodo (vs. ERH) em $\mathrm{H}_{2} \mathrm{SO}_{4} 0,5 \mathrm{~mol} \mathrm{~L}^{-1}$.

Figura 9: Voltamograma cíclico para o eletrodo de $\mathrm{Pt} / \mathrm{C} 20 \%$, em solução de $\mathrm{H}_{2} \mathrm{SO}_{4}$ 0,5 $\mathrm{M}$ saturado com $\mathrm{N}_{2}, \mathrm{v}=50 \mathrm{mV} / \mathrm{s}$.

Figura 10: Curva potenciodinâmica $\left(5 \mathrm{mV} / \mathrm{s}\right.$ ) para a $\mathrm{RRO}$ sob Pt/C em $\mathrm{H}_{2} \mathrm{SO}_{4} 0,5 \mathrm{M}, \omega=$ 3600rpm.

Figura 11: Curva de polarização de estado estacionário para a RRO sobre $\mathrm{Pt} / \mathrm{C}$ comercial em $\mathrm{H}_{2} \mathrm{SO}_{4}$ 0,5 M. (A) eletrodo de disco, (B) eletrodo de anel.

Figura 12: Gráfico de Koutecky-Levich para RRO em Pt/C 20\% comercial em 0,5 M $\mathrm{H}_{2} \mathrm{SO}_{4}$ em diferentes potenciais.

Figura 13: Diagrama de Tafel corrigido por transporte de massa para $\mathrm{Pt} / \mathrm{C} 20 \%$ Etek em $0,5 \mathrm{M} \mathrm{H}_{2} \mathrm{SO}_{4}, \omega=900 \mathrm{rpm}$.

Figura 14: Difração de raio-x da Pt e das ligas de Pt dispersas em carbono 
Figura 15: Curva de polarização de estado estacionário para a RRO sobre $\mathrm{PtV} / \mathrm{C}$ preparado por impregnação em $\mathrm{H}_{2} \mathrm{SO}_{4}$ 0,5 M. (A) eletrodo de disco, (B) eletrodo de anel.....40

Figura 16: Curva de polarização de estado estacionário para diferentes ligas $\mathrm{PtM} / \mathrm{C}$ preparado por impregnação frente à $\mathrm{RRO}$ em $\mathrm{H}_{2} \mathrm{SO}_{4}$ 0,5 M. (A) eletrodo de disco, (B) eletrodo de anel.

Figura 17: Diagramas de Tafel para diversos catalisadores preparados pelo método de impregnação.

Figura 18: Espectros Xanes a $600 \mathrm{mV}$ para diversos catalisadores preparados pelo método de impregnação.

Figura 19: Espectros Xanes a $900 \mathrm{mV}$ para diversos catalisadores preparados pelo

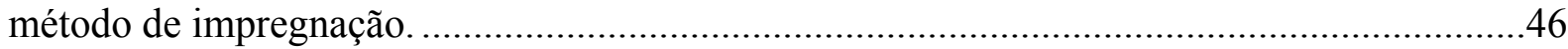

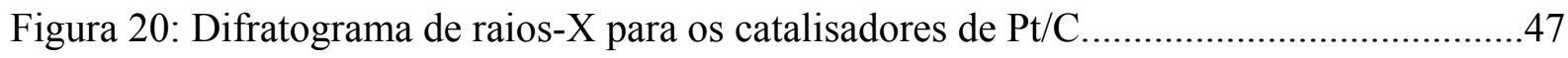

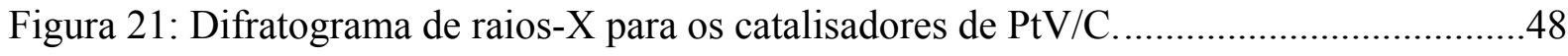

Figura 22: Espectro XANES em diferentes potenciais para $\mathrm{Pt} / \mathrm{C}$ (como recebido) ................50

Figura 23: Espectro XANES em diferentes potenciais para $\mathrm{Pt}-\mathrm{V} / \mathrm{C}$ (como recebido)............51

Figura 24: Espectro XANES a $650 \mathrm{mV}$ para Pt/C e Pt-V/C (como recebido). .......................51

Figura 25: Espectro XANES a $900 \mathrm{mV}$ para Pt/C e Pt-V/C (como recebido). .......................52

Figura 26: Espectro XANES para Pt/C a $900 \mathrm{mV}$ após os diversos tratamentos térmicos......52

Figura 27: Espectro XANES para PtV/C a $900 \mathrm{mV}$ após os diversos tratamentos

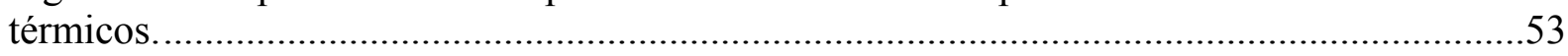

Figura 28: Voltamograma cíclico para $\mathrm{Pt} / \mathrm{C}$ tratados em diversas temperaturas de

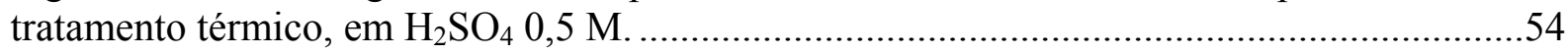

Figura 29: Voltamograma cíclico para Pt-V/C 500 (preto) e $800{ }^{\circ} \mathrm{C}$ (vermelho) em $\mathrm{H}_{2} \mathrm{SO}_{4}$ $0,5 \mathrm{M}$.......

Figura 30: Curva de polarização em estado estacionário para RRO em catalisadores de $\mathrm{Pt} / \mathrm{C}$ com diferentes temperaturas de tratamento térmico. $\mathrm{H}_{2} \mathrm{SO}_{4} 0,5$ mol. $\mathrm{L}^{-1}, \omega=900$ rpm. (a) disco e (b) anel. $\mathrm{E}_{\mathrm{a}}=1,2 \mathrm{~V}$. 
Figura 31: Curva de polarização em estado estacionário para RRO em catalisadores de $\mathrm{Pt}-\mathrm{V} / \mathrm{C}$ com diferentes temperaturas de tratamento térmico. $\mathrm{H}_{2} \mathrm{SO}_{4} 0,5$ mol.L $\mathrm{L}^{-1}, \omega=900$ rpm. (a) disco e (b) anel. $\mathrm{E}_{\mathrm{a}}=1,2 \mathrm{~V}$.

Figura 32: Diagramas de Tafel para RRO em diversos catalisadores de $\mathrm{Pt} / \mathrm{C}$ em $\mathrm{H}_{2} \mathrm{SO}_{4}$ $0,5 \mathrm{~mol} \cdot \mathrm{L}^{-1}$

Figura 33: Diagramas de Tafel para RRO em diversos catalisadores de $\mathrm{Pt}-\mathrm{V} / \mathrm{C} \mathrm{em} \mathrm{H}_{2} \mathrm{SO}_{4}$ 0,5 mol. $\mathrm{L}^{-1}$

Figura 34: Difratograma de raio-X para os catalisadores de $\mathrm{Pt} / \mathrm{C}$ comercial e $\mathrm{Pt} / \mathrm{C}$ preparado pelo método de refluxo em THF.

Figura 35: Imagem de HRTEM obtida para as nanopartículas de $\mathrm{Pt} / \mathrm{C}$ preparadas pelo método de refluxo em THF.

Figura 36: Espectro XANES para $\mathrm{Pt} / \mathrm{C}$ preparado por refluxo em THF em diversos potenciais e $\mathrm{Pt} / \mathrm{C}$ E-tek a $600 \mathrm{mV}$ em $\mathrm{H}_{2} \mathrm{SO}_{4}$ 0,5 M.

Figura 37: Voltametria cíclica para $\mathrm{Pt} / \mathrm{C}$ E-tek e Pt/C preparada por refluxo em $\mathrm{H}_{2} \mathrm{SO}_{4} 0,5$ $\mathrm{M}$

Figura 38: Curva de polarização de estado estacionário para a RRO em Pt/C E-tek e para $\mathrm{Pt} / \mathrm{C}$ preparada por refluxo em THF em $\mathrm{H}_{2} \mathrm{SO}_{4}$ 0,5 M. (A) eletrodo de disco, (B) eletrodo de anel. $\omega=900 \mathrm{rpm}$.

Figura 39: Diagramas de Tafel para RRO em catalisadores Pt/C E-tek e Pt/C preparados por refluxo; em $\mathrm{H}_{2} \mathrm{SO}_{4} 0,5$ mol. $\mathrm{L}^{-1}$.

Figura 40: Espectro Xanes para $\mathrm{Pt} / \mathrm{C}$ comercial e $\mathrm{Pt} / \mathrm{C}$ preparado pelo método de refluxo modificado (Pt/C A) a $900 \mathrm{mV}$ em $\mathrm{H}_{2} \mathrm{SO}_{4} 0,5 \mathrm{M}$.

Figura 41: Curva de polarização de estado estacionário para a RRO em Pt/C E-tek e para $\mathrm{Pt} / \mathrm{C}$ preparada por refluxo em THF em $\mathrm{H}_{2} \mathrm{SO}_{4}$ 0,5 M. (A) eletrodo de disco, (B) eletrodo de anel. $\omega=900 \mathrm{rpm}$.

Figura 42: Difratograma para os catalisadores $\mathrm{Pt} / \mathrm{C}, \mathrm{PtFe} / \mathrm{C}$ (PtFe A) e $\mathrm{PtFe} / \mathrm{C}$ preparado na presença de PVP (PtFe B).

Figura 43: Difratograma para os catalisadores $\mathrm{Pt} / \mathrm{C}, \mathrm{PtV} / \mathrm{C}(\mathrm{PtFe} \mathrm{A})$ e $\mathrm{PtV} / \mathrm{C}$ preparado na presença de PVP (PtV B).

Figura 44: Imagens de MET para $\mathrm{PtFe} / \mathrm{C}$ preparada por refluxo em $\mathrm{THF}$ sem a presença de PVP. 
Figura 45: Imagens de MET para $\mathrm{PtFe} / \mathrm{C}$ preparada por refluxo em $\mathrm{THF}$ com a presença de PVP.

Figura 46: Imagens de MET para PtV/C preparada por refluxo em THF sem a presença de PVP.

Figura 47: Imagens de MET para PtV/C preparada por refluxo em THF sem a presença de PVP.

Figura 48: Curva de polarização em estado estacionário para RRO em catalisadores de $\mathrm{PtFe} / \mathrm{C}$ em $\mathrm{H}_{2} \mathrm{SO}_{4}$ 0,5 mol.L ${ }^{-1}, \omega=900 \mathrm{rpm}$. (a) disco e (b) anel. $\mathrm{E}_{\mathrm{a}}=1,2 \mathrm{~V}$. PtFe $\mathrm{A}=$ sem PVP; PtFe B = com PVP.

Figura 49: Curva de polarização em estado estacionário para RRO em catalisadores de $\mathrm{PtFe} / \mathrm{C}$ em $\mathrm{H}_{2} \mathrm{SO}_{4}$ 0,5 mol.L ${ }^{-1}, \omega=900 \mathrm{rpm}$. (a) disco e (b) anel. $\mathrm{E}_{\mathrm{a}}=1,2 \mathrm{~V}$. PtV A = sem PVP; PtV B = com PVP.

Figura 50: Diagramas de Tafel para RRO em catalisadores $\mathrm{Pt} / \mathrm{C}$ E-tek, $\mathrm{PtFe} / \mathrm{C}$ e $\mathrm{PtV} / \mathrm{C}$ preparados por refluxo em THF na presença de PVP; em $\mathrm{H}_{2} \mathrm{SO}_{4} 0,5$ mol. $\mathrm{L}^{-1}$.

Figura 51: Espectro Xanes para $\mathrm{Pt} / \mathrm{C}$ E-tek, $\mathrm{PtFe} / \mathrm{C}$ e $\mathrm{PtV} / \mathrm{C}$, ambos preparados pelo método de refluxo em THF na presença de PVP, a $900 \mathrm{mV}$ em $\mathrm{H}_{2} \mathrm{SO}_{4}$ 0,5 mol.L ${ }^{-1}$....

Figura 52: Imagens e histogramas para imagens de TEM para catalisadores $\mathrm{Pt}-\mathrm{Ni} / \mathrm{C}$ preparadas pelo método de microemulsão.

Figura 53: Difratogramas de raios-X para os catalisadores de $\mathrm{Pt}-\mathrm{Ni} / \mathrm{C}$ em diferentes proporções atômicas.

Figura 54: Voltamogramas cíclicos obtidos para os catalisadores de $\mathrm{Pt}-\mathrm{Ni} / \mathrm{C}$ em $\mathrm{H}_{2} \mathrm{SO}_{4}$ $0,5 \mathrm{molL}^{-1}$ a $50 \mathrm{mVs}^{-1}$. Inset: Varredura catódica expandida na região de redução dos óxidos.

Figura 55: Curva de polarização em estado estacionário para RRO em catalisadores de Pt-Ni/C em $\mathrm{H}_{2} \mathrm{SO}_{4}$ 0,5 mol.L $\mathrm{L}^{-1}, \omega=900 \mathrm{rpm}$. (a) disco e (b) anel. $\mathrm{E}_{\mathrm{a}}=1,2 \mathrm{~V}$.

Figura 56: Diagramas de Tafel para RRO em catalisadores de $\mathrm{Pt}-\mathrm{Ni} / \mathrm{C}$ com diferentes razões atômicas em $\mathrm{H}_{2} \mathrm{SO}_{4} 0,5$ mol. $\mathrm{L}^{-1}$

Figura 57: Correlação entre atividade e fração atômica de Ni do catalisador .

Figura 58: Espectro XANES para diversos catalisadores de $\mathrm{PtNi} / \mathrm{C}$ a $900 \mathrm{mV}$ em $\mathrm{H}_{2} \mathrm{SO}_{4}$ $0,5 \mathrm{M}$

Figura 59: Ampliação do espectro XANES para diversos catalisadores de $\mathrm{PtNi} / \mathrm{C}$ a 900 $\mathrm{mV}$ em $\mathrm{H}_{2} \mathrm{SO}_{4} 0,5 \mathrm{M}$ 
Figura 60: Difratogramas de raios- $\mathrm{X}$ para os catalisadores $\mathrm{PtFe} / \mathrm{C}$ em diferentes composições e Pt/C

Figura 61: Voltamogramas cíclicos para $\mathrm{PtFe} / \mathrm{C}$ com diferentes composições em $\mathrm{H}_{2} \mathrm{SO}_{4}$ $0,5 \mathrm{M}$

Figura 62: Curva de polarização de estado estacionário para a RRO em diversos catalisadores em $\mathrm{H}_{2} \mathrm{SO}_{4}$ 0,5 M. (A) eletrodo de disco, (B) eletrodo de anel.....

Figura 63: Diagramas de Tafel para RRO em catalisadores de $\mathrm{PtFe} / \mathrm{C}$ preparados por microemulsão com surfactante aniônico com diferentes composições em $\mathrm{H}_{2} \mathrm{SO}_{4} 0,5 \mathrm{M}$

Figura 64: Imagens de microscopia eletrônica de transmissão de alta resolução (HRTEM) do catalisador $\mathrm{PtFe} / \mathrm{C}$ preparado pelo método de microemulsão com surfactante catiônico. O histograma mostra a distribuição numérica relativa de tamanho de partícula do catalisador..

Figura 65: Imagens de microscopia eletrônica de transmissão de alta resolução (HRTEM) do catalisador $\mathrm{PtFe} / \mathrm{C}$ preparado pelo método de microemulsão com surfactante aniônico. O histograma mostra a distribuição numérica relativa de tamanho de partícula do catalisador..

Figura 66: Curva de polarização de estado estacionário para a RRO em diversos catalisadores preparados com surfactante aniônico em H2SO4 0,5 M. (A) eletrodo de disco, (B) eletrodo de anel..

Figura 67: Curva de polarização de estado estacionário para a RRO em diversos catalisadores preparados com surfactante catiônico em H2SO4 0,5 M. (A) eletrodo de disco, (B) eletrodo de anel.....

Figura 68: Diagramas de Tafel para RRO em catalisadores preparados por microemulsão com surfactante aniônico com diferentes composições em H2SO4 0,5 mol.L-1.

Figura 69: Diagramas de Tafel para RRO em catalisadores preparados por microemulsão com surfactante catiônico com diferentes composições em H2SO4 0,5 M.

Figura 70: Diagramas de Tafel para RRO em catalisadores $\mathrm{PtFe} / \mathrm{C}$ preparados com diferentes surfactantes; em H2SO4 0,5 M.

Figura 71: Variação da atividade específica em função da energia do centro da banda 5 d da Pt para catalisadores Pt:M preparados por impregnação e para catalisadores de PtFe e PtNi 75:25 preparados por microemulsão utilizando surfcatante catiônico.. 


\section{LISTA DE TABELAS}

Tabela 1: Número de elétrons em diferentes potenciais calculados a partir do coeficiente angular do gráfico de Koutecky-Levich (K-L) e utilizando os dados do eletrodo discoanel rotatório (EDAR) para Pt/C comercial...................................................................35

Tabela 2: Propriedades físicas de diferentes ligas de PtM/C..............................................39

Tabela 3: Coeficientes de Tafel e número de elétrons para diversos catalisadores

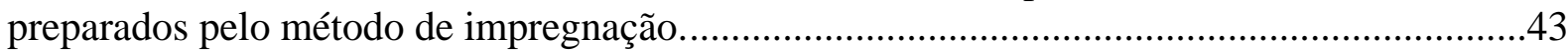

Tabela 4: Parâmetros estruturais obtidos por DRX para Pt/C e PtV/C tratados

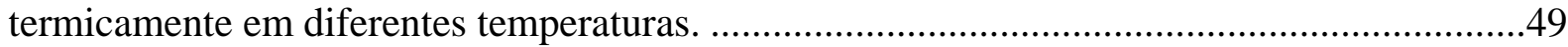

Tabela 5: Parâmetros cinéticas para a RRO em meio ácido em diversos catalisadores. ..........59

Tabela 6: Tamanho de partícula obtido para os catalisadores preparados por refluxo em THF.

Tabela 7: Parâmetros estruturais para catalisadores de Pt-Ni/C e Pt/C.................................76

Tabela 8: Parâmetros cinéticos para RRO em catalisadores de Pt-Ni/C. ...............................82

Tabela 9: Tamanho médio da partícula e parâmetro de rede (a) obtidos a partir dos

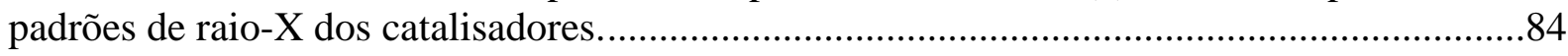




\section{RESUMO}

A reação de redução de oxigênio (RRO) foi estudada em eletrocatalisadores formados por ligas de Pt-M/C (M = V, Cr, Co, Fe e Ni) em eletrólito de $\mathrm{H}_{2} \mathrm{SO}_{4}$, sendo estes catalisadores preparados por diversos métodos. As propriedades eletrônicas foram investigadas por XAS (X-Ray Absorption Spectroscopy) in situ, na região de XANES (X-ray absorption near edge structure) e as propriedades estruturais por DRX (difração de raio-X). As atividades eletrocatalíticas para a $\mathrm{RRO}$ dos diferentes eletrocatalisadores foram comparadas por curvas de Tafel corrigidas por transporte de massa. Em todos os casos, as propriedades eletrônicas dos metais eletrocatalisadores, caracterizadas pela magnitude da absorção de raio-X, foram usadas para a compreensão da atividade eletrocatalítica dos materiais, e para estabelecer a relação propriedade eletrônica/cinética da RRO. Os resultados de XANES para as ligas Pt-M/C em altos potenciais do eletrodo mostraram uma menor vacância da banda $5 \mathrm{~d}$ da $\mathrm{Pt}$ comparada com $\mathrm{Pt} / \mathrm{C}$, indicando menor reatividade para adsorbatos da $\mathrm{Pt}$ nas ligas. As medidas eletroquímicas evidenciaram um aumento da atividade eletrocatalítica da Pt nas ligas, em comparação com Pt pura e isto foi atribuído à menor força de adsorção de espécies oxigenadas causada pelo menor valor de energia docentro da banda $\mathrm{d}\left(\varepsilon_{\mathrm{d}}\right)$ ou menor reatividade da Pt. 


\section{ABSTRACT}

The oxygen reduction reaction (ORR) was studied in $\mathrm{H}_{2} \mathrm{SO}_{4}$ electrolyte on different Pt-M/C (M = V, Cr, Co, Fe e Ni) alloys electrocatalysts, prepared by several methods. The electronic properties of the materials have been investigated by in situ XAS (X-ray absorption spectroscopy) in the XANES (X-ray absorption near edge structure) region and the structural properties by XRD (X-ray diffraction). The electrocatalytic activity for the ORR on the different catalysts was compared through mass-transport corrected Tafel plots. In all cases, the electronic properties of $\mathrm{Pt}$ on the metal electrocatalysts, as characterized by the magnitude of X-ray absorption, were used to understand the electrocatalytic activity and to establish a relationship between the electronic/kinetic properties. XANES results for the PtM/C alloys at high electrode potentials had shown lower Pt 5d band vacancy compared to Pt/C, indicating lower reactivity for adsorbates for the Pt alloys. The electrochemical experiments had shown enhancement of the catalytic activity in for the Pt alloys when compared with pure Pt and this was attributed to a lower adsorption strength of oxygenate species caused by the lower reactivity of Pt. 


\section{CAPÍTULO I}

\section{INTRODUÇÃO E OBJETIVOS}

\subsection{Células a combustível}

Ao longo do último século a humanidade vivenciou provavelmente a mais importante das revoluções, uma nova revolução industrial. A industrialização propiciou mudanças radicais nos mais variados setores da atividade humana, de forma que hoje vivemos em uma sociedade quase que completamente automatizada, que tem na eletricidade a sua base de funcionamento. Esta demanda crescente de energia, aliada ao iminente esgotamento de fontes energéticas não renováveis e aos problemas ambientais ocasionados pela queima dos combustíveis fósseis, fez com que, nas últimas décadas, se intensificasse a busca por fontes energéticas renováveis e de baixo impacto ambiental, que estejam de acordo com a necessidade da manutenção dos recursos naturais [1], do custo cada vez mais alto da extração de combustíveis fósseis e da demanda cada vez maior por energia em equipamentos eletrônicos. Assim, o desenvolvimento científico e tecnológico na área energética destinada a aplicações automobilísticas e em dispositivos eletrônicos está em constante crescimento.

Neste âmbito, uma das alternativas mais promissoras que tem aparecido para aplicação como fonte de energia elétrica em sistemas estacionários, portáteis e móveis (veículos) são as 
células a combustível, particularmente aquelas que são alimentadas pelos combustíveis: hidrogênio, metanol, ou etanol. Uma célula a combustível opera como uma célula galvânica convencional com a exceção de que os reagentes são supridos pelo lado de fora da célula ao invés de formar uma parte integralmente de sua construção. Na célula, o combustível é continuamente oxidado em um dos eletrodos, o ânodo, enquanto o oxigênio (por exemplo, do ar) é reduzido no outro eletrodo, o cátodo. A reação se completa com a circulação dos elétrons no circuito externo, que realizam o trabalho elétrico. Atualmente, o combustível que tem apresentado maior interesse prático é o hidrogênio, porém células que utilizam diretamente metanol como combustível já existem, mas as correntes obtidas ainda são relativamente baixas. Assim, quando se dispõe de outros combustíveis como gás natural, metanol, etanol, biogás, etc. o procedimento usual é submetê-los a uma reforma catalítica a vapor para se obter o hidrogênio que é então introduzido na célula.

Dentre os vários tipos de células a combustível que têm sido desenvolvidos, os que utilizam um eletrólito polimérico (PEMFC) têm recebido especial destaque nos últimos anos, tanto em nível mundial [2] como no IQSC-USP [3-5]. Nestas células, o eletrólito consiste de uma membrana condutora iônica umedecida com água e a temperatura de operação está por volta de $80{ }^{\circ} \mathrm{C}$. Platina é o catalisador usualmente empregado nos eletrodos, na forma de partículas finamente divididas e ancoradas numa matriz hidrofóbica de carbono. As reações que ocorrem em um sistema PEMFC são usuais e bem difundidas na literatura [2]. Hidrogênio proveniente do gás combustível é consumido no ânodo, gerando elétrons e íons hidrogênio. No cátodo, o oxigênio se combina com os íons hidrogênio e os elétrons provenientes da reação anódica para produzir água.
Reação anódica: $\quad \mathrm{H}_{2} \rightarrow 2 \mathrm{H}^{+}+2 \mathrm{e}^{-}$
Reação catódica: $1 / 2 \mathrm{O}_{2}+2 \mathrm{H}^{+}+2 \mathrm{e}^{-} \rightarrow \mathrm{H}_{2} \mathrm{O}$ 
sendo a água gerada pela reação catódica expelida do cátodo através de canais de saída para o excesso de gás.

O desempenho das PEMFC é limitado por perdas relacionadas à membrana, eletrodos e ao sistema eletro-eletrônico. Perdas catódicas, particularmente quando a célula está usando ar como combustível oxidante são significantes e são originadas de: i) cinética reacional limitada, em particular da reação de redução de oxigênio; ii) condutividade protônica limitada na camada catalisadora do eletrodo; iii) permeabilidade efetiva limitada do oxigênio na camada catalisadora do eletrodo, iv) limitação difusional do gás na camada difusora do eletrodo. Dentre estes fatores, aquele relacionado com a cinética da reação de redução de oxigênio (RRO) tem sido o mais importante em condições normais de operação de um sistema funcionando com hidrogênio puro.

\subsection{Eletrocatálise da reação de redução de oxigênio}

A reação de redução de oxigênio (RRO) é considerada como uma das reações eletrocatalíticas mais importantes por causa da sua função em conversores eletroquímicos de energia (células a combustível e bateria metal/ar), vários processos industriais, como no cátodo da indústria cloro-soda, em processos biológicos e em corrosão. Conseqüentemente, há muitos anos a RRO é foco de interesse das pesquisas eletroquímicas [6]. Contudo, a redução de oxigênio continua a ser um desafio para eletroquímicos devido à sua complexidade cinética e a conseqüente necessidade de melhores eletrocatalisadores para a utilização em células a combustível. 
São vários os fatores que contribuem para este fato:

- a RRO é extremamente lenta comparada a outras reações eletródicas como a reação de oxidação de hidrogênio;

- a faixa de potencial na qual a reação ocorre situa-se em uma região bastante anódica. Nesta faixa de potencial, a maioria dos metais dissolve-se ou forma óxidos passivos, que são cataliticamente inativos. Por este motivo, o número de eletrocatalisadores que pode ser usado para a RRO em meio ácido é praticamente restrito a metais nobres.

A redução de oxigênio é uma reação multi-eletrônica que usualmente inclui várias etapas elementares no mecanismo reacional. A RRO em soluções aquosas ácidas ocorre segundo dois mecanismos globais clássicos já conhecidos [7]:

I) Mecanismo direto ou mecanismo 4-elétrons:

$$
\mathrm{O}_{2}+4 \mathrm{H}^{+}+4 \mathrm{e}^{-} \rightarrow 2 \mathrm{H}_{2} \mathrm{O} \quad \mathrm{E}^{0}=1,23 \mathrm{~V}
$$

Equação 1

II) Mecanismo peróxido ou mecanismo 2-elétrons:

$$
\mathrm{O}_{2}+2 \mathrm{H}^{+}+2 \mathrm{e}^{-} \rightarrow \mathrm{H}_{2} \mathrm{O}_{2} \quad \mathrm{E}^{0}=0,67 \mathrm{~V}
$$

sendo que o peróxido de hidrogênio pode ser reduzido numa etapa posterior:

$$
\mathrm{H}_{2} \mathrm{O}_{2}+2 \mathrm{H}^{+}+2 \mathrm{e}^{-} \rightarrow 2 \mathrm{H}_{2} \mathrm{O} \quad \mathrm{E}^{0}=1,77 \mathrm{~V}
$$

$$
2 \mathrm{H}_{2} \mathrm{O}_{2} \rightarrow 2 \mathrm{H}_{2} \mathrm{O}+\mathrm{O}_{2}
$$

Equação 4

$\mathrm{O}$ potencial $\mathrm{E}^{\mathrm{o}}$ nestas equações corresponde ao valor padrão da reação em função do eletrodo reversível de hidrogênio $(\mathrm{ERH})$ a $25{ }^{\circ} \mathrm{C}$. Um quadro apresentando as possíveis rotas reacionais para a redução de $\mathrm{O}_{2}$ está apresentado na Figura 1.

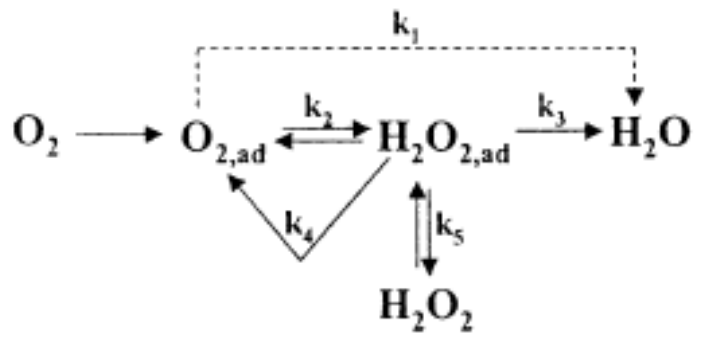

Figura 1: Possíveis rotas reacionais para a RRO 
A distinção entre estes dois mecanismos acima descrita é dificultada pelo fato de que a redução direta também pode envolver a formação de peróxido, desde que este permaneça adsorvido na superfície do eletrodo sem sofrer dessorção ou decomposição, e a sua redução ocorra subseqüentemente, sendo este processo também de 4 elétrons, porém, chamado de mecanismo em série. Em potenciais mais catódicos juntamente com o mecanismo via 4 elétrons pode ocorrer também o mecanismo via 2 elétrons sendo chamado de mecanismo paralelo. Em geral, a técnica de eletrodos de disco-anel rotatório é muito utilizada na verificação e diferenciação entre os dois mecanismos operacionais que regem a reação de redução da molécula de $\mathrm{O}_{2}$, sendo que nesta técnica o eletrodo de anel é utilizado somente para monitorar a produção de peróxido oriunda do eletrodo de disco [7]. O mecanismo direto e o mecanismo em série são indistinguíveis pelo método do eletrodo de disco-anel rotatório. A redução de oxigênio procede quantitativamente através do mecanismo peróxido em um grande número de superfícies eletródicas, particularmente em meio alcalino. As possíveis rotas reacionais e o número de elétrons envolvidos na RRO estão relacionados com os diferentes tipos de adsorção da molécula de $\mathrm{O}_{2}$. Na Figura 2 são apresentadas as prováveis formas de adsorção da molécula de $\mathrm{O}_{2}$. De acordo com o esquema da Figura 2, há três formas pelas quais as moléculas de oxigênio podem se adsorver na superfície do eletrodo, sendo elas indicadas pelos modelos de Griffith, Pauling e Ponte [8]. Se a adsorção seguir os modelos de adsorção de Griffith e de Ponte, o mecanismo de redução envolverá 4 elétrons. Por outro lado, se a adsorção seguir o modelo de Pauling, eventualmente a redução dar-se-á segundo um mecanismo envolvendo 2 elétrons, resultando como produto o $\mathrm{H}_{2} \mathrm{O}_{2}$ notando-se que neste caso não ocorre a ruptura da ligação O-O. Adicionalmente, as etapas de adsorção poderão ocorrer simultaneamente e a preponderância de um ou outro mecanismo dependerá dos impedimentos estéricos, das propriedades eletrônicas e do espaçamento entre os sítios ativos ou, em outras palavras, do material eletródico e/ou das condições experimentais empregadas. 


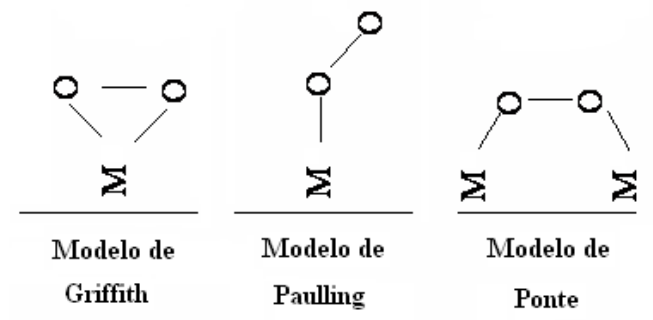

a)
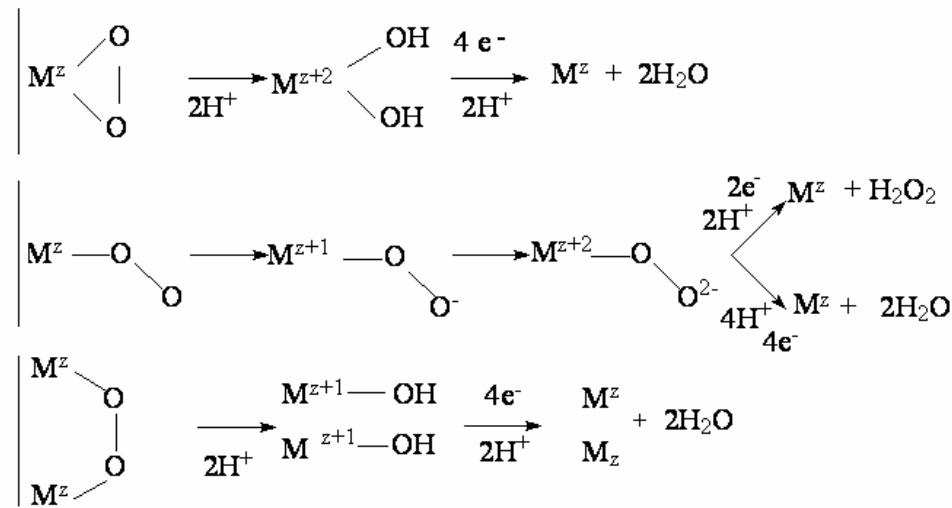

b)

Figura 2: Possíveis formas de adsorção da molécula de $\mathrm{O}_{2}$ (a) e possíveis rotas reacionais da reação de redução de oxigênio em meio ácido (b).

Nas últimas décadas, muitos esforços têm sido dedicados ao estudo do mecanismo da RRO em soluções aquosas ácidas sobre diferentes materiais de eletrodo [9-29]. Platina e ligas de platina ainda são consideradas as melhores opções para a redução de oxigênio, tanto em termos dos mais baixos sobrepotenciais desejáveis para promover a reação, quanto da estabilidade requerida. Assim, os eletrocatalisadores baseados em platina são necessários para prover estabilidade no ambiente corrosivo da PEMFC e neste sentido as ligas de platina favorecem a atividade catalítica desejada ao mesmo tempo em que permitem a diminuição do teor de Pt, com conseqüente ganho econômico. Os catalisadores bimetálicos constituídos por Pt-M, onde $\mathrm{M}$ é usualmente um metal da primeira fileira dos metais de transição exibem atividade catalítica frente a RRO de duas a dez vezes maior do Pt pura. Entretanto, a extensão do aumento da atividade tem variado amplamente entre diversos resultados, mesmo para o mesmo metal M, bem como as explicações do porque desta melhora na atividade não são 
consensuais. O método de preparação dos catalisadores bimetálicos certamente afeta a composição final e a estrutura da superfície dos catalisadores, o qual, também pode alterar a atividade.

Sobre platina e metais da família da platina ocorre o mecanismo paralelo, mas a predominância é do mecanismo direto via 4 elétrons [6]. Para estes metais há 2 propostas para a primeira etapa reacional. De acordo com Murthi [30], a primeira proposta é de Damjanovic e col. [31], em que a transferência de prótons ocorre simultaneamente com a transferência de carga, em um processo envolvendo $\mathrm{O}_{2} \leftrightarrow \mathrm{O}_{2 \text { (ads) }}$, seguido pelo passo determinante da reação que é a transferência de carga: $\mathrm{O}_{2(\text { ads })}+\mathrm{H}^{+}+\mathrm{e}^{-} \rightarrow$ produtos. A segunda proposta é de Yeager e co-autores [32], onde o mecanismo mais comum, a redução via 4 elétrons sobre Pt, envolve adsorção química seguida de dissociação da molécula de $\mathrm{O}_{2}$ sobre a superfície de platina, que provavelmente ocorre simultaneamente com a transferência de carga, conforme ilustra o esquema da Figura 2.

Assim, catalisadores baseados em ligas de vários metais de transição são empregados para aumentar a atividade catalítica e reduzir custos. A dependência da atividade para a reação de redução de oxigênio em função do metal eletrocatalisador e das modificações no metal eletrocalisador tem sido discutida em vários trabalhos prévios [33,34]. Nesses estudos, a adsorção de oxigênio em metais é relacionada com o número de elétrons desemparelhados no metal, com cada átomo de oxigênio requerendo dois elétrons da banda d para a formação da ligação. Nessa situação, uma alta cobertura por oxigênio é prevista para metais com alto número de elétrons desemparelhados. Assim, ouro, que não possui elétrons d desemparelhados, tem a menor cobertura por óxidos que rutênio, que apresenta maior número de elétrons desemparelhados. Neste enfoque, as propriedades catalíticas são governadas pela força de adsorção dos intermediários. Alta força de adsorção resulta em alto grau de recobrimento e a saída mais difícil do intermediário do eletrodo. Por outro lado, uma fraca 
força de adsorção resulta em baixo grau de cobertura e mais fácil saída dos intermediários. Em função da redução de oxigênio envolver um passo de adsorção no mecanismo da reação, a vacância da banda d do metal eletrocatalisador é um importante fator na cinética da redução. Curvas do tipo "vulcão" foram obtidas por Appleby [35], onde a densidade de corrente para a redução de oxigênio foi graficada em função da vacância da banda d para diferentes metais. Verificou-se maior atividade para a Pt, com vacância da banda d de 0,6 por átomo, o que evidencia uma adsorção de oxigênio que é nem tão fraca nem tão forte.

Um outro efeito que altera a força de adsorção de intermediários tem sido proposto por Mukerjee e co-autores [9]. Neste caso, a RRO foi investigada em meio ácido em Pt e ligas de Pt dispersas sobre carbono, onde a força de adsorção foi associada com a eletronegatividade do metal eletrocatalisador. Curvas do tipo "Vulcão" foram obtidas para a dependência da atividade para a RRO com a vacância da banda 5d da Pt. O ganho de atividade para a RRO mostrada pelas ligas de Pt foi explicado considerando mudanças na eletronegatividade de Pauli. Foi verificado que o grau de recobrimento por óxidos superficiais provenientes do eletrólito em potenciais altos (onde a RRO ocorre) é menor nas ligas de Pt em comparação com Pt/C. Isso foi explicado com base na equação de Pauli, que define a força de adsorção como diretamente proporcional à diferença dos quadrados das eletronegatividades do metal e do adsorbato. Assim, verificou-se por medidas de XANES (X-ray absorption) que, metais como $\mathrm{Cr}$, $\mathrm{Co}, \mathrm{Fe}$ e $\mathrm{Ni}$, retiram densidade eletrônica da $\mathrm{Pt}$, fazendo com que a eletronegatividade da Pt aumente. Dessa forma, a diferença entre as eletronegatividades do metal (Pt na liga) e do adsorbato (espécies oxigenadas) deve diminuir, o que reduz a força de adsorção. Em conseqüência disso, a cobertura de óxidos provenientes do eletrólito diminui, aumentando o número de sítios livres para a adsorção de $\mathrm{O}_{2}$, o que explica maior atividade das ligas de Pt em relação à Pt pura. 
Catalisadores de Pt e ligas de platina dispersos em carbono mostram aumento da atividade específica com o decréscimo da área superficial, fato que indica que a reação é sensível à estrutura [25]. De acordo com os resultados das técnicas de voltametria cíclica e XANES a sensibilidade à estrutura dos catalisadores de Pt e ligas de Pt para a RRO parece estar associada com a força de adsorção de intermediários oxigenadas junto à superfície da platina [25]. Jalan e Taylor [36] estudaram a reação de redução de oxigênio em diversas ligas de platina suportadas em carbono (Pt-Cr, Pt-V, Pt-Ti e Pt-Al) em ácido fosfórico e propuseram que a melhora da atividade catalítica da platina nas ligas resulta do encurtamento da distância inter-atômica Pt-Pt quando comparadas à Pt pura. A mesma interpretação foi dada por Mukerjee e Srinivasan [37]. Entretanto, Glass e colaboradores [38] consideraram que a melhora é específica para ligas catalíticas altamente dispersas, porque o efeito não foi observado para macro aglomerados de ligas de Pt-Cr.

Outros pesquisadores também têm mostrado que a maior atividade eletrocatalítica da Pt em ligas em relação à Pt pode ser atribuída a vários outros fatores, como por exemplo, o número de átomos de Pt vizinhos, densidade eletrônica no orbital Pt 5d e a presença de óxidos superficiais. Toda et al. [24] têm explicado a melhora na atividade catalítica baseados no aumento da vacância do orbital $\mathrm{Pt} 5 \mathrm{~d}$, conduzindo a uma forte interação $\mathrm{Pt}_{-} \mathrm{O}_{2}^{-}$. Isto causa um enfraquecimento e um distanciamento da ligação O-O e sua fácil ruptura resultando em um aumento na cinética da RRO. Por outro lado, Min et al. [25] tem demonstrado que a cinética da RRO aumenta com o decréscimo na vacância da banda $5 \mathrm{~d}$ da Pt. Foi visto que a vacância depende do tamanho das partículas de Pt. A hibridização do estado 5d com estados vazios acima do nível de Fermi reduz o número de elétrons verdadeiro, e esta hibridização torna-se menos favorável com um aumento no tamanho de partícula. Isto implica que a força da adsorção de espécies oxigenadas decresce com o aumento do tamanho da partícula e, então, a redução dos intermediários contendo oxigênio na superfície da $\mathrm{Pt}$ se torna mais fácil. 
Entretanto, a atividade catalítica varia mesmo para sistemas com a mesma área superficial ou tamanho de partícula, dependendo do elemento de transição usado na formação da liga, indicando a ocorrência de outros fatores que afetam a atividade catalítica, em adição ao tamanho de partícula. Arico at al. [39] têm atribuído o ganho da atividade catalítica como decorrente da diminuição da cobertura superficial por óxidos e um enriquecimento na fração dos sítios de Pt livres de óxidos. Outros pesquisadores têm explicado o aumento da atividade baseados no decréscimo da cobertura por intermediários oxigenados na Pt em ligas de Pt, em função da variação da eletronegatividade da Pt e na diminuição da distância interatômica Pt-Pt $[9,22,30,37]$.

Investigações anteriores indicam que a atividade catalítica das ligas de Pt está relacionada com o ordenamento atômico entre a Pt e o metal M que está formando a liga [38,40]. Glass [38] e colababoradores compararam a atividade catalítica de ligas de Pt-Cr com várias composições e estruturas em ácido fosfórico e encontraram que ligas ordenadas de PtCr exibem maior atividade catalítica para a RRO do que ligas desordenadas. Watanabe e colaboradores [41] estudaram ligas comerciais de Pt-Co com composição atômica de 55:45 e também encontraram que estruturas ordenadas mostram melhor atividade catalítica do que estruturas desordenadas, mas esta última exibe maior estabilidade em ácido fosfórico. Fatores como a mudança na estrutura superficial e na energia de interação do oxigênio com o material da liga também podem alterar as propriedades eletrocatalíticas da platina nas ligas e assim o tratamento térmico dos materiais pode exercer função primordial na obtenção de eletrocatalisadores à base de platina. Para dois catalisadores dispersos em carbono com a mesma composição e obtidos pelo mesmo método, diferentes tratamentos térmicos podem produzir atividades catalíticas completamente diferentes. O tratamento térmico permite controlar o tamanho de partículas e limpar a superfície dos catalisadores de impurezas, sendo 
observado que com o aumento da temperatura há um aumento do tamanho das partículas e, portanto, um decréscimo da área superficial.

Ligas binárias de Pt-Fe exibem melhor resistência à sinterização das partículas a elevadas temperaturas do que catalisadores que contêm platina pura. Este efeito é chamado de "efeito âncora" do ferro sobre a platina, que faz com que a mobilidade dos átomos de platina sobre substrato de carbono seja dificultada quando o ferro esta presente [42].

Recentemente a melhora na atividade catalítica para platina e suas ligas frente à RRO tem sido explicada do ponto de vista microscópico, através das modificações do centro de energia da banda d, $\varepsilon_{\mathrm{d}}$, empregando-se cálculos teóricos realizados com a técnica de DFT (density functional theory).

Em trabalhos recentes, Nǿrskov et al. $[43,44]$ mostraram que a reatividade dos metais pode ser racionalizada em termos do centro de energia da banda $\mathrm{d}, \varepsilon_{\mathrm{d}}$. O modelo de Nórskov é baseado no deslocamento do centro de energia da banda, que aumenta ou diminui a reatividade do metal catalisador. Quando o $\varepsilon_{\mathrm{d}}$ desloca-se para cima, um estado anti-ligante distinto aparece acima do nível de Fermi. Os orbitais ou estados anti-ligantes estão acima do nível de Fermi, e portanto estão menos vazios sendo que a ligação torna-se gradativamente mais forte com o aumento número de orbitais anti-ligantes vazios. Dessa forma, os cálculos para o modelo são baseados em um princípio geral sobre ligação química. Ligações fortes ocorrem se orbitais anti-ligantes são deslocados para cima do nível de Fermi (e tornam-se vazios). O oposto é verdadeiro se orbitais anti-ligantes são deslocados para baixo do nível de Fermi (e tornam-se ocupados).

Tem sido demonstrado [45] que uma monocamada de um metal depositada em diferentes substratos metálicos é sujeita a tensões compressivas ou extensivas, o que é determinado pelo parâmetro de rede do substrato metálico. Isto pode causar o aumento ou diminuição da largura da banda d do metal, conduzindo a um deslocamento do centro de 
energia da banda d para conservar o grau de ocupação do mesmo. No geral, a tensão extensiva causa o distanciamento entre os átomos, resultando em um afunilamento em energia da banda d dos metais, o que conduz ao aumento do centro em energia da banda. Contrariamente, a tensão compressiva leva a um alargamento da banda d, conduzindo a um abaixamento do centro da banda d do metal. A variação do centro da banda d também tem sido demonstrada quando se obtém ligas entre dois ou mais metais, ou em ligas com estruturas com segregação superficial de um dos elementos na superfície do outro metal, como em nanopartículas metálicas [46,47]. Tem sido visto, por exemplo, que ligas entre Pt e outros metais de transição como Ni, Co, Fe, V e/ou, tendo-se esses metais como "solvente" e Pt como "soluto" (maior quantidade do outro metal em relação a Pt), há uma segregação superficial dos átomos de Pt. Para estas estruturas, cálculos por DFT (Density Functional Theory) têm apontado para um deslocamento do centro da banda d da Pt para menores valores de energia, o que evidenciaria menor força de adsorção de adsorbatos.

Baseado nisso, Adzic et al. $[12,13,48]$ têm estudado a cinética da reação de redução de $\mathrm{O}_{2}$ usando a técnica de disco-anel rotatórios, em monocamadas de $\mathrm{Pt}$ depositadas na superfície de diferentes monocristais e em nanopartículas desses metais dispersas em carbono. Tem sido observado um comportamento da atividade catalítica das monocamadas de Pt em diferentes monocristais seguindo uma curva tipo "vulcão" em função do centro de energia da banda d da Pt. A monocamada de Pt suportada sobre Pd(111) está no topo da curva vulcão e mostra um aumento de atividade em relação à $\operatorname{Pt}(111)$. Foi demonstrado que o comportamento é determinado por duas tendências opostas: enquanto um alto $\varepsilon_{\mathrm{d}}$ tende a facilitar a quebra da ligação O-O, devido à formação de ligação Pt-O mais forte, um menor $\varepsilon_{d}$ tende a fortalecer a ligação dos átomos de oxigênio. Esse efeito aumenta cinética de hidrogenação ou da eletroredução de espécies oxigenadas na superfície, aumentando a cinética da RRO. A confirmação do decréscimo da cobertura por óxidos ou mais fraca ligação 
Pt-O foi feita baseada em medidas de XANES in situ na borda $\mathrm{L}_{3}$ da Pt em diferentes potenciais do eletrodo.

\subsection{Objetivos}

Apesar de todos estes esforços, os desafios da complexidade cinética da RRO e da necessidade de superação de uma barreira de energia de ativação significativa ainda permanecem e requerem o desenvolvimento de catalisadores alternativos, eficientes e de baixo custo, associados com informações mais detalhadas dos mecanismos reacionais que ainda não são totalmente entendidos. O que se pode afirmar é que se trata de uma reação altamente irreversível em soluções aquosas, gerando perdas excessivas de voltagem e, portanto, limitando sua aplicação em sistemas eletroquímicos que utilizam o eletrodo de oxigênio, em particular as células a combustível. Um dos grandes desafios no desenvolvimento de catalisadores para a RRO a serem aplicados em sistemas práticos é a utilização de materiais de baixo custo e bom desempenho.

Diante deste quadro foram definidos os seguintes objetivos para o presente trabalho:

a) aumentar a atividade eletrocatalítica da Pt pela formação de liga com metais não nobres: $\mathrm{PtM} / \mathrm{C}$, com $\mathrm{M}=\mathrm{V}, \mathrm{Cr}, \mathrm{Co}, \mathrm{Ni}$ e $\mathrm{Fe}$, em diferentes composições percentuais, e estudar as propriedades eletrônicas e estruturais desses materiais por XANES (X-ray absorption near

edge structure), DRX (difração de raios X) e MET (microscopia eletrônica de transmissão) e eletroquímica por voltametria cíclica e curvas de polarização de estado estacionário. 
b) preparar as ligas acima citadas, através de diferentes métodos de preparação de nanopartículas, a fim de verificar a influencia do método de preparação na RRO. 


\section{CAPÍtULUO II}

\section{PARTE EXPERIMENTAL:}

\subsection{Preparação dos eletrocatalisadores dispersos em carbono pelo método de impregnação}

A preparação dos catalisadores pelo método de impregnação em ultra-som foi conduzida à temperatura ambiente, $25^{\circ} \mathrm{C}$, dissolvendo-se os sais dos metais precursores, $\mathrm{H}_{2} \mathrm{PtCl}_{6}, \mathrm{Fe}\left(\mathrm{NO}_{3}\right)_{3},(\mathrm{CrCl})_{2} \cdot 6 \mathrm{H}_{2} \mathrm{O}, \mathrm{NiCl}_{2} \cdot 6 \mathrm{H}_{2} \mathrm{O}, \mathrm{Co}\left(\mathrm{NO}_{3}\right)_{2} \cdot 2 \mathrm{H}_{2} \mathrm{O}, \mathrm{VBr}$ em água, e em seguida feita uma suspensão com a adição de carbono previamente tratado (Vulcan XC-72). Esta suspensão foi mantida por 30 minutos em ultra-som para a impregnação dos sais precursores sobre carbono. Depois da evaporação total do solvente, o material foi tratado em um forno tubular (Maitec) em atmosfera oxidante a $100{ }^{\circ} \mathrm{C}$ por $1 \mathrm{~h}$ e em seguida em atmosfera redutora de $\mathrm{H}_{2}$ a $650{ }^{\circ} \mathrm{C}$ por $1 \mathrm{~h}$. Todos os catalisadores foram preparados com a composição $75: 25$ (Pt:M em átomos) 


\subsection{Preparação dos eletrocatalisadores dispersos em carbono pelo método refluxo em THF}

Foram preparados catalisadores de platina e ligas de PtFe e PtV ancorada em carbono com a composição de 80:20, pelo método de refluxo em THF. Os catalisadores foram sintetizados de acordo com o seguinte procedimento: uma quantidade apropriada do sal precursor e de carbono Vulcan foram dissolvidas em THF e a mistura foi levada ao ultra-som por 15 minutos. A essa mistura, foi adicionado $40 \mathrm{ml}$ de ácido fórmico e a mistura permaneceu em refluxo por 6 horas. Após esse processo, o excesso de agente redutor e o solvente presente na mistura foram evaporados em banho-maria a $60^{\circ} \mathrm{C}$ e o pó resultante seco em um forno a $80{ }^{\circ} \mathrm{C}$ por uma hora. Posteriormente, o pó catalisador foi dissolvido em uma mistura 1:1 contendo água e etanol e a mistura levada ao ultra-som por 15 min. Finalmente o catalisador foi filtrado, lavado em abundância com água e seco em forno a $80{ }^{\circ} \mathrm{C}$ por uma hora. O processo descrito acima foi posteriormente repetido, porém, juntamente com o ácido fórmico foi adicionado PVP (polivinilporrilidona) como agente estabilizante.

\subsection{Preparação dos eletrocatalisadores dispersos em carbono pelo método de microemulsão}

\subsection{1 - Preparação utilizando surfactante aniônico}

Para preparar os catalisadores por microemulsão foram preparadas duas soluções de microemulsão, uma contendo os sais precursores, água ultra-pura, heptano e o surfactante AOT (sodium bis(2-ethylhexyl)sulfosuccinate) que foi mantida sob agitação por 2 horas. A outra solução de microemulsão foi preparada adicionando-se $\mathrm{NaBH}_{4}$, heptano, água ultrapura e AOT. Esta solução também foi mantida sob agitação pelo período de 2 horas. Após este tempo as soluções foram misturadas e mantidas sob agitação por mais duas horas para se processar a reação de redução dos íons metálicos pelo borohidreto. Após a reação de redução 
uma quantidade apropriada de carbono (Vulcan XC-72) foi adicionada à solução e esta permaneceu em agitação por 24 horas para ancoragem do catalisador sobre o carbono. A solução foi finalmente filtrada e o catalisador lavado copiosamente com acetona e água ultrapura para retirada das moléculas do surfactante. O catalisador pronto foi finalmente levado ao forno a $80{ }^{\circ} \mathrm{C}$ por uma hora para secagem. O $\omega$ (razão molar entre água e surfactante) utilizado foi de 8 .

\subsection{2 - Preparação utilizando surfactante catiônico}

$\mathrm{Na}$ preparação dos eletrocatalisadores utilizando-se surfactante catiônico, foi seguido o mesmo procedimento, porém, utilizando-se n-octano como fase oleosa, CTAB (brometo de cetiltrimetilamônio) como surfactante e 1-butanol como co-surfactante.

\section{$\underline{\text { 2.3.3 - Preparação utilizando surfactante não iônico }}$}

Na preparação dos eletrocatalisadores utilizando-se surfactante não iônico, foi seguido o mesmo procedimento, porém, utilizando-se heptano como fase oleosa e $\mathrm{Brij}^{\circledR} 30$ como surfactante.

\subsection{Eletrocatalisadores comerciais: Pt/C e Pt-V/C}

Os eletrocatalisadores considerados foram constituídos por $20 \%$ (em massa), em materiais comerciais (E-Tek, Inc) formados por platina dispersa em carbono (Pt/C), e liga de platina e vanádio dispersa em carbono $(\mathrm{Pt}-\mathrm{V} / \mathrm{C})$ sendo de 1:1 a razão atômica entre os metais na liga. Estes materiais foram submetidos a um tratamento térmico em um forno tubular (MAITEC) em atmosfera de $\mathrm{H}_{2}$ em diferentes temperaturas, 300, 500 e $800{ }^{\circ} \mathrm{C}$ por $1 \mathrm{~h}$. 


\subsection{Caracterização dos eletrocatalisadores}

\subsubsection{Caracterização física por EDX}

A composição final dos catalisadores foi determinada usando a técnica de energia dispersiva de raios-X (EDX) em um sistema de microscópio de varredura de elétrons LEO, 440 SEM-EDX (Leica-Zeiss, DSM-960) com um microanalisador (Link Analytical QX 2000), tendo SiLi como detector e usando um feixe de elétrons com $20 \mathrm{keV}$ de energia.

\subsubsection{Caracterização física por DRX e MET}

A caracterização física de todos os catalisadores foi feita por difração de raios-X (DRX - RIGAKU modelo RU200B) conduzidas em um intervalo de $2 \theta$ de $10^{\circ}$ até $100^{\circ}$ usando radiação $\mathrm{Cu} \mathrm{K}_{\alpha}$ (com velocidade de varredura de $2^{\circ} \cdot \min ^{-1}$ ). A média dos tamanhos dos cristalitos foi estimada usando a equação de Scherrer [49] (equação 5) e o parâmetro de rede da estrutura cfc (cúbica de face centrada) utilizando a equação 6;

$$
\begin{aligned}
& d=\frac{k \lambda}{B \cos \theta} \\
& a=\frac{\sqrt{2} \lambda}{\operatorname{sen} \theta}
\end{aligned}
$$

Equação 5

Equação 6

onde d é a média do tamanho de partícula em $\AA$, $a$ é o parâmetro de rede, k é um coeficiente tido como $0,9, \lambda$ o comprimento de onda do raio-X usado $\left(\mathrm{K}_{\alpha} \mathrm{Cu} 1,5406 \AA\right), B$ a largura do pico de difração à metade da altura em radianos e $\theta$ o ângulo da posição do pico máximo. Os catalisadores também foram caracterizados utilizando-se microscopia de transmissão de 
elétrons (MET) em um equipamento Carl Zeiss A CEM 902 80KeV acoplado a uma câmera de baixa velocidade de varredura modelo Proscan HSC-2. As amostras foram preparadas com a dispersão dos catalisadores de em álcool isopropílico e tratamento em um banho ultrasônico durante 10 minutos. Posteriormente, o material foi depositado sobre uma grade de $\mathrm{Cu}$ (3 mm de diâmetro e 300 mesh) recoberta com grafite. As imagens de MET foram analisadas com a utilização do software Analysis. Para cada amostra várias micrografias de MET foram coletadas e estas foram utilizadas para determinar o tamanho médio e a distribuição das nanopartículas.

O tamanho médio das partículas foi calculado de acordo com a equação:

$d=\frac{\sum_{i} n_{i} d_{i}}{\sum_{i} n_{i}}$

Equação 7

onde $n_{i}$ é a freqüência de ocorrência das partículas de tamanho $d_{i}$.

\subsubsection{Caracterização física por Absorção de Raio-X (XAS)}

As medidas de XAS (X-ray absorption spectroscopy) "in situ” foram feitas na borda de absorção $\mathrm{L}_{3}$ da Pt, usando uma célula espectroeletroquímica apropriada [9]. A borda de absorção $L_{3}$ da Pt relaciona-se a transições eletrônicas do orbital $2 \mathrm{p}_{2}$ à banda $5 \mathrm{~d}$, sendo a magnitude do pico localizado a $5 \mathrm{eV}$ estreitamente relacionado à ocupação da banda $5 \mathrm{~d}$. Os eletrodos de trabalho foram formados com o material catalisador disperso aglutinado com Nafion (ca. 35 wt. \%) e álcool isopropílico, contendo aproximadamente $7 \mathrm{mg} . \mathrm{cm}^{-2}$ de Pt. As medidas foram feitas em vários potenciais do eletrodo de trabalho, tendo como referência o ERH (eletrodo reversível de hidrogênio). O contra eletrodo foi formado por uma tela de platina. Esse eletrodo foi cortado no centro para permitir a livre passagem do feixe de raio-X. 
Antes de cada experimento, os eletrodos de trabalho eram embebidos em $\mathrm{H}_{2} \mathrm{SO}_{4} 0,5$ mol. $\mathrm{L}^{-1}$. Os experimentos de XAS foram feitos depois de ciclar os eletrodos no intervalo de $0,05-1,0 \mathrm{~V}$ para ativação dos mesmos. Todos os experimentos foram conduzidos na linha de XAS do Laboratório Nacional de Luz Síncrotron (LNLS). O sistema de aquisição de dados para o XAS foi composto por três detectores de ionização (incidência $I_{0}$, transmitido $I_{t}$, referência $\mathrm{I}_{\mathrm{r}}$ ). $\mathrm{O}$ canal de referência foi empregado primeiramente para a calibração interna da posição das bordas usando uma folha do metal puro. Nitrogênio foi usado nas câmaras $\mathrm{I}_{0}, \mathrm{I}_{\mathrm{t}} \mathrm{e}$ Ir. Em função da baixa energia crítica do anel do LNLS $(2,08 \mathrm{keV})$, a contaminação por harmônico de terceira ordem do feixe do monocromador $\mathrm{Si}$ (111) é esperado ser negligenciável para energias acima de $5 \mathrm{eV}$ [50].

O programa utilizado para a análise dos dados de XAS foi o pacote WinXAS [51]. A análise dos dados foi feita de acordo com os procedimentos descritos em detalhes na literatura [52,53]. O espectro de XANES foi primeiramente corrigido pelo background, ajustando a préborda (de -60 até $-20 \mathrm{eV}$ abaixo da borda) a uma fórmula linear e a pós-borda a uma função de segundo grau, seguida por extrapolação e subtração das linhas de base geradas no intervalo de energia de interesse. Depois disso, o espectro foi calibrado em relação à posição da borda usando o método da segunda derivada para a determinação do ponto de inflexão na região da borda de absorção para os dados obtidos no canal de referência. Finalmente, o espectro foi normalizado, tomando como referência um dos pontos de inflexão da oscilação EXAFS (extended X-ray absorption fine structure). 


\subsection{Caracterização Eletroquímica}

Uma célula eletroquímica convencional de um compartimento foi usada nos experimentos eletroquímicos. Platina de alta área (platinizada) serviu como contra-eletrodo e um eletrodo reversível de hidrogênio (ERH) como referência. Todos os experimentos foram conduzidos em solução de $\mathrm{H}_{2} \mathrm{SO}_{4} 0,5 \mathrm{M}$, preparada a partir de reagentes de alta pureza e água destilada e purificada em um sistema Milli-Q (Millipore). O eletrólito foi saturado com $\mathrm{N}_{2}$ ou $\mathrm{O}_{2}$ purificados, dependendo do experimento.

Voltametria cíclica foi utilizada para analisar as propriedades superficiais dos eletrodos. Os experimentos voltamétricos foram conduzidos em um intervalo de potencial de 0,05 - 1,1 V usando um bipotenciostato AUTOLAB (PGSTAT 30). Curvas de polarização de estado estacionário foram obtidas potenciostaticamente (ponto a ponto), com tempo de estabilização de 30 segundos em cada ponto, em várias velocidades de rotação para avaliar os parâmetros cinéticos da RRO. Todos os experimentos foram realizados a temperatura ambiente $\left(25^{\circ} \mathrm{C}\right)$. Antes de cada experimento o eletrodo foi ciclado várias vezes até a obtenção de um perfil voltamétrico estável em um intervalo de potencial entre $0,05-1,1 \mathrm{~V}$ para limpeza da superfície.

O eletrodo de trabalho foi composto pelos catalisadores (metal/C) em uma camada ultrafina depositada em um disco de carbono pirolítico com 5,0 mm de diâmetro $\left(0,196 \mathrm{~cm}^{2}\right)$ em um eletrodo de disco-anel rotatórios. Nesse sistema, o anel (platina) foi usado como sensor do $\mathrm{H}_{2} \mathrm{O}_{2}$ produzido no eletrodo de disco. Isto foi feito medindo a magnitude da corrente de oxidação do mesmo a um potencial constante de 1,2 V vs. ERH, no qual a corrente de redução ou geração de oxigênio é negligenciável. Para a preparação da camada catalítica, uma suspensão aquosa de 1,0 mg.mL $\mathrm{m}^{-1}$ de metal/C era produzida por dispersão em ultra-som em água pura (Millipore). Uma alíquota de $20 \mu \mathrm{l}$ da suspensão era pipetada e colocada sobre a 
superfície do substrato de carbono pirolítico e em seqüência a evaporação do solvente era feita a vácuo em um dessecador. Depois disso, uma alíquota de $20 \mu 1$ de solução $0,05 \%$, em massa de Nafion em metanol era colocada sobre a camada catalítica, para a fixação do material catalisador; em sequiência procedia-se a evaporação do solvente com o mesmo procedimento. Logo após a preparação, os eletrodos eram imediatamente imersos no eletrólito de $\mathrm{H}_{2} \mathrm{SO}_{4} 0,5$ mol. $\mathrm{L}^{-1}$ desaerado.

\subsubsection{Obtenção do Fator de Eficiência do eletrodo de anel}

Cálculos quantitativos da resposta do eletrodo anel têm mostrado que mesmo na ausência de qualquer reação química adicional envolvendo o produto reacional, nem todo o produto gerado no disco é detectado no eletrodo anel, uma vez que parte pode se difundir para o seio da solução. Na realidade, verifica-se que, independentemente da velocidade de rotação $(\omega)$, apenas uma fração constante do produto é detectada no eletrodo anel. Esta fração é chamada de eficiência de coleção ou fator de eficiência $(\mathrm{N})$, sendo esta somente função de parâmetros geométricos do sistema, tais como: o raio do eletrodo de disco e o raio interno e externo do eletrodo de anel [54]. Na prática $\mathrm{N}$ pode ser obtida experimentalmente para um sistema específico usando um processo eletroquímico muito bem definido que é o caso do par redox $\mathrm{Fe}^{2+} / \mathrm{Fe}^{3+}$. No presente trabalho para a obtenção da eficiência do eletrodo disco-anel rotatório, o eletrodo de disco foi preparado como citado anteriormente, utilizando-se $\mathrm{Pt} / \mathrm{C}$ $20 \%$. O eletrólito utilizado foi uma solução desaerada de $\mathrm{K}_{3} \mathrm{Fe}(\mathrm{CN})_{6} 10 \mathrm{mM}$ em $\mathrm{H}_{2} \mathrm{SO}_{4} \quad 0,5$ M, um composto típico para a determinação da eficiência de coleção conforme mencionado acima, pois, este sistema é altamente reversível tendo cinética reacional rápida. A Figura 3 mostra o voltamograma cíclico para o sistema. Para a obtenção de $\mathrm{N}$, as correntes do eletrodo de disco foram coletadas com velocidade de varredura de $20 \mathrm{mV} / \mathrm{s}$ e com o potencial do anel 
$\left(E_{d}\right)$ mantido constante em 1,55 V, sendo estes resultados mostrados na Figura 4. Neste potencial do eletrodo de anel, a oxidação do $\left[\mathrm{Fe}(\mathrm{CN})_{6}\right]^{4-}$ produzido no eletrodo de disco procede sob limite difusional puro, devendo-se notar que a corrente devida a evolução de oxigênio é negligenciável nestas condições.

A determinação da eficiência de coleção $(\mathrm{N})$ do eletrodo disco-anel foi determinada através da razão entre a corrente do eletrodo de anel $\left(I_{a}\right)$ e a corrente do eletrodo de disco $\left(I_{d}\right)$, segundo a expressão:

$N=-\frac{I_{a}}{I_{d}}$

Equação 8

que resultou $\mathrm{N}=0,36$, independente da velocidade de rotação. Este dado significa que 36\% do intermediário formado no eletrodo de disco é coletado no eletrodo anel, sendo este parâmetro também válido para o caso da RRO que é o objeto da presente investigação.

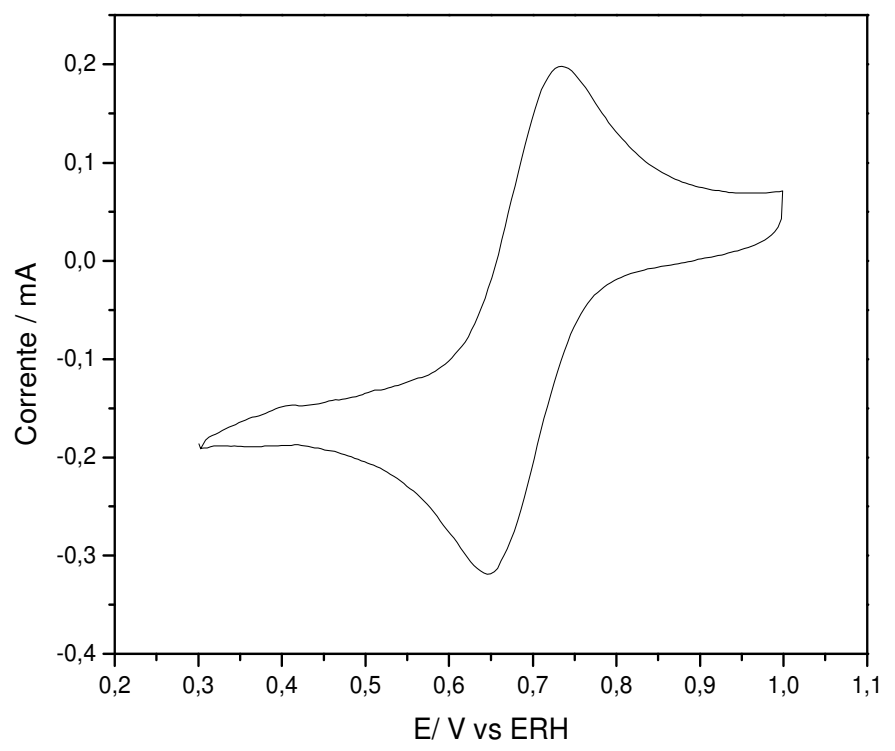

Figura 3: Voltamograma cíclico do $\mathrm{K}_{3} \mathrm{Fe}(\mathrm{CN})_{6} 10 \mathrm{mM}$ em $\mathrm{H}_{2} \mathrm{SO}_{4} 0,5 \mathrm{M}$ saturado com $\mathrm{N}_{2}$. Velocidade de varredura de $50 \mathrm{mV} / \mathrm{s}$. 


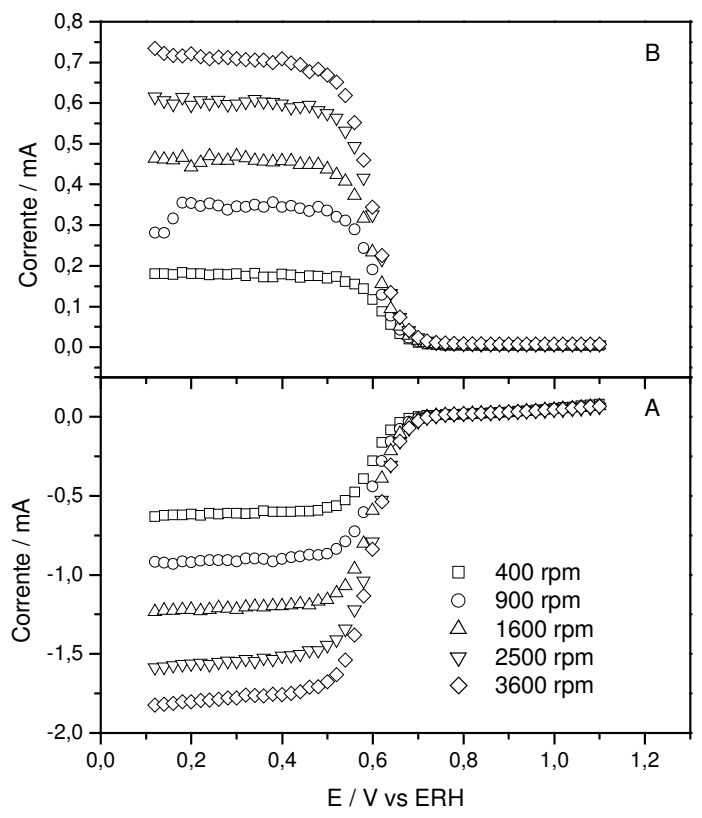

Figure 4: Varredura linear (positiva) para o sistema $\mathrm{Fe}(\mathrm{CN})_{6}{ }^{3-} 10 \mathrm{mM} \mathrm{em} \mathrm{H}_{2} \mathrm{SO}_{4} 0,5 \mathrm{M}$, velocidade de varredura de $20 \mathrm{mV} / \mathrm{s}$. $E_{d}=1,55 \mathrm{~V}$. A) eletrodo de disco e $B$ ) eletrodo de anel. 


\section{CAPÍTULO III}

\section{RESULTADOS E DISCUSSÃO}

\subsection{Estudo da RRO sobre o substrato}

Inicialmente, foram realizados experimentos para a obtenção de voltamogramas cíclicos do substrato de carbono pirolítico e do substrato carbono Vulcan XC-72 em solução de $\mathrm{H}_{2} \mathrm{SO}_{4}$ 0,5 M saturada com $\mathrm{N}_{2}$. A Figura 5 mostra os resultados obtidos, notando-se que os perfis são aqueles tipicamente encontrados para os substratos carbono pirolítico e carbono Vulcan XC-72 em meio ácido [55]. O comportamento voltamétrico é caracterizado por uma extensa faixa de potencial disponível para estudos eletroquímicos, que somente é limitada por processos de corrosão do carbono e/ou pela evolução de oxigênio (limite anódico) e de hidrogênio (limite catódico). A inexistência de picos de corrente em toda faixa de potencial, como apresentado por estes materiais, indica que as correntes observadas são de natureza capacitiva. Voltamogramas cíclicos oferecem poucas informações sobre as propriedades intrínsecas de superfícies como carbono. Entretanto, constituem numa maneira útil para demonstrar a estabilidade deste material em meio ácido no intervalo de potencial utilizado durante o estudo da reação de redução de oxigênio. 


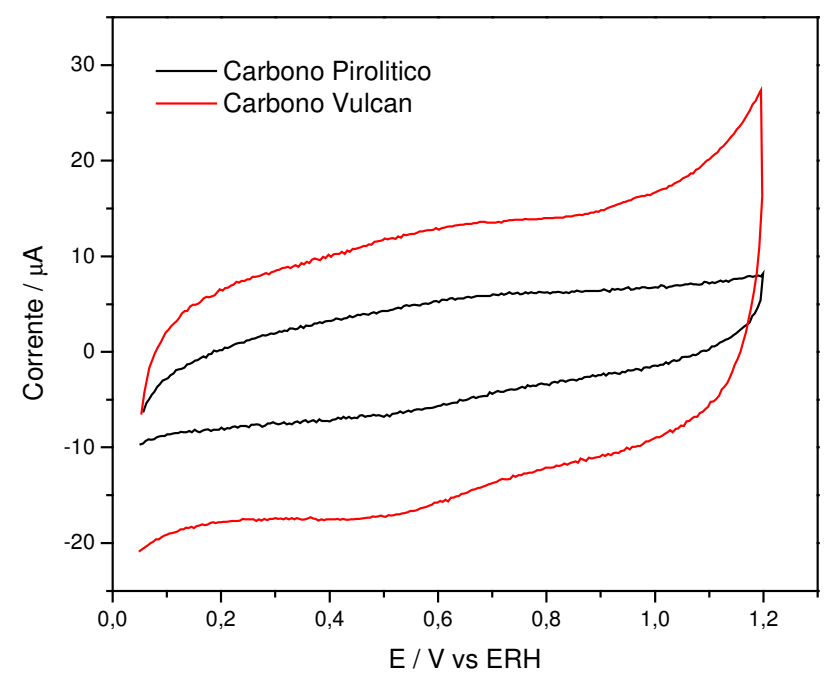

Figura 5: Voltamograma cíclico para o eletrodo de carbono pirolítico e para o eletrodo de camada ultrafina de carbono Vulcan XC-72 em $\mathrm{H}_{2} \mathrm{SO}_{4}$ 0,5 M saturado com $\mathrm{N}_{2} \mathrm{em} 50 \mathrm{mV} / \mathrm{s}$.

As curvas de polarização para a RRO sobre carbono pirolítico, que compõe o substrato do eletrodo de disco rotatório, bem como sobre este substrato com uma camada ultrafina de carbono Vulcan XC-72 foram obtidas potenciostaticamente, ponto a ponto, com tempo de estabilização de 30 segundos em cada ponto. A obtenção dos dados foi iniciada após borbulhar $\mathrm{O}_{2}$ na solução por 40 minutos para que houvesse saturação da mesma. Os resultados são mostrados na Figura 6. Nota-se que tanto o carbono pirolítico como o carbono Vulcan são inativos frente à $\mathrm{RRO}$ em meio ácido para potenciais maiores que $0,20 \mathrm{~V}$ versus $\mathrm{ERH}$, que representa a região de maior interesse para o caso dos eletrodos de disco que contém platina. Consistentemente não foi notado valor significativo de corrente para o eletrodo de anel. 


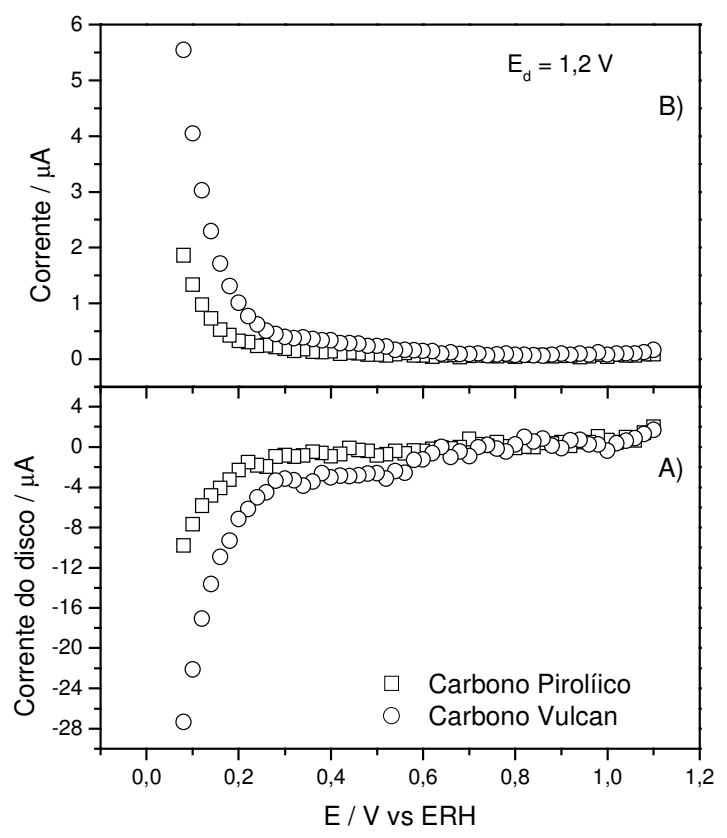

Figura 6: Curvas de polarização de estado estacionário, obtidos ponto a ponto para a redução de $\mathrm{O}_{2}$ sobre diferentes substrato em $\mathrm{H}_{2} \mathrm{SO}_{4}$ 0,5 M a $1600 \mathrm{rpm}$. A) eletrodo de disco e B) eletrodo de anel.

\subsection{Estudo da RRO sobre catalisador de Pt/C comercial}

Na Figura 7 é apresentado o difratograma de raio-X para o catalisador de Pt/C (ETek). A reflexão observada em $2 \theta=25^{\circ}$ é associada ao carbono que serve de suporte para o metal catalítico. O padrão do difratograma é o característico da platina apresentando estrutura cúbica de face centrada. Os largos picos do difratograma indicam que o catalisador apresentase com baixo tamanho de cristalito. O tamanho de cristalito foi calculado através dos dados de difração de raio-X utilizando-se a equação de Scherrer, resultando em um valor médio de 2,7 $\mathrm{nm}$. 


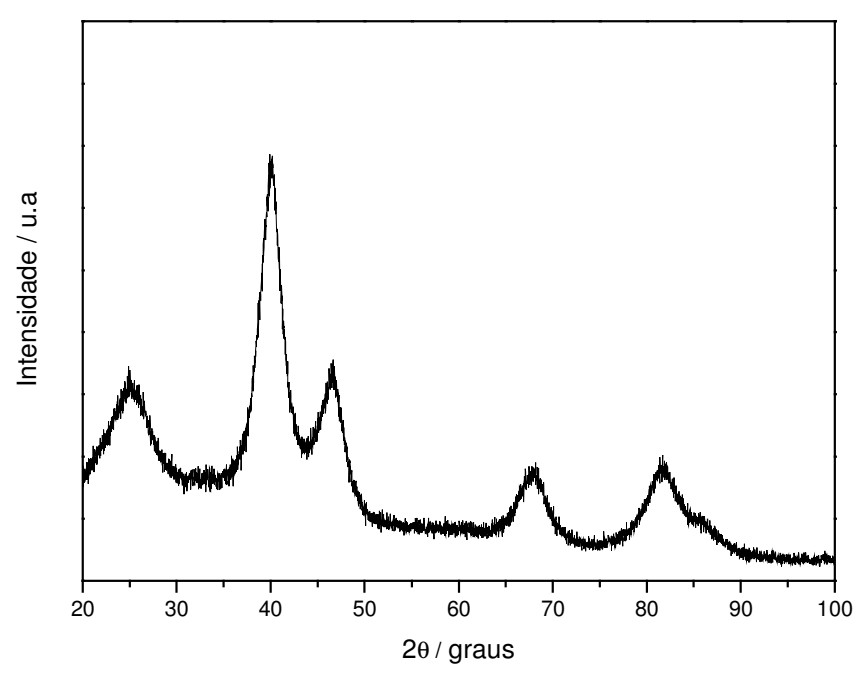

Figura 7: Difratograma para Pt/C comercial (E-tek)

A Figura 8 apresenta os resultados obtidos por espectroscopia de absorção de raios-X, sendo mostrados os espectros XANES na borda $\mathrm{L}_{3}$ da Pt, relativos aos eletrocatalisadores de $\mathrm{Pt} / \mathrm{C}$ submetidos a diferentes potenciais. A absorção na borda $\mathrm{L}_{3}$ da $\mathrm{Pt}$ corresponde à transição eletrônica $2 p_{z}-5 d$ e a magnitude do pico de absorção, chamada de linha branca, localizado em torno $5 \mathrm{eV}$ está diretamente relacionada com a ocupação do estado eletrônico $5 \mathrm{~d}$. Analisando-se a Figura 8 nota-se claramente que a ocupação da banda 5d da Pt é alterada quando se varia o potencial do eletrodo, sendo que na região onde se inicia a RRO, em torno de 0,9 V há uma diminuição da ocupação da banda 5d da Pt (aumento da vacância), sendo que a vacância aumenta com o aumento do potencial do eletrodo. Este aumento da vacância devese ao fato da formação de óxidos de platina, o qual retira densidade eletrônica da platina. 


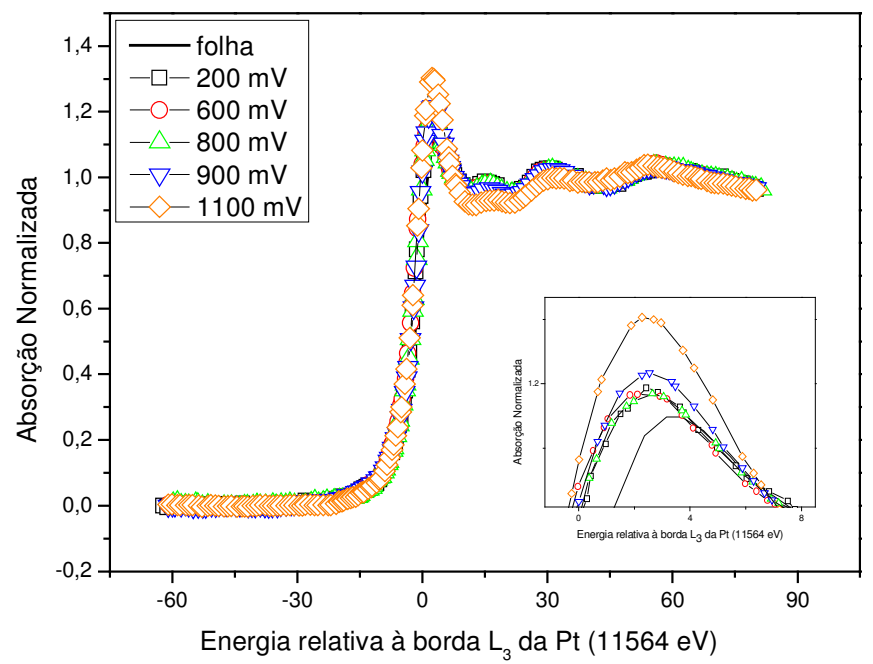

Figura 8: Espectro de XANES na borda $\mathrm{L}_{3} \mathrm{Pt}$ para o eletrocatalisador de $\mathrm{Pt} / \mathrm{C}$ em diferentes potenciais do eletrodo (vs. ERH) em $\mathrm{H}_{2} \mathrm{SO}_{4} 0,5 \mathrm{~mol} \mathrm{~L}^{-1}$.

A Figura 9 apresenta o voltamograma cíclico de eletrodo de disco contendo camada ultrafina de Pt/C 20\% (comercial E-Tek). Notam-se claramente os picos referentes aos processos de adsorção-dessorção de hidrogênio, formação e redução de óxidos, estando o perfil voltamétrico em concordância com os amplamente apresentados na literatura.

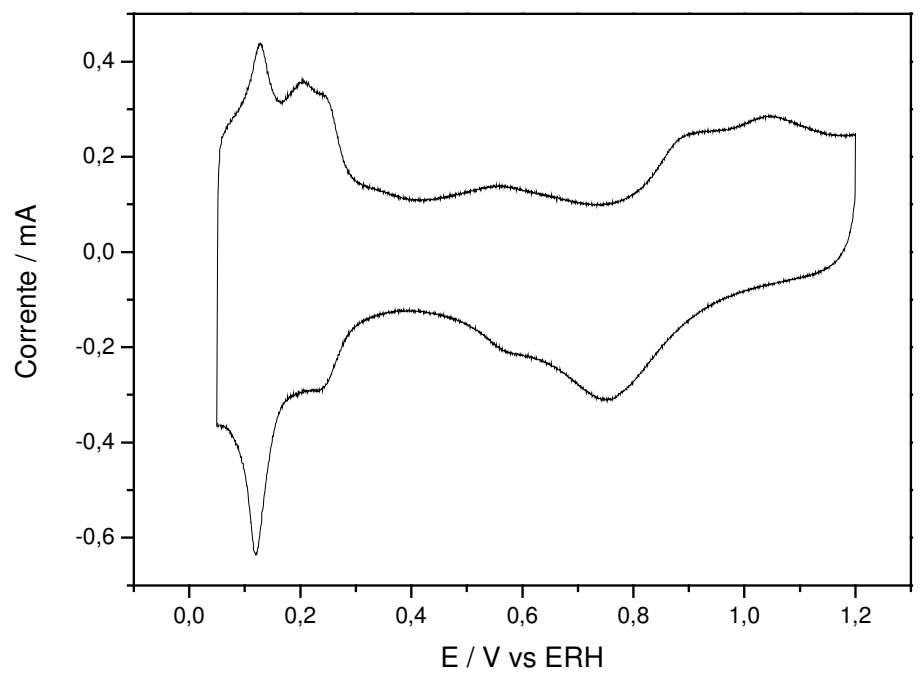

Figura 9: Voltamograma cíclico para o eletrodo de Pt/C $20 \%$, em solução de $\mathrm{H}_{2} \mathrm{SO}_{4}$ 0,5 M saturado com $\mathrm{N}_{2}, \mathbf{v}=\mathbf{5 0} \mathrm{mV} / \mathrm{s}$. 
As curvas de polarização para a redução de oxigênio sobre o eletrodo de $\mathrm{Pt} / \mathrm{C}$ em solução de $\mathrm{H}_{2} \mathrm{SO}_{4}$ 0,5 $\mathrm{M}$ saturada com $\mathrm{O}_{2}$ foram registradas de forma similar à mencionada anteriormente para o substrato de carbono Vulcan e pirolítico. Entretanto, as curvas sempre apresentaram pronunciada histerese entre as polarizações na direção catódica e anódica de varredura do potencial, conforme ilustra a Figura 10, fato que tem sido também observado anteriormente para este catalisador [56]. Este comportamento é normalmente explicado pelo fato de que a superfície da Pt está inicialmente recoberta com óxidos nos estágios iniciais da polarização no sentido catódico, mas encontra-se na forma reduzida após a reversão do sentido de polarização, conforme é comprovado por um exame do comportamento voltamétrico da superfície de Pt e pelos resultados de XANES. Analisando os resultados das Figuras 8 e 9 nota-se que quando se inicia a varredura de potencial no sentido catódico, a superfície do eletrodo se encontra bastante recoberta com óxidos o que inibe a adsorção de $\mathrm{O}_{2}$, portanto, afetando a atividade catalítica.

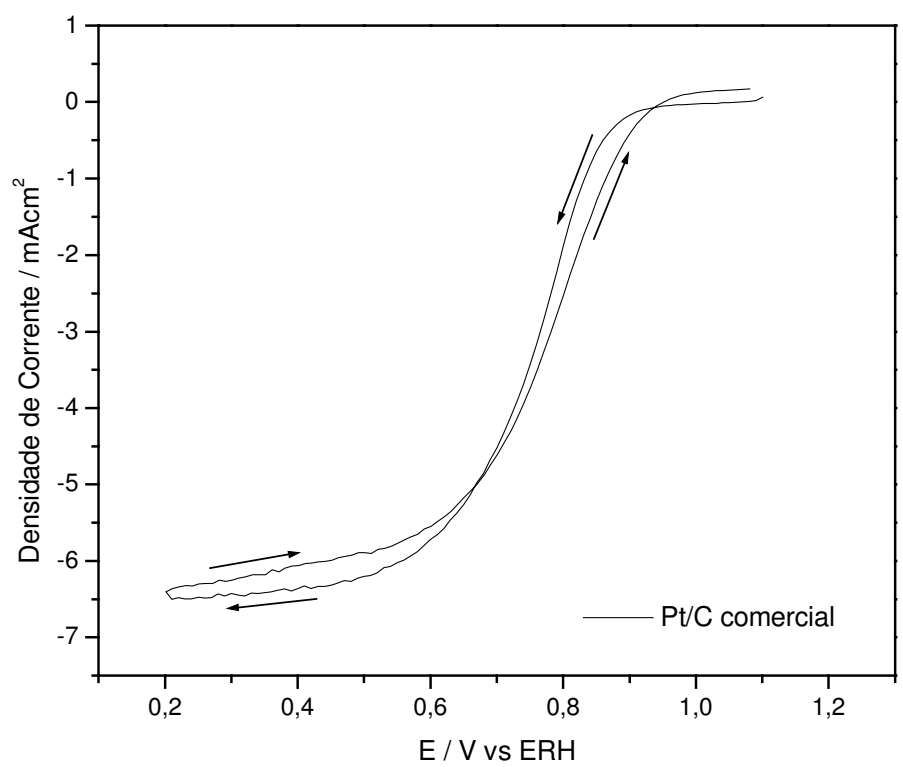

Figure 10: Curva potenciodinâmica (5 mV/s) para a RRO sob Pt/C em $\mathrm{H}_{2} \mathrm{SO}_{4} 0,5 \mathrm{M}, \omega=3600 \mathrm{rpm}$. 
Devido ao fato de que a curva de polarização registrada no sentido catódico apresenta um patamar de corrente difusional bem definido e o potencial de circuito aberto (aproximadamente $1 \mathrm{~V}$ ) já ser o suficiente para haver a formação de óxidos sobre a superfície do eletrodo, somente os resultados obtidos durante as varreduras catódicas foram consideradas para as análises a seguir.

As curvas de polarização obtidas para o catalisador com $20 \%$ Pt/C em várias velocidades de rotação estão mostradas na Figura 11, onde se inclui os perfis de corrente no disco referentes a RRO em Vulcan (a 1600 rpm) e no anel referentes à oxidação do peróxido de hidrogênio formado no disco $\left(E_{d}=1,2 \mathrm{~V}\right)$. Nota-se que, como esperado, há um aumento da corrente limite difusional (Figura 11a) assim como um aumento nas correntes de oxidação de íons peróxido (Figura 11b) com o aumento da velocidade de rotação do eletrodo.

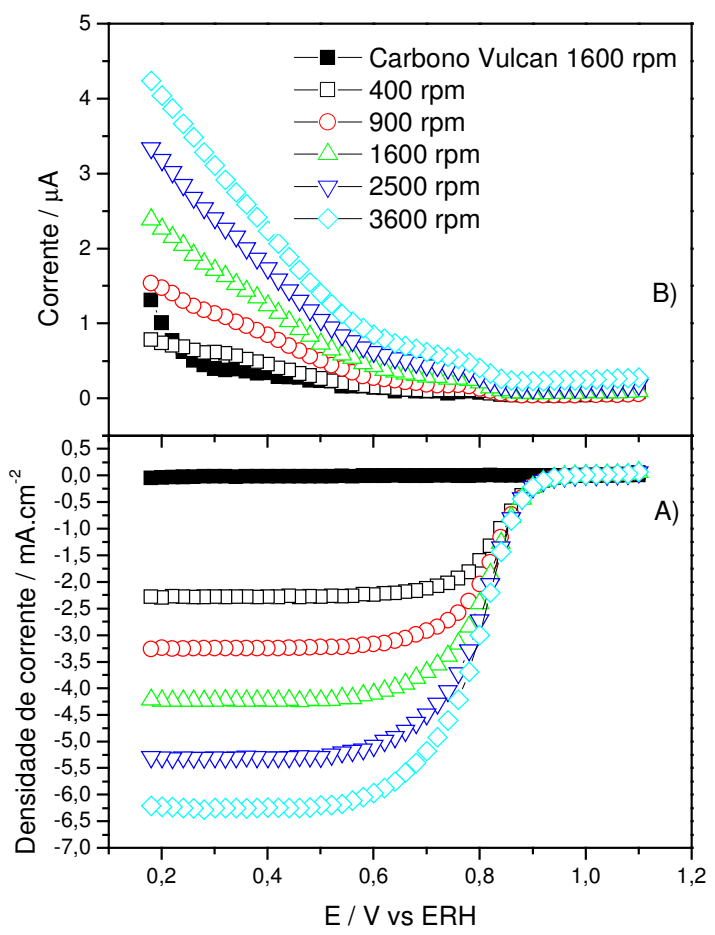

Figura 11: Curva de polarização de estado estacionário para a RRO sobre Pt/C comercial em $\mathrm{H}_{2} \mathrm{SO}_{4} 0,5$ M. (A) eletrodo de disco, (B) eletrodo de anel. 
Conforme já mencionado, observa-se através da Figura 11 que o carbono Vulcan apresenta atividade catalítica desprezível frente à RRO em meio ácido, em comparação ao efeito catalítico devido às partículas de Pt. Neste último caso, a RRO tem início em aproximadamente $0,94 \mathrm{~V}$, evidenciando o elevado sobrepotencial inicial da reação (cerca de $290 \mathrm{mV}$ em relação ao valor termodinâmico padrão $\mathrm{E}^{\mathrm{o}}=1,23 \mathrm{~V}$ ) devido à baixa cinética reacional. $\mathrm{Na}$ região de potencial entre $0,9-0,6 \mathrm{~V}$ a $\mathrm{RRO}$ está atuando sob controle misto, cinético e difusional (transporte de massa), a qual é seguida por uma região controlada puramente pelo transporte de massa (controle difusional).

Uma análise mais detalhada destes resultados pode ser feita através do equacionamento para a resposta do eletrodo de disco efetuada por Koutecký-Levich (K-L). Para uma reação de primeira ordem com relação às espécies reagentes, a corrente observada (i) num eletrodo de disco rotatório pode ser expressa por [57]:

$\frac{1}{\mathrm{i}}=\frac{1}{\mathrm{i}_{\mathrm{k}}}+\frac{1}{\mathrm{i}_{\mathrm{d}}}$

Equação 9

sendo $i_{d}$ a corrente limite difusional expressa por

$i_{d}=B \omega^{1 / 2}$

Equação 10

sendo B o coeficiente de Levich

$B=0,62 n F A D^{2 / 3} \boldsymbol{V}^{-1 / 6} C^{*}$

Equação 11

e $i_{k}$ a corrente cinética expressa por

$i_{k}=\operatorname{FAnk}(E) C^{*}$

Equação 12

onde:

n = número de elétrons envolvido por mol da espécie reagente

$\mathrm{A}=$ área do eletrodo

$\mathrm{F}=$ constante de Faraday

$\mathrm{D}=$ coeficiente de difusão da espécie reagente 
$v=$ viscosidade cinemática

$\mathrm{C}^{*}=$ concentração da espécie reagente no seio da solução

$\mathrm{k}(\mathrm{E})=$ constante de velocidade da reação, à qual é dependente do potencial do eletrodo

$\omega=$ velocidade angular em $\mathrm{rad} . \mathrm{s}^{-1}$

Esta equação envolve a suposição de uma distribuição uniforme de corrente e uma contribuição desprezível da reação no sentido inverso (reação irreversível). Portanto, os gráficos de $\mathrm{i}^{-1}$ versus $\omega^{-1 / 2}$, para diferentes valores de potencial, devem apresentar um comportamento linear com interceptos correspondentes a $i_{k}$ e inclinações que permitem avaliar n (equação 9).

A Figura 12 apresenta os gráficos de $\mathrm{i}^{-1}$ versus $\omega^{-1 / 2}$ para a RRO sobre Pt/C $20 \% \mathrm{em}$ solução $0,5 \mathrm{M}$ de $\mathrm{H}_{2} \mathrm{SO}_{4}$ para diferentes potenciais do eletrodo. A linearidade e o alto paralelismo destes gráficos indicam que a equação 9 é perfeitamente aplicável. Portanto, conclui-se que a reação processa-se segundo uma cinética de primeira ordem com relação ao $\mathrm{O}_{2}$ dissolvido. Além disso, por meio do coeficiente angular calculado e da equação 10, com os seguintes parâmetros [58]: $\mathrm{D}=1,4 \times 10^{-5} \mathrm{~cm}^{2} \mathrm{~s}^{-1}, \mathrm{C}^{*}=1,1 \times 10^{-6} \mathrm{molcm}^{-3}, v=1 \times 10^{-2} \mathrm{~cm}^{2} \mathrm{~s}^{-1}, \mathrm{~F}=$ $96485 \mathrm{Cmol}^{-1}$ e $\mathrm{A}=0,196 \mathrm{~cm}^{2}$ (área geométrica), o valor de $\mathrm{n}$ pode ser obtido em diferentes potenciais sendo os mesmos apresentados na Tabela 1 (p.35). O valor do coeficiente angular e conseqüentemente o valor de B obtido para Pt/C foi de $0,34 \mathrm{mAcm}^{-2} \mathrm{rad}^{-0,5} \mathrm{~s}^{0,5}$, estando este valor muito próximo ao valor calculado utilizando os parâmetros obtidos da literatura $(0,33$ $\left.\mathrm{mAcm}^{-2} \mathrm{rad}^{-0,5} \mathrm{~s}^{0,5}\right)$, indicando que o número de elétrons envolvido na RRO para este eletrodo é muito próximo de 4. 


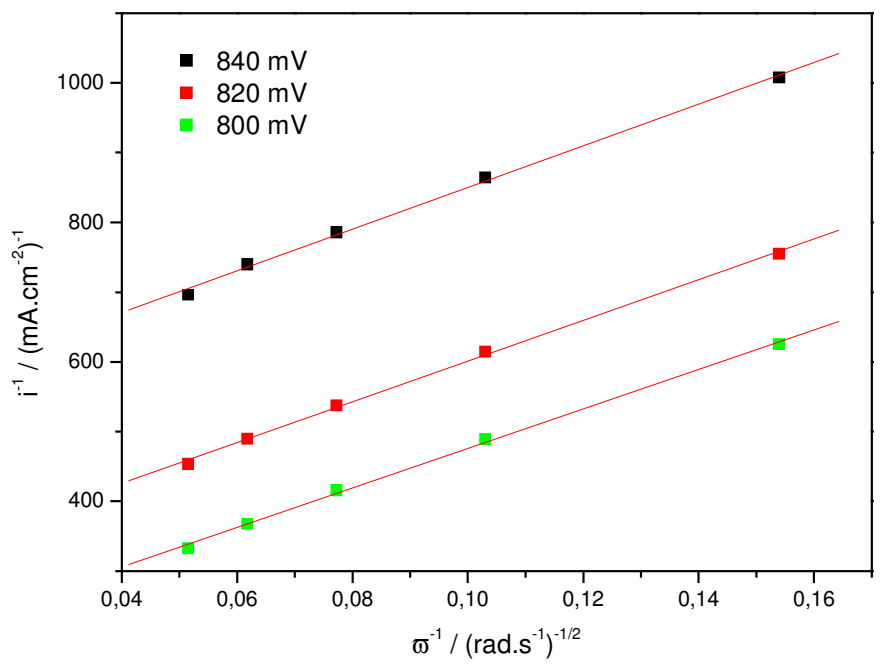

Figura 12: Gráfico de Koutecky-Levich para RRO em Pt/C $20 \%$ comercial em $0,5 \mathrm{M} \mathrm{H}_{2} \mathrm{SO}_{4}$ em diferentes potenciais.

O número de elétrons (n) envolvido durante a RRO também pode ser obtido utilizando-se as correntes dos eletrodos de disco $\left(I_{D}\right)$ e anel $\left(I_{R}\right)$ [59], levando-se em conta as equações de balanço de carga e massa para o sistema. A corrente relacionada ao mecanismo de reação em série está inclusa na corrente do disco via mecanismo direto (4 elétrons). Assim o número de elétrons pode ser obtido diretamente utilizando-se o sistema eletrodo disco-anel rotatórios

$I_{2 e}=\frac{I_{R}}{N}$

Equação 13

$I_{D}=I_{4 e}+I_{2 e}$

Equação 14

$\frac{I_{D}}{n}=\frac{I_{4 e}}{4}+\frac{I_{2 e}}{2}$

Equação 15

Rearranjando temos a equação para o número de elétrons (n)

$n=\left(\frac{4 I_{D}}{I_{D}+\frac{I_{R}}{N}}\right)$

Equação 16 
onde:

$\mathrm{N}$ = fator de eficiência do eletrodo disco-anel rotatório

$\mathrm{I}_{2 \mathrm{e}}=$ corrente no disco devida ao mecanismo via 2 elétrons

$\mathrm{I}_{4 \mathrm{e}}=$ corrente no disco devida ao mecanismo via 4 elétrons

Os resultados obtidos para os valores de n estão incluídos na Tabela 1. Observa-se que em ambos os materiais o número de elétrons envolvido na RRO resulta muito próximo de 4, independentemente do potencial, sendo esse o valor esperado para o catalisador de $\mathrm{Pt} / \mathrm{C}$ em meio ácido [6].

Tabela 1: Número de elétrons em diferentes potenciais calculados a partir do coeficiente angular do gráfico de Koutecky-Levich (K-L) e utilizando os dados do eletrodo disco-anel rotatório (EDAR) para $\mathrm{Pt} / \mathrm{C}$ comercial.

\begin{tabular}{|l|l|l|l|l|l|l|}
\hline Material & $\mathrm{n}_{(0,78 \mathrm{~V})}$ & $\mathrm{n}_{(0,68 \mathrm{~V})}$ & $\mathrm{n}_{(0,58 \mathrm{~V})}$ & $\mathrm{n}_{(0,78 \mathrm{~V})}$ & $\mathrm{n}_{(0,68 \mathrm{~V})}$ & $\mathrm{n}_{(0,58 \mathrm{~V})}$ \\
K-L & K-L & K-L & EDAR & EDAR & EDAR \\
\hline $\mathrm{Pt} / \mathrm{C}$ & 4 & 3,9 & 3,9 & 3,9 & 3,9 & 3,9 \\
\hline
\end{tabular}

As análises comparativas da atividade eletrocatalítica dos diferentes materiais tem sido realizadas através de gráficos de Tafel, construídos com as correntes no disco corrigidas por transporte de massa [30]. Os conceitos fundamentais que dão suporte a estas análises serão discutidos a seguir por razões de consistência. A relação entre a corrente e o potencial para uma reação de transferência de carga mono-eletrônica simples em um dado eletrodo é expressa pela equação de Butler-Volmer [57]:

$i=i_{0}\left\lfloor e^{-\alpha f \eta}-e^{(1-\alpha) f \eta}\right\rfloor$

onde:

$\mathrm{i}_{0}=$ densidade de corrente de troca

$\eta=$ sobrepotencial 
$\mathrm{f}=\mathrm{F} / \mathrm{RT}$

$\alpha=$ coeficiente de simetria

Para elevados valores de $\eta$ um dos termos entre as chaves torna-se negligenciável. Por exemplo, para sobrepotenciais elevados e negativos, que é o caso da RRO, a $\exp (-\alpha f \eta)>>$ $\exp [(1-\alpha) f \eta]$, e a Eq. 17 torna-se:

$i=i_{0} e^{-\alpha f \eta}$

Equação 18

ou aplicando o logarítimo

$\eta=\frac{2,3 R T}{\alpha F} \log i_{0}-\frac{2,3 R T}{\alpha F} \log i$

Equação 19

a qual é conhecida como Equação de Tafel, e o termo $\frac{2,3 R T}{\alpha F}$ como coeficiente de Tafel (b).

Um gráfico de $\eta$ versus $\log$ i é conhecido como diagrama de Tafel. A forma linear do diagrama de Tafel é esperada sempre que a reação reversa contribui com menos de $1 \%$ da corrente, a qual implica que $\eta \mathrm{l}>118 \mathrm{mV}$ a $25^{\circ} \mathrm{C}$. As considerações acima são válidas para regiões de densidades de corrente não muito elevadas onde a corrente do sistema é controlada pela cinética da reação eletródica propriamente dita, (corrente cinética) e não para a região de alta densidade de corrente, onde limitações difusionais contribuem para a polarização do eletrodo, alterando os valores de $\eta$.

Para o caso de uma reação sob controle misto como no presente caso, cuja cinética é governada tanto por parâmetros relacionados à cinética da transferência de carga quanto por transporte de massa, as equações acima são aplicáveis desde que haja correção da corrente para se compensar o efeito difusional. Isto foi efetuado anteriormente [30,57], chegando-se a conclusão de que a corrente cinética $\left(\mathrm{i}_{\mathrm{k}}\right)$ pode ser expressa como: 
$i_{k}=\left(\frac{i_{d}^{*} i}{i_{d}-i}\right)$

Equação 20

onde $\mathrm{i}_{\mathrm{d}}$ é a corrente limite difusional. A equação de Tafel corrigida por transporte de massa assume então a forma:

$\eta=\frac{2,3 R T}{\alpha F} \log i_{0}-\frac{2,3 R T}{\alpha F} \log \left(\frac{i_{d}^{*} i}{i_{d}-i}\right)$

Equação 21

Os diagramas de Tafel corrigidos pelo transporte de massa (E vs. $\left.\log \left(\mathrm{i}_{\mathrm{d}} * \mathrm{i}\right) /\left(\mathrm{i}_{\mathrm{d}}-\mathrm{i}\right)\right)$, para a rotação do eletrodo de 900 rpm é apresentado na Figura 13, para Pt/C. Duas regiões lineares são observadas nesta curva, com coeficientes angulares (inclinações de Tafel) próximos de 60 e $120 \mathrm{mV} \cdot \mathrm{dec}^{-1}$ para regiões de baixas e altas densidades de corrente, respectivamente, sendo estes valores inteiramente concordantes com aqueles apresentados na literatura para eletrocatalisadores de Pt. Considerando que a primeira transferência de carga é a etapa determinante da velocidade (edv) em toda a região de corrente, a mudança na inclinação é atribuída a uma diferença nas condições de adsorção da molécula de oxigênio bem como de espécies contendo oxigênio e intermediários reacionais. A inclinação de aproximadamente 60 $\mathrm{mV} \cdot \mathrm{dec}^{-1}$ ocorre na região de potenciais onde o eletrodo encontra-se recoberto com óxidos superficiais e a mudança na inclinação para aproximadamente $120 \mathrm{mVdec}^{-1}$ inicia-se na região de potenciais abaixo da qual a superfície da platina torna-se livre de óxidos. Portanto, as condições superficiais para a adsorção da molécula de oxigênio, bem como de intermediários reacionais, são totalmente distintas. A adsorção em baixa densidade de corrente ocorre segundo as condições da isoterma de Temkin e em altas densidades de corrente segundo as condições da isoterma de Langmuir. 


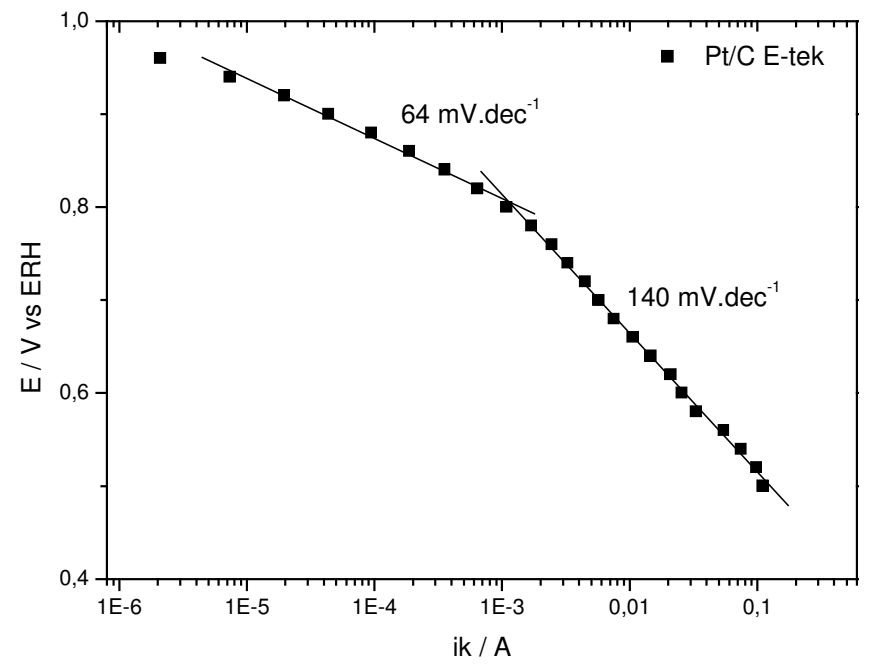

Figure 13: Diagrama de Tafel corrigido por transporte de massa para Pt/C 20\% Etek em 0,5 $\mathrm{M} \mathrm{H}_{2} \mathrm{SO}_{4}, \omega$ $=900 \mathrm{rpm}$.

\subsection{Eletrocatalisadores de Pt-M/C preparados por impregnação}

A Figura 14 apresenta os perfis de difração de raio-X para as diferentes ligas PtM/C preparadas pelo método de impregnação. Para todos os catalisadores, os picos largos indicam materiais nano-estruturados com pequenos tamanhos de cristalito. Os espectros para as ligas apresentam as mesmas características da estrutura cfc da platina pura, porém com picos em ângulos de reflexão deslocados para maiores valores de $2 \theta$, indicando contração dos parâmetros de rede e portanto formação de liga. Exceção foi observada para o catalisador PtV/C, para o qual o deslocamento para maiores valores de $2 \theta$ não foi significativo. Contudo a análise de EDX confirma a presença de vanádio no catalisador, estando o valor da quantidade de vanádio obtido concordante com o valor nominal, assim como para os demais materiais. Em trabalho de Yano et al. [23] foi verificado deslocamento no pico de difração para o catalisador PtV/C preparado pelo método do etileno glicol, contudo essa alteração foi mínima. Este fato evidencia que há dificuldades em se inserir o vanádio no retículo cristalino 
da platina. Nenhum pico relacionado aos metais isolados, $\mathrm{Cr}, \mathrm{Co}, \mathrm{Fe}, \mathrm{V}$ ou Ni é observado. No entanto, a presença de uma fase segregada contendo esses elementos não pode ser descartada, pois podem estar presentes em pequena quantidade ou formando uma fase de óxido amorfo. Os valores dos parâmetros de rede, bem como o tamanho de cristalito dos diferentes materiais estão mostrados na Tabela 2.

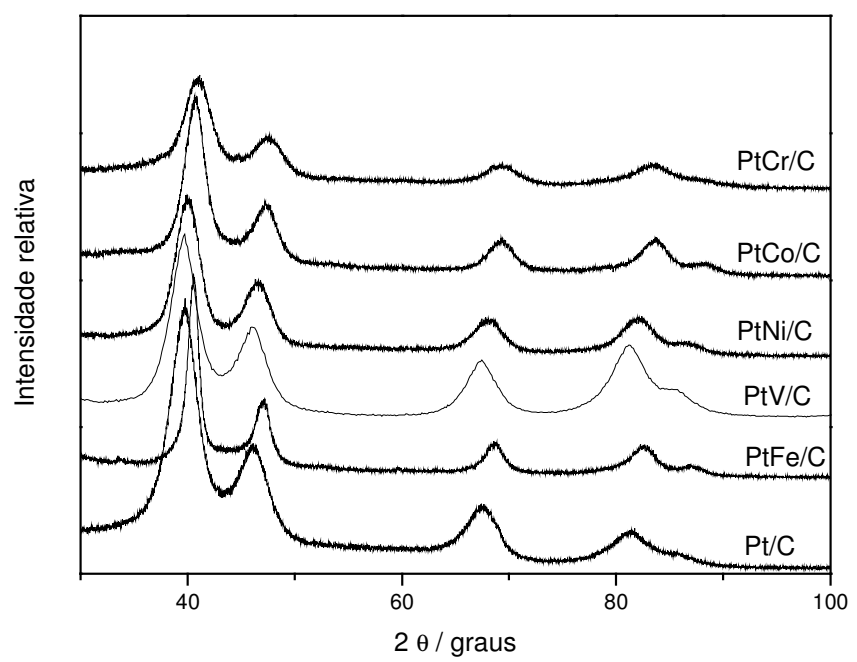

Figura 14: Difração de raio-x da Pt e das ligas de Pt dispersas em carbono

Tabela 2: Propriedades físicas de diferentes ligas de PtM/C.

\begin{tabular}{|c|c|c|}
\hline Catalisador & Tamanho de Partícula $(\mathrm{nm})$ & Parâmetro de Rede $(\AA)$ \\
\hline $\mathrm{Pt} / \mathrm{C}$ & 2,7 & 3,922 \\
\hline $\mathrm{PtV} / \mathrm{C}$ & 3,3 & 3,923 \\
\hline $\mathrm{PtCr} / \mathrm{C}$ & 3,2 & 3,832 \\
\hline $\mathrm{PtFe} / \mathrm{C}$ & 4,8 & 3,868 \\
\hline $\mathrm{PtCo} / \mathrm{C}$ & 4,0 & 3,831 \\
\hline $\mathrm{PtNi} / \mathrm{C}$ & 3,5 & 3,905 \\
\hline
\end{tabular}


A Figura 15 apresenta as curvas de polarização obtidas para o catalisador PtV/C, onde se inclui os perfis de corrente no disco referentes a RRO e no anel referentes à oxidação do peróxido de hidrogênio formado no disco $\left(\mathrm{E}_{\mathrm{d}}=1,2 \mathrm{~V}\right)$, para várias velocidades de rotação. Analisando-se as curvas de polarização nota-se que a resposta do eletrodo segue a mesma tendência que o catalisador de Pt/C (Fig. 11), com um aumento da corrente limite difusional (Figura 15a) assim como um aumento nas correntes de oxidação de íons peróxido (Figura 15b) com o aumento da velocidade de rotação do eletrodo. Devido a este comportamento semelhante, não serão apresentadas as curvas de polarização em todas as velocidades de rotação para todos os materiais, e sim a comparação das respostas dos materiais em uma dada velocidade de rotação. O comportamento muito similar entre as curvas de polarização deve-se ao fato de que o mecanismo da reação deve ser o mesmo tanto em platina quanto em ligas de platina, sendo a diferença no desempenho devida a fatores intrínsecos de cada material.

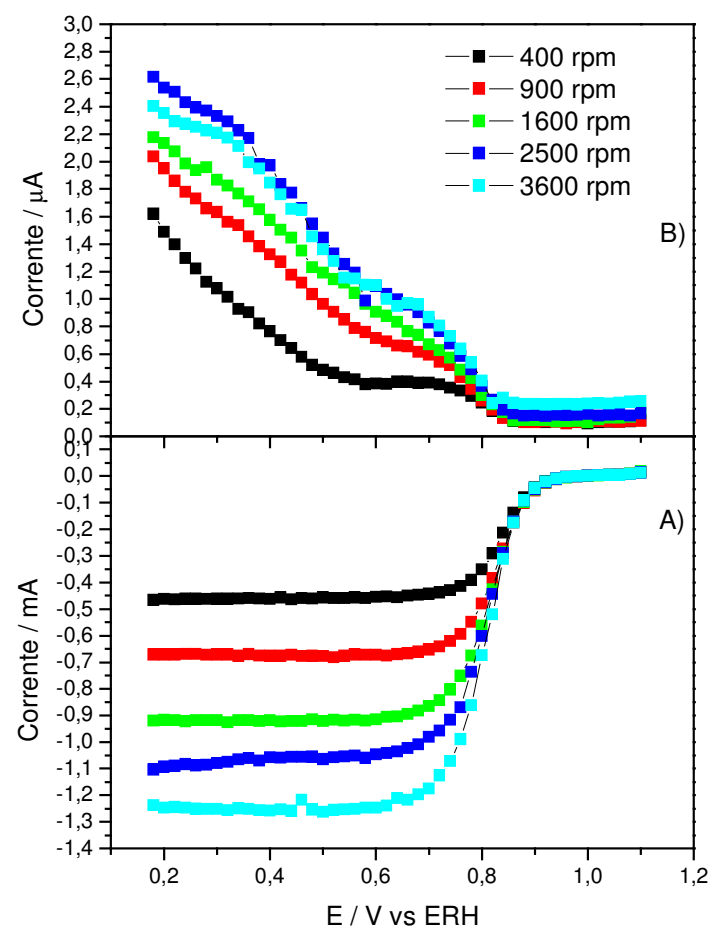

Figura 15: Curva de polarização de estado estacionário para a RRO sobre PtV/C preparado por impregnação em $\mathrm{H}_{2} \mathrm{SO}_{4}$ 0,5 M. (A) eletrodo de disco, (B) eletrodo de anel. 
A Figura 16 mostra as curvas de polarização de estado estacionário no eletrodo de disco e as correntes para a oxidação de $\mathrm{H}_{2} \mathrm{O}_{2}$ no eletrodo anel obtidas a $900 \mathrm{rpm}$, para a RRO nos diversos catalisadores. Nota-se claramente uma diferença de desempenho catalítico para os catalisadores na região de controle cinético misto, que é também a região de interesse prático para a utilização em células a combustível. Ao observar a Figura 16 percebe-se que os eletrodos de $\mathrm{PtCr} / \mathrm{C}$ e PtNi/C, ambos com composição de 75:25, apresentam desempenho catalítico semelhante ao da $\mathrm{Pt} / \mathrm{C}$, iniciando a $\mathrm{RRO}$ praticamente no mesmo valor de sobrepotencial. Por outro lado, os catalisadores de $\mathrm{PtFe} / \mathrm{C}, \mathrm{PtCo} / \mathrm{C}$ e $\mathrm{PtV} / \mathrm{C}$ apresentam uma diminuição do sobrepotencial, o que indica atividade catalítica superior quando comparado a $\mathrm{Pt} / \mathrm{C}$.

É notado que a densidade da corrente limite assume valores próximos para todos os catalisadores e estes apresentam baixos sinais de corrente no anel. A pequena diferença nos valores de corrente limite pode ser atribuída ao fato de que as camadas catalíticas não apresentarem áreas geométricas totalmente iguais de um eletrodo para o outro.

Inaba [60] estudou o efeito da aglomeração do catalisador para a RRO, e verificou que variando-se a carga de catalisador sobre o eletrodo, a morfologia do mesmo se modifica. Com maiores teores de catalisador sobre o eletrodo, o mesmo se apresenta mais aglomerado. Como observado através das micrografias apresentadas por Inaba em seu trabalho, a distância entre as partículas de platina aumenta (o eletrodo está menos aglomerado) com a diminuição da carga de catalisador. Conseqüentemente, a espessura da camada de difusão do oxigênio, paralela a superfície do carbono pirolítico, não pode ser ignorada. O autor encontrou significativa diminuição nos valores da corrente limite para a RRO, uma acentuada queda na atividade catalítica, bem como um drástico aumento na formação de $\mathrm{H}_{2} \mathrm{O}_{2}$, chegando a ser de $65 \%$ o percentual de $\mathrm{H}_{2} \mathrm{O}_{2}$ formado durante a $\mathrm{RRO}$ utilizando o mesmo catalisador, apenas variando a sua quantidade no eletrodo. Como a carga utilizada no presente trabalho foi 
praticamente constante para todos os catalisadores e como as diferenças nos valores de corrente do eletrodo anel e do disco são muito pequenas, pode-se assumir que a morfologia da camada catalítica é semelhante para todos os eletrodos, sendo a diferença na atividade atribuída somente às diferenças das propriedades intrínsecas de cada material.

As curvas de corrente para o eletrodo de anel indicam que o mecanismo e a quantidade de peróxido formado são praticamente iguais para todos os eletrodos. A variação é inferior a 1 $\mu \mathrm{A}$, e em decorrência dos baixos valores da corrente no eletrodo de anel, o mesmo é suscetível a impurezas do eletrólito. Assim conclui se que no intervalo de operação da célula a combustível $(0,7-0,8 \mathrm{~V})$ a quantidade de peróxido formado é desprezível.

Para melhor comparação da atividade catalítica dos eletrodos os resultados foram analisados através dos diagramas de Tafel apresentados na Figura 17. Estes resultados mostraram que o catalisador de $\mathrm{PtCr}$ tem atividade catalítica semelhante à da $\mathrm{Pt} / \mathrm{C}$, e as demais ligas tem atividade catalítica superior a da Pt/C. Analisando a região de baixo sobrepotencial nota-se que os três melhores catalisadores foram: $\mathrm{PtCo} / \mathrm{C}, \mathrm{PtFe} / \mathrm{C}$ e $\mathrm{PtV} / \mathrm{C}$. O fato dos eletrodos com cobalto e ferro serem melhores do que os com níquel e cromo são coerentes aos vários resultados da literatura, sendo novo o desempenho do catalisador de PtV, uma vez que são escassos os resultados para este catalisador. Nos resultados apresentado por Yano et. al [23] para diversos catalisadores preparados pelo método do etilenoglicol, o catalisador $\mathrm{PtV} / \mathrm{C}$ apresentou o segundo melhor desempenho, perdendo apenas para o $\mathrm{PtCr} / \mathrm{C}$. Como descrito por Mukerjee, há diversos resultados inconsistentes na literatura, materiais iguais apresentam desempenho diferentes dependente do método de preparação, o que parece indicar que os diversos métodos proporcionam composições superficiais distintas.

A Tabela 3 apresenta os valores do coeficiente de Tafel para os catalisadores testados, bem como os valores do número de elétrons obtidos. Os valores obtidos estão coerentes com 
os valores esperados para catalisadores baseados em Pt, conforme já discutidos na seção precedente.

Tabela 3: Coeficientes de Tafel e número de elétrons para diversos catalisadores preparados pelo método de impregnação.

\begin{tabular}{|c|c|c|c|}
\hline Catalisador & $\mathrm{b} 1\left(\mathrm{mVdec}^{-1}\right)$ & $\mathrm{b} 2\left(\mathrm{mVdec}^{-1}\right)$ & $\mathrm{n}$ \\
\hline $\mathrm{Pt} / \mathrm{C}$ & 64 & 140 & 4 \\
\hline $\mathrm{PtCr} / \mathrm{C}$ & 60 & 140 & 4 \\
\hline $\mathrm{PtNi} / \mathrm{C}$ & 55 & 119 & 4 \\
\hline $\mathrm{PtFe} / \mathrm{C}$ & 61 & 130 & 4 \\
\hline $\mathrm{PtCo} / \mathrm{C}$ & 60 & 100 & 4 \\
\hline $\mathrm{PtV} / \mathrm{C}$ & 55 & 131 & 4 \\
\hline
\end{tabular}

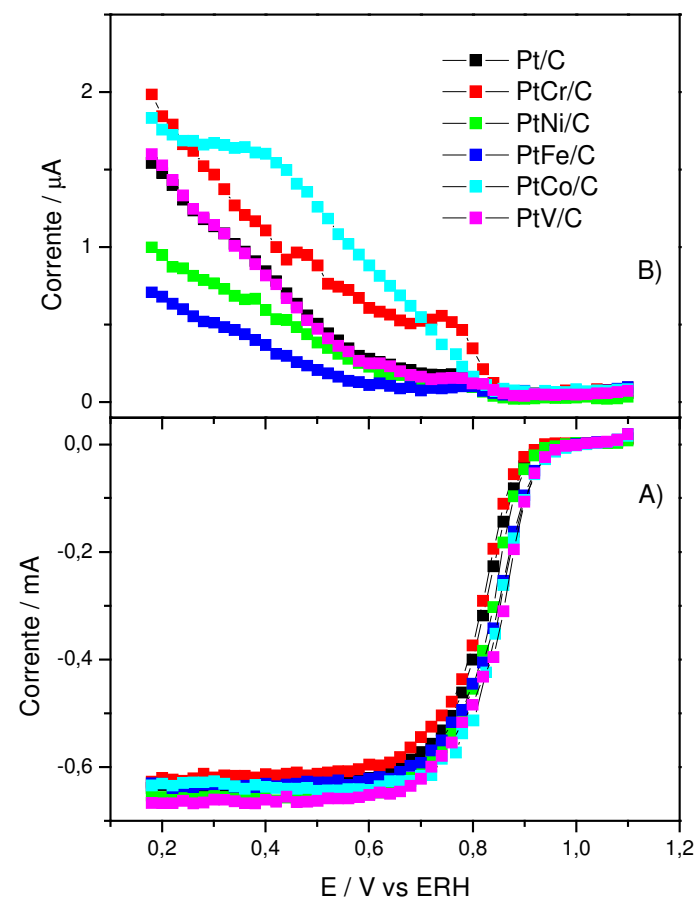

Figura 16: Curva de polarização de estado estacionário para diferentes ligas PtM/C preparado por impregnação frente à $\mathrm{RRO} \mathrm{em}_{2} \mathrm{HO}_{4} \mathrm{0,5}$ M. (A) eletrodo de disco, (B) eletrodo de anel. 


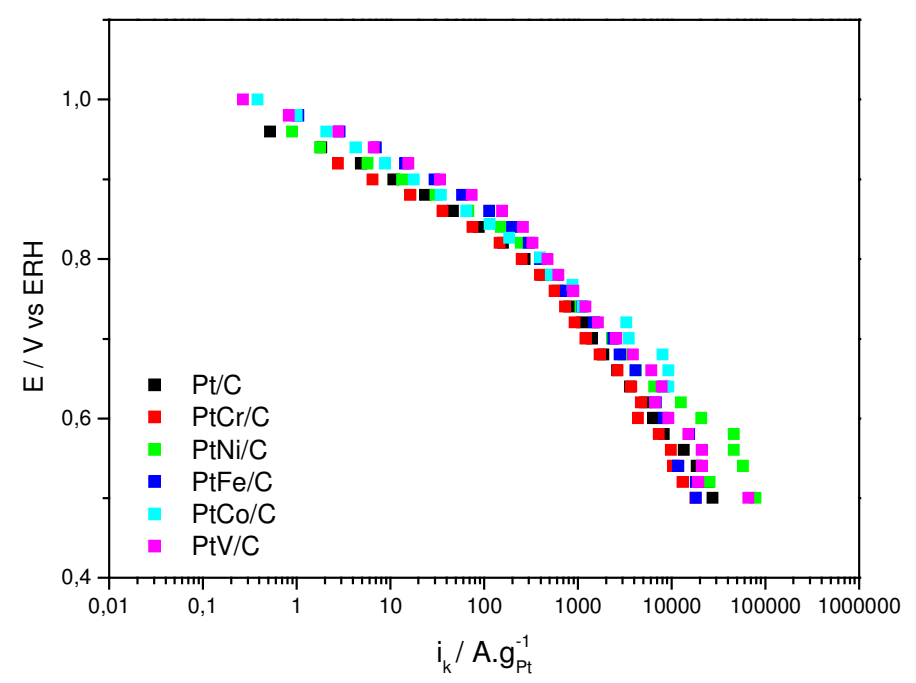

Figura 17: Diagramas de Tafel para diversos catalisadores preparados pelo método de impregnação

As Figuras 18 e 19 apresentam os resultados de XANES obtidos na borda $\mathrm{L}_{3}$ da $\mathrm{Pt}$ a $600 \mathrm{mV}$ e $900 \mathrm{mV}$, respectivamente, para os diversos catalisadores preparados por impregnação. A absorção na borda $\mathrm{L}_{3}$ da Pt $(11564 \mathrm{eV})$ inicia-se com a transição eletrônica $2 p_{3 / 2}-5 d$ e a magnitude do pico de absorção ou linha branca, localizado em 5 eV é diretamente relacionada à ocupação dos estados eletrônicos 5d. Quanto maior a absorção, menor é a ocupação e vice-versa.

Para o eletrocatalisador $\mathrm{Pt} / \mathrm{C}$ em meio ácido, na Figura 8 foi observado que a magnitude da linha branca aumenta com o aumento do potencial do eletrodo. Este fenômeno foi atribuído ao esvaziamento da banda Pt 5d, em concordância com a presença de um efeito de retirada de elétrons pelo oxigênio presente na camada de óxidos formada acima de $0,8 \mathrm{~V}$ na superfície da partícula eletrocatalisadora.

Pela Figura 18, é observado que em $0,6 \mathrm{~V}$ a magnitude da linha branca da Pt é essencialmente a mesma para as diferentes ligas, mostrando que a presença do segundo metal leva a variações desprezíveis na ocupação da banda $5 \mathrm{~d}$ da Pt. Por outro lado, um importante 
fato é observado na Figura 19, onde é notado que o aumento da vacância da banda Pt 5d, causada pela formação de óxidos sobre platina, é menos pronunciado para as ligas, como observado pela magnitude da absorção, que é menor do que a da Pt. Estes resultados indicam menor formação de óxidos sobre a platina nas ligas, com um maior efeito para ligas de $\mathrm{V}, \mathrm{Fe}$ e Co seguindo a tendência com respeito a ordem de atividade dos catalisadores observados pelo diagrama de Tafel. Estes resultados estão em concordância com estudos de XANES prévios obtidos para ligas de Pt em meio ácido [61].

Dois modelos são freqüentemente mencionados na explicação dos resultados da atividade de ligas frente à RRO. Uma hipótese [24] assume que a melhora na atividade catalítica frente à RRO pode ser devida ao aumento da vacância da banda $5 \mathrm{~d}$ da $\mathrm{Pt}$, a qual poderia resultar em uma maior interação do $\mathrm{O}_{2}$ adsorvido na $\mathrm{Pt}$, facilitando a ruptura da ligação O-O. Ao contrário, seguindo outro modelo [25], a melhora na atividade cinética frente à RRO poderia ser assumida como devida a diminuição da ocupação da banda $5 \mathrm{~d}$ da $\mathrm{Pt}$, o que diminuiria a força de adsorção das espécies oxigenadas, e então a redução dos intermediários contendo espécies oxigenadas tornar-se-ia facilitada. Deste modo no presente caso a melhora na atividade catalítica para os diversos catalisadores pode ser atribuída ao decréscimo da reatividade da Pt para adsorbatos evidenciado pelo menor recobrimento superficial por espécies oxigenadas, conforme observado pelos espectros XANES. 


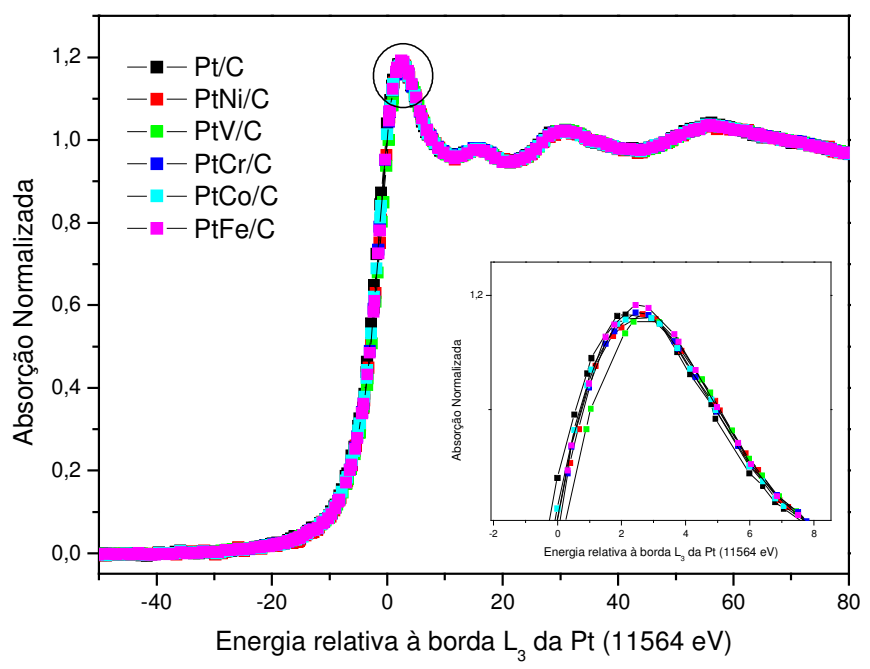

Figura 18: Espectros Xanes a $600 \mathrm{mV}$ para diversos catalisadores preparados pelo método de impregnação.

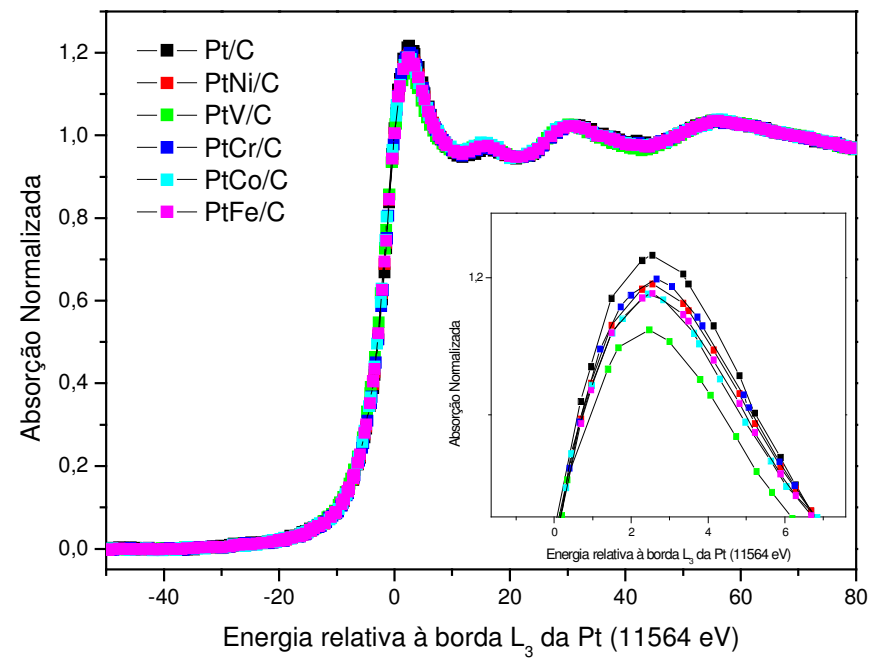

Figura19: Espectros Xanes a $900 \mathrm{mV}$ para diversos catalisadores preparados pelo método de impregnação. 


\subsection{Efeito do tratamento térmico em eletrocatalisadores $\mathrm{Pt} / \mathrm{C}$ e $\mathrm{Pt}-\mathrm{V} / \mathrm{C}$}

$\mathrm{O}$ estudo do efeito do tratamento térmico foi realizado em catalisadores de $\mathrm{Pt} / \mathrm{C}$ e PtV/C comerciais (E-tek). Foram obtidos os difratogramas de raios-X, os quais são apresentados nas Figuras 20 e 21, para os catalisadores de Pt/C e Pt-V/C, respectivamente. A reflexão observada em $2 \theta=25^{\circ}$ é associada ao carbono que serve de suporte para o metal catalítico. Os padrões dos difratogramas indicam que todos os eletrocatalisadores apresentam estrutura cúbica de face centrada, característica de Pt e suas ligas. Assim como o catalisador $\mathrm{PtV} / \mathrm{C}$ preparado por impregnação, o catalisador PtV/C comercial apresenta os picos de reflexão muito pouco deslocados para maiores valores de $2 \theta$ com relação a Pt/C. Os tamanhos de cristalitos para os eletrocatalisadores foram calculados através dos dados de difração de raio-X utilizando-se a equação de Scherrer, sendo os resultados apresentados na Tabela 4.

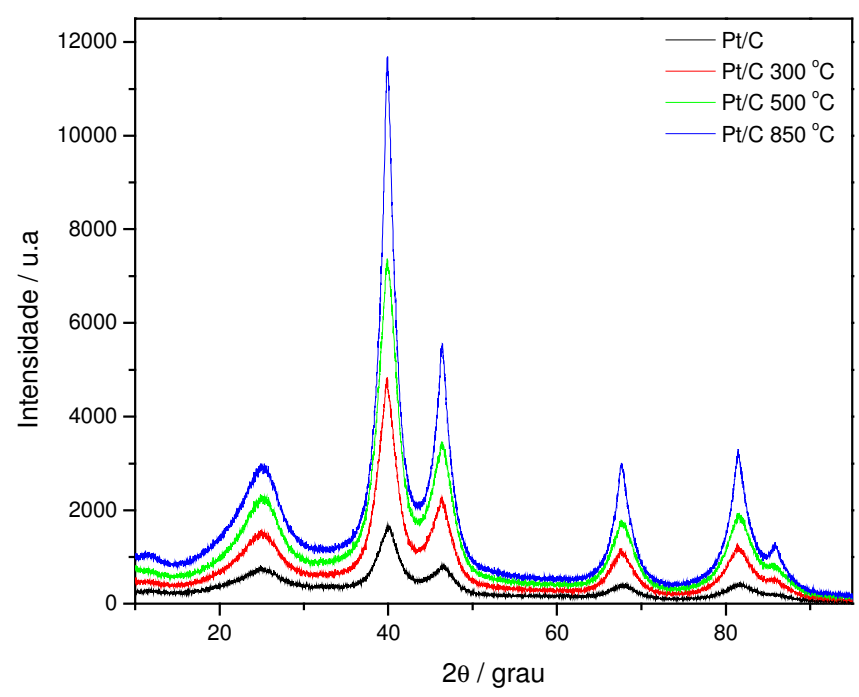

Figura 20: Difratograma de raios-X para os catalisadores de $\mathrm{Pt} / \mathrm{C}$. 


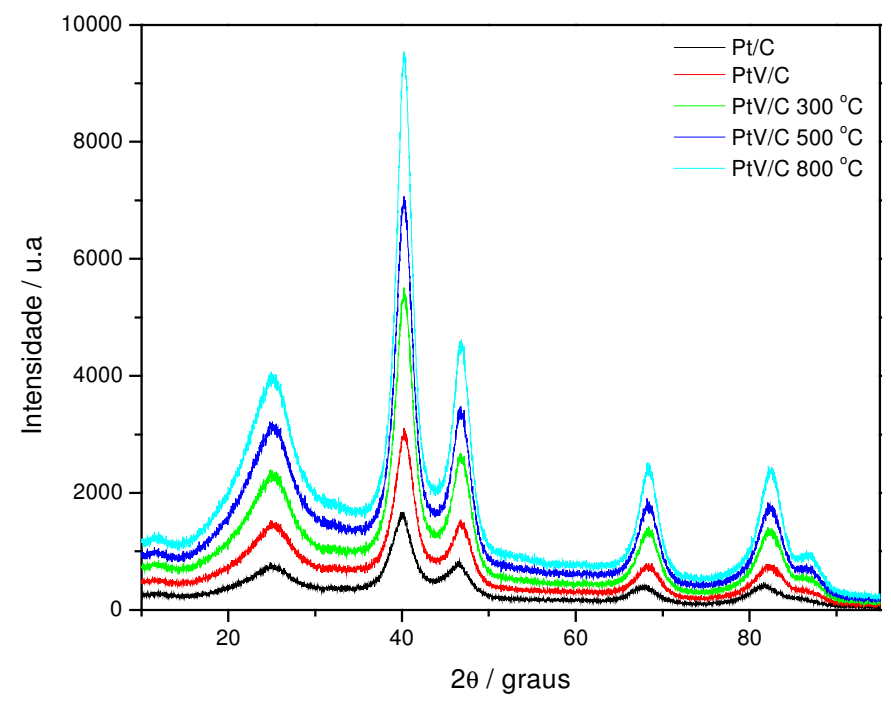

Figura 21: Difratograma de raios-X para os catalisadores de PtV/C.

Os resultados indicam coalescência dos cristalitos dos catalisadores com o aumento da temperatura, sendo observado um claro aumento no tamanho dos cristalitos para os eletrocatalisador de Pt pura tratado termicamente. Os resultados da Tabela 4 também revelam que o catalisador bimetálico PtV/C exibe maior resistência a coalescência dos cristalitos do que os catalisadores contendo somente Pt. Isso pode ser atribuído à menor mobilidade dos átomos de Pt sobre a superfície de carbono quando o vanádio está presente. Tal efeito, denominado efeito âncora, também foi verificado para outras ligas, como o PtFe [42]. Outra possível explicação é o fato de o catalisador PtV/C comercial já sofrer prévio tratamento térmico. 
Tabela 4: Parâmetros estruturais obtidos por DRX para Pt/C e PtV/C tratados termicamente em diferentes temperaturas.

\begin{tabular}{c|c|c}
\hline Catalisador & $\begin{array}{c}\text { Tamanho de } \\
\text { cristalito }(\mathrm{nm})\end{array}$ & $\begin{array}{c}\text { Parâmetro de } \\
\text { rede }(\AA)\end{array}$ \\
\hline $\mathrm{Pt} / \mathrm{C}$ & 2,7 & 3,922 \\
\hline $\mathrm{Pt} / \mathrm{C} 300{ }^{\circ} \mathrm{C}$ & 3,0 & 3,913 \\
\hline $\mathrm{Pt} / \mathrm{C} 500{ }^{\circ} \mathrm{C}$ & 3,2 & 3,918 \\
\hline $\mathrm{Pt} / \mathrm{C} 850{ }^{\circ} \mathrm{C}$ & 7,7 & 3,920 \\
\hline $\mathrm{Pt}-\mathrm{V} / \mathrm{C}$ & 3,5 & 3,8656 \\
\hline $\mathrm{Pt}-\mathrm{V} / \mathrm{C} 300{ }^{\circ} \mathrm{C}$ & 3,7 & 3,8780 \\
\hline $\mathrm{Pt}-\mathrm{V} / \mathrm{C} 500{ }^{\circ} \mathrm{C}$ & 3,9 & 3,8801 \\
\hline $\mathrm{Pt}-\mathrm{V} / \mathrm{C} 850{ }^{\circ} \mathrm{C}$ & 4,4 & 3,8747 \\
\hline
\end{tabular}

As Figuras 22 e 23 apresentam os resultados obtidos por espectroscopia de absorção de raio-X, sendo mostrados os espectros XANES na borda $\mathrm{L}_{3}$ da $\mathrm{Pt}$, relativos aos eletrocatalisadores de Pt/C e Pt-V/C, respectivamente, submetidos a dois potenciais; $650 \mathrm{mV}$ (região da dupla camada) e $900 \mathrm{mV}$ (região do início da RRO). Analisando-se as Figuras 22 e 23 nota-se claramente que a ocupação da banda $5 \mathrm{~d}$ da Pt sofre uma pequena alteração quando se varia o potencial do eletrodo, sendo que na região onde se inicia a RRO há uma diminuição da ocupação da banda 5d da Pt (aumento da vacância), o que indica que a superfície das partículas de ambos os eletrocatalisadores estão ligeiramente oxidadas neste potencial $(0,9 \mathrm{~V})$.

Nas Figuras 24 e 25 apresentam-se os espectros XANES a $650 \mathrm{mV}$ e $900 \mathrm{mV}$, respectivamente, onde se compara a intensidade de absorção para $\mathrm{Pt} / \mathrm{C}$ e $\mathrm{PtV} / \mathrm{C}$ sem tratamento térmico. Nota-se pela Figura 24 que em $650 \mathrm{mV}$, na região da dupla camada, onde não há formação de óxidos sobre os sítios de platina a ocupação da banda $5 \mathrm{~d}$ da platina é muito semelhante para ambos os catalisadores. Entretanto, em $900 \mathrm{mV}$, região na qual há formação de óxidos sobre os sítios de platina, mesmo havendo esvaziamento da banda $5 \mathrm{~d}$ da platina para o catalisador PtV/C como mostra a Figura 25, a mesma encontra-se com maior ocupação do que no catalisador Pt/C, corroborando o resultado de XANES para o catalisador 
PtV/C preparado por impregnação. Essa alteração de propriedade eletrônica, ocasionada pela maior ocupação na banda 5d da Pt no catalisador PtV/C quando comparado ao Pt/C, ambos a $900 \mathrm{mV}$, tem como conseqüência, menor interação dos sítios de platina com espécies oxigenadas, o qual reduz a formação superficial de óxidos, provendo mais sítios livres para a adsorção de oxigênio. As Figuras 26 e 27 apresentam exemplos dos resultados de XANES a $900 \mathrm{mV}$, relativos aos catalisadores de $\mathrm{Pt} / \mathrm{C}$ e PtV/C submetidos a diversas temperaturas de tratamento térmico em atmosfera redutora. Nota-se pela Figura 26, que conforme se aumenta à temperatura do tratamento térmico, aumenta-se ligeiramente à ocupação da banda $5 \mathrm{~d}$ da Pt. Entretanto, o mesmo não ocorre para o catalisador $\mathrm{Pt}-\mathrm{V} / \mathrm{C}$ onde praticamente não ocorre alteração na ocupação, como indicado na Figura 27. A ocupação da banda 5d da Pt depende do tamanho de partícula, portanto, a alteração na ocupação da banda 5d observada na Figura 26, pode estar em parte associada à grande variação no tamanho de partícula observada para a Pt pura com o aumento da temperatura. Tendo em vista que para o catalisador Pt-V/C não foi observada uma mudança significativa no tamanho de partícula, a ocupação da banda $5 \mathrm{~d}$ da $\mathrm{Pt}$ manteve-se praticamente inalterada.

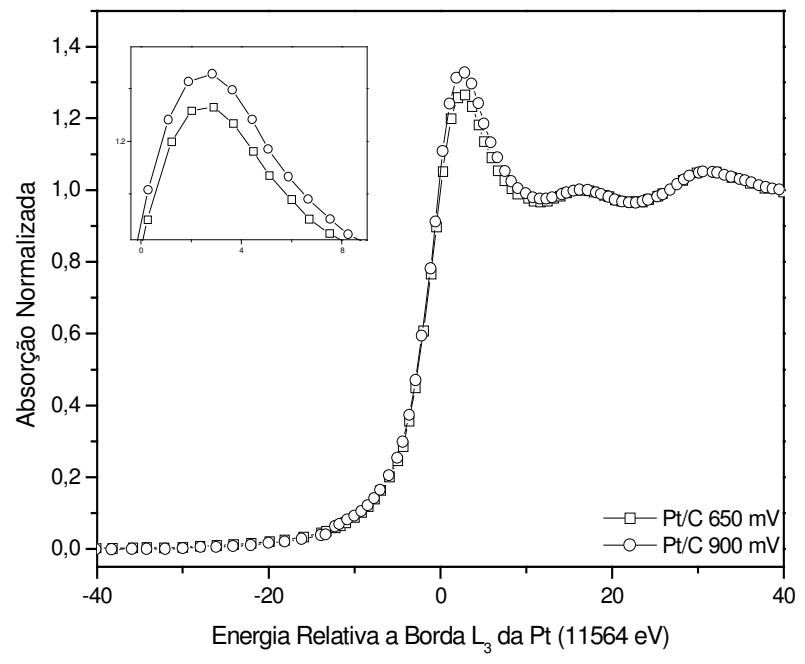

Figura 22: Espectro XANES em diferentes potenciais para $\mathrm{Pt} / \mathrm{C}$ (como recebido). 


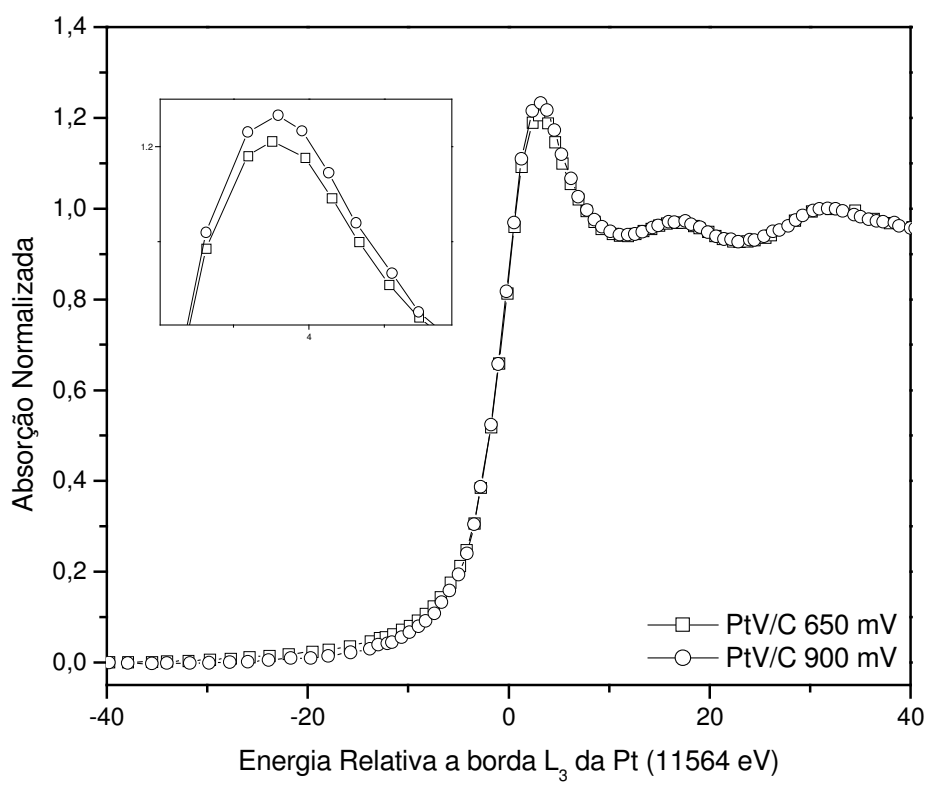

Figura 23: Espectro XANES em diferentes potenciais para Pt-V/C (como recebido)

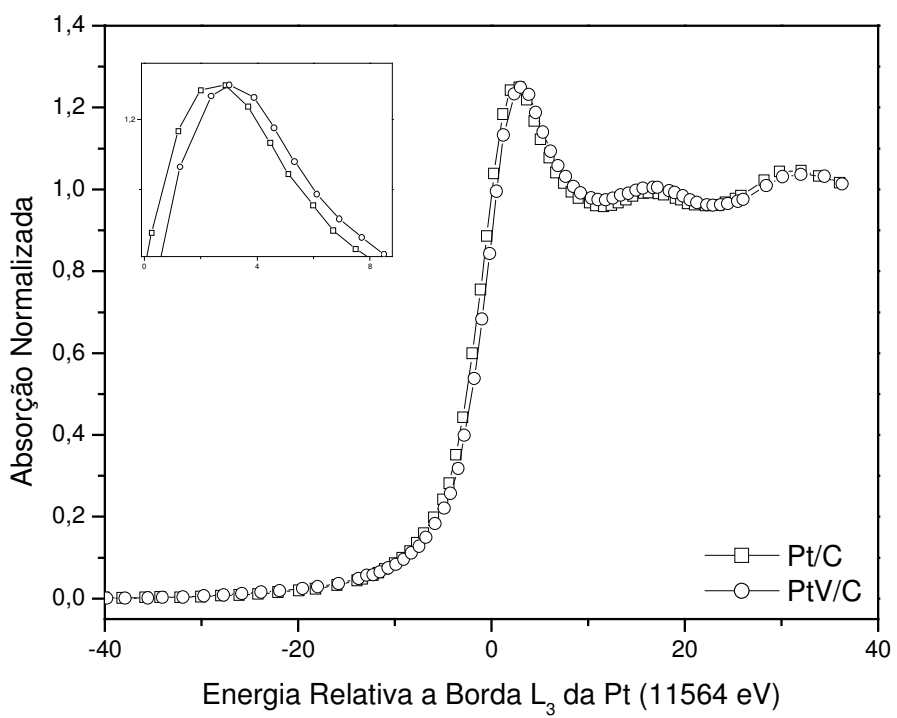

Figura 24: Espectro XANES a $650 \mathrm{mV}$ para Pt/C e Pt-V/C (como recebido). 


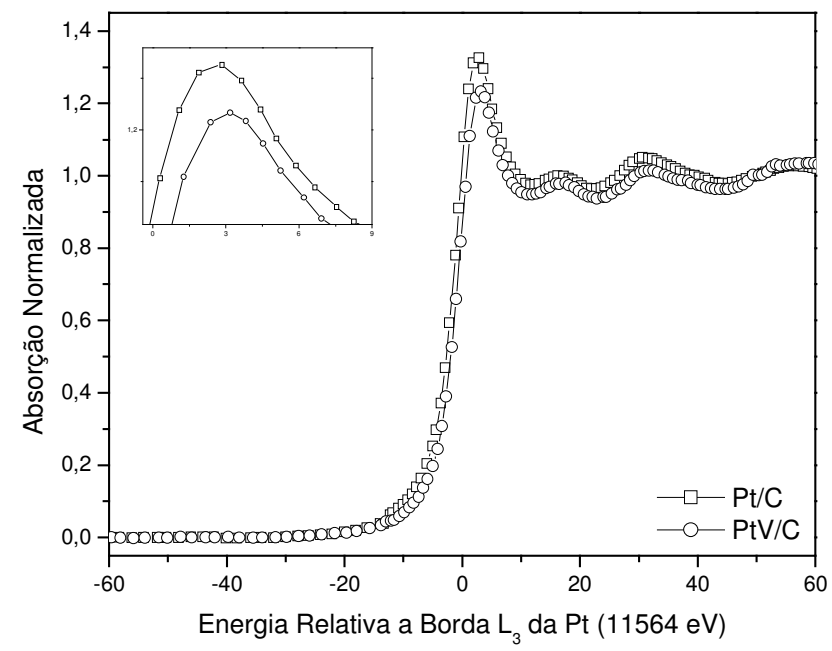

Figura 25: Espectro XANES a $900 \mathrm{mV}$ para Pt/C e Pt-V/C (como recebido).

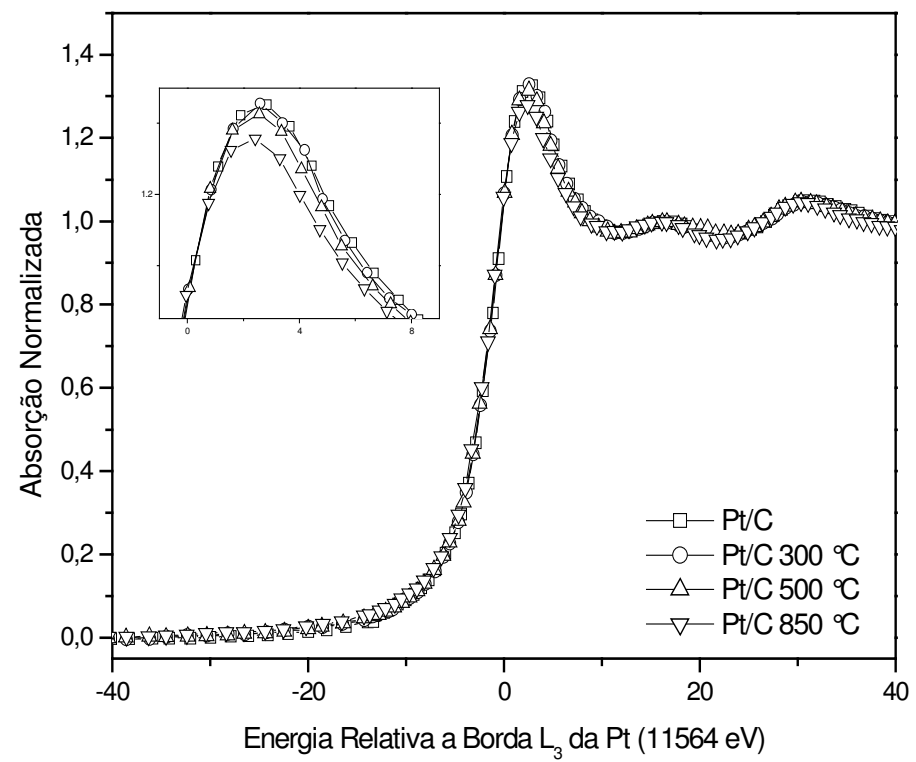

Figura 26: Espectro XANES para Pt/C a $900 \mathrm{mV}$ após os diversos tratamentos térmicos. 


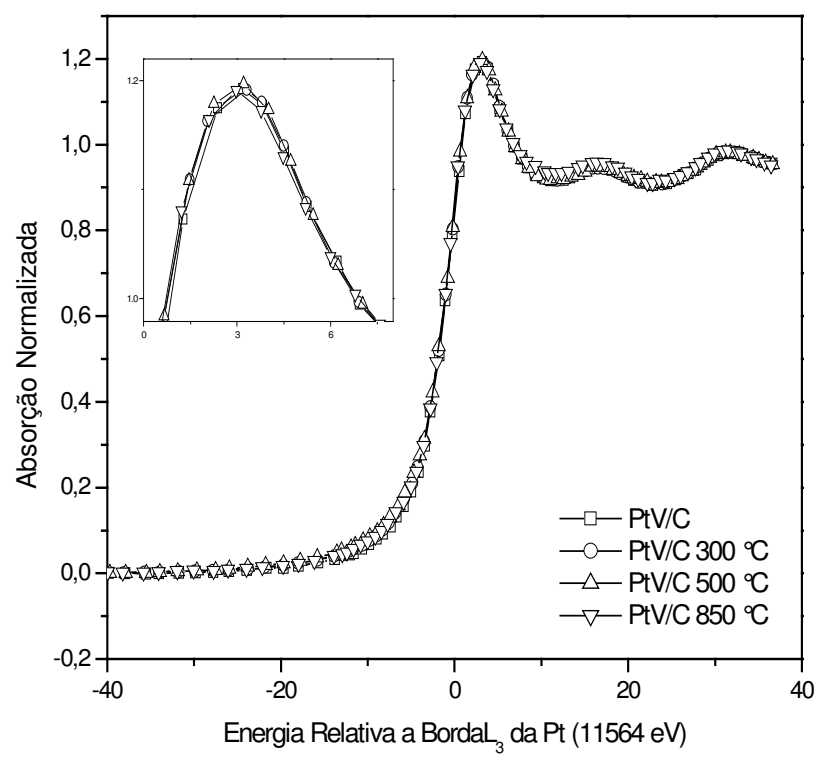

Figura 27: Espectro XANES para PtV/C a $900 \mathrm{mV}$ após os diversos tratamentos térmicos.

Na Figura 28 são apresentados os voltamogramas cíclicos normalizados por área ativa para os catalisadores de $\mathrm{Pt} / \mathrm{C}$ tratados em diferentes temperaturas de tratamento térmico. A área ativa foi obtida integrando-se a carga da região de adsorção/dessorção de hidrogênio, conforme procedimento amplamente descrito na literatura. Pode ser observado na Figura 28 um deslocamento para maiores valores de potenciais (potenciais mais anódicos) do pico de redução dos óxidos de $\mathrm{Pt}$, para o catalisador $\mathrm{Pt} / \mathrm{C}$ tratado a $800{ }^{\circ} \mathrm{C}$, indicando que a redução dos óxidos superficiais é facilitada devido à diminuição da força de adsorção destas espécies com os sítios de platina. Esta observação está de acordo com os dados de XANES, onde observa-se maior ocupação da banda $5 \mathrm{~d}$ para o catalisador $\mathrm{Pt} / \mathrm{C} 800^{\circ} \mathrm{C}$, e portanto apesar das diferenças de tamanho de partículas evidenciar menor interação com espécies oxigenadas. 


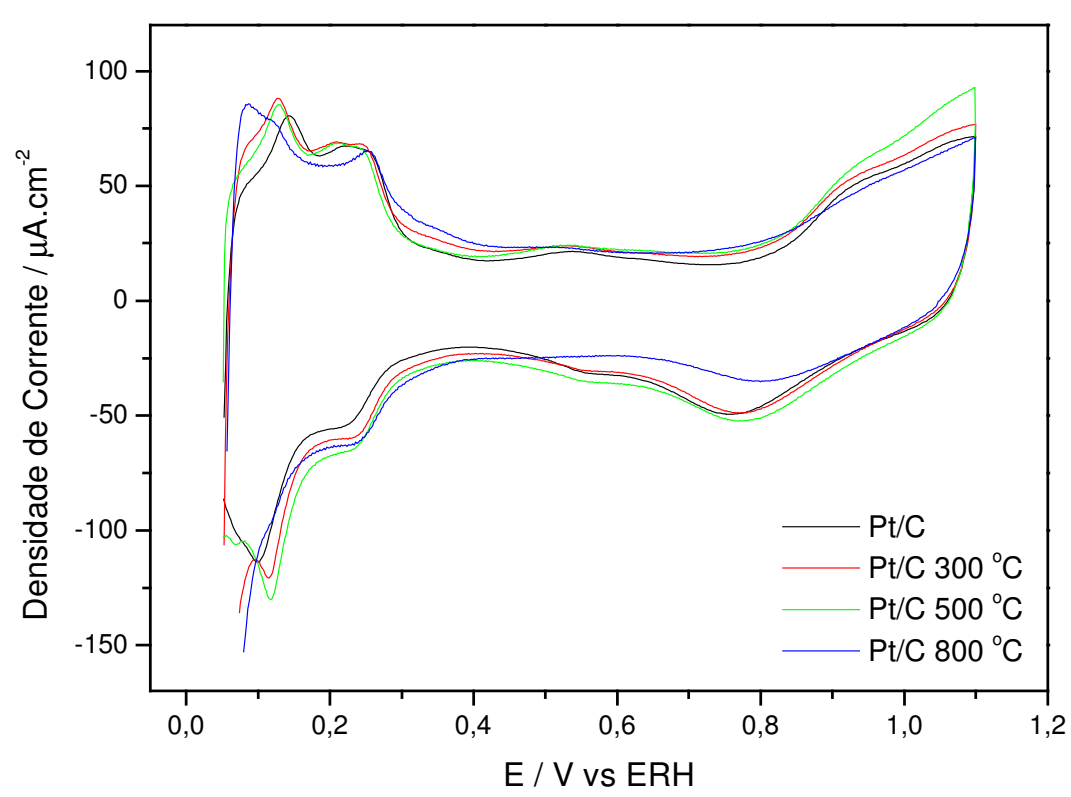

Figura 28: Voltamograma cíclico para Pt/C tratados em diversas temperaturas de tratamento térmico, em $\mathrm{H}_{2} \mathrm{SO}_{4}$ 0,5 M.

Na Figura 29 é apresentado o voltamograma cíclico para PtV/C tratado a 500 e 800 ${ }^{\circ} \mathrm{C}$. Nota-se que o perfil voltamétrico para este catalisador é semelhante ao da platina, não havendo picos adicionais referentes ao vanádio. Não foi verificada diferença significativa nos voltamogramas durante a realização das medidas, mostrando que os catalisadores apresentam estabilidade durante os experimentos. O comportamento voltamétrico dos demais materiais é semelhante ao apresentado na Figura 29, por isso foram omitidos. Deslocamentos anódicos no pico de redução podem ser atribuídos a diminuição da energia livre de adsorção $\left(\Delta \mathrm{G}_{\mathrm{ads}}\right)$ de $\mathrm{Pt}$ $\mathrm{OH}$, Pt-O ou Pt- $\mathrm{O}_{2}$, devido a presença do segundo metal na liga, fato este que facilita a redução das espécies oxigenadas. 


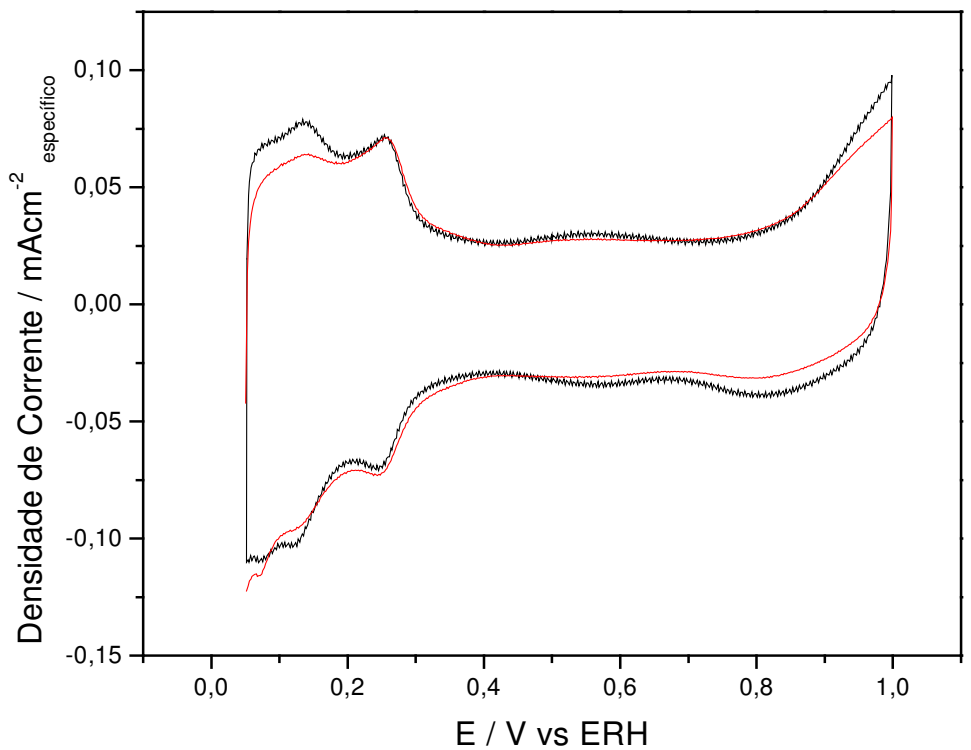

Figura 29: Voltamograma cíclico para Pt-V/C 500 (preto) e $800{ }^{\circ} \mathrm{C}$ (vermelho) em $\mathrm{H}_{2} \mathrm{SO}_{4} 0,5 \mathrm{M}$.

As Figuras 30 e 31 mostram as curvas de polarização de estado estacionário no eletrodo de disco e as correntes para a oxidação de $\mathrm{H}_{2} \mathrm{O}_{2}$ no eletrodo anel obtidas a $900 \mathrm{rpm}$, para a RRO nos catalisadores $\mathrm{Pt} / \mathrm{C}$ e $\mathrm{Pt}-\mathrm{V} / \mathrm{C}$ submetidos aos diferentes tratamentos térmicos. 


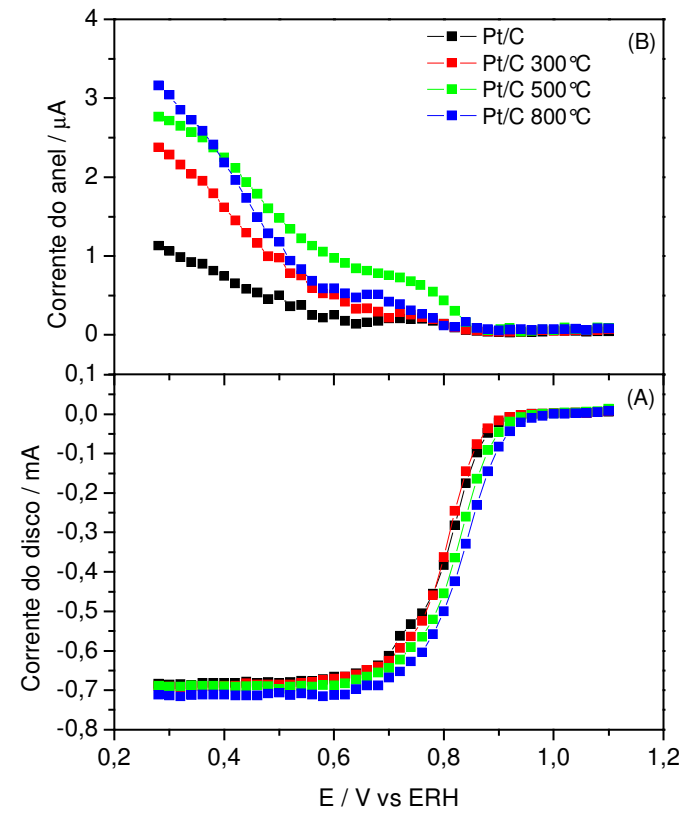

Figura 30: Curva de polarização em estado estacionário para RRO em catalisadores de Pt/C com diferentes temperaturas de tratamento térmico. $\mathrm{H}_{2} \mathrm{SO}_{4}$ 0,5 mol.L ${ }^{-1}, \omega=900$ rpm. (a) disco e (b) anel. $E_{a}=1,2$ V

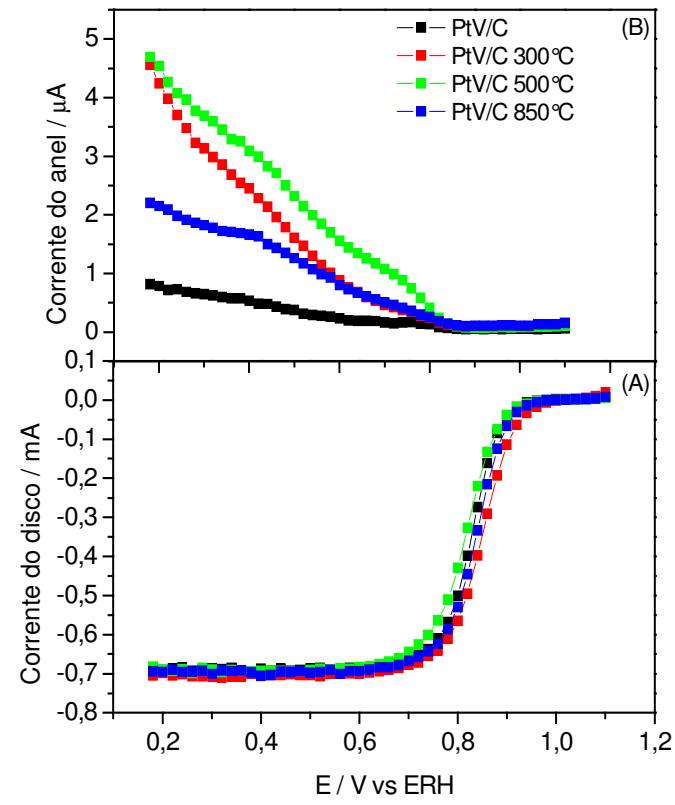

Figura 31: Curva de polarização em estado estacionário para RRO em catalisadores de Pt-V/C com diferentes temperaturas de tratamento térmico. $\mathrm{H}_{2} \mathrm{SO}_{4} 0,5 \mathrm{~mol} . \mathrm{L}^{-1}, \omega=900 \mathrm{rpm}$. (a) disco e (b) anel. $\mathrm{E}_{\mathrm{a}}=\mathbf{1 , 2 \mathrm { V }}$

Os diagramas de Tafel corrigidos pelo transporte de massa, para a rotação do eletrodo de 900 rpm são apresentados nas Figuras 32 e 33, para Pt/C e Pt-V/C, respectivamente. Duas regiões lineares são observadas nestas curvas, com coeficientes angulares (inclinações de Tafel) próximos de 60 e $120 \mathrm{mVdec}^{-1}$ para regiões de baixas e altas densidades de corrente, respectivamente, ( $b_{1}$ e $b_{2}$ apresentados na Tabela 5) sendo estes valores inteiramente concordantes com aqueles apresentados anteriormente para os eletrocatalisadores de Pt e ligas de Pt. 


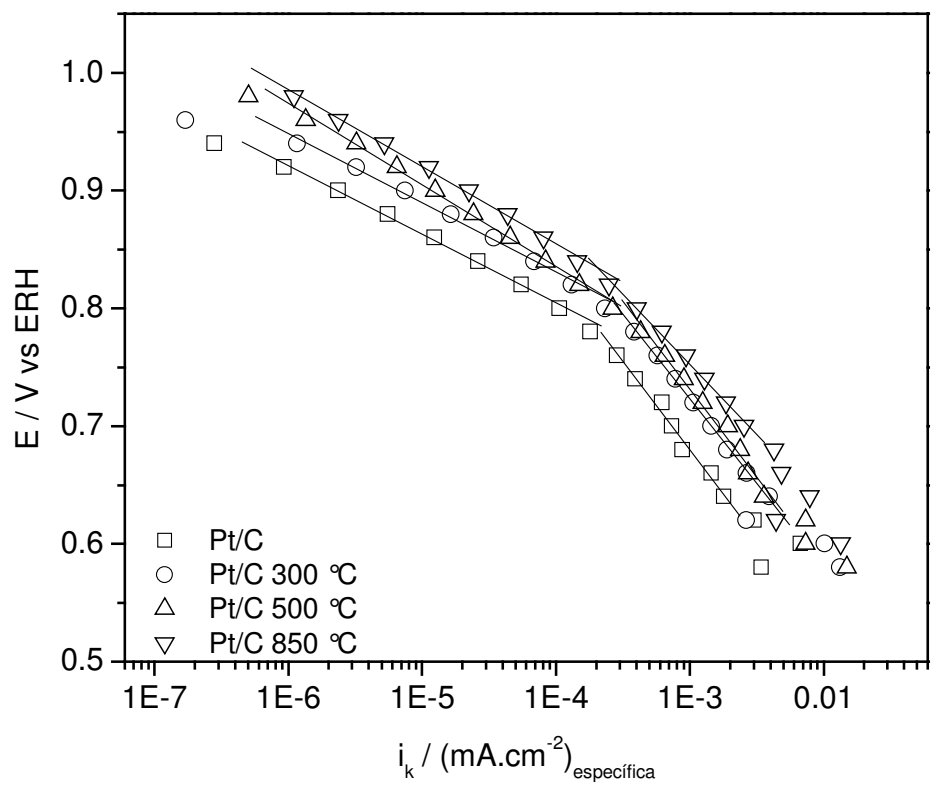

Figura 32: Diagramas de Tafel para RRO em diversos catalisadores de $\mathrm{Pt} / \mathrm{C}$ em $\mathrm{H}_{2} \mathrm{SO}_{4}$ 0,5 mol.L ${ }^{-1}$.

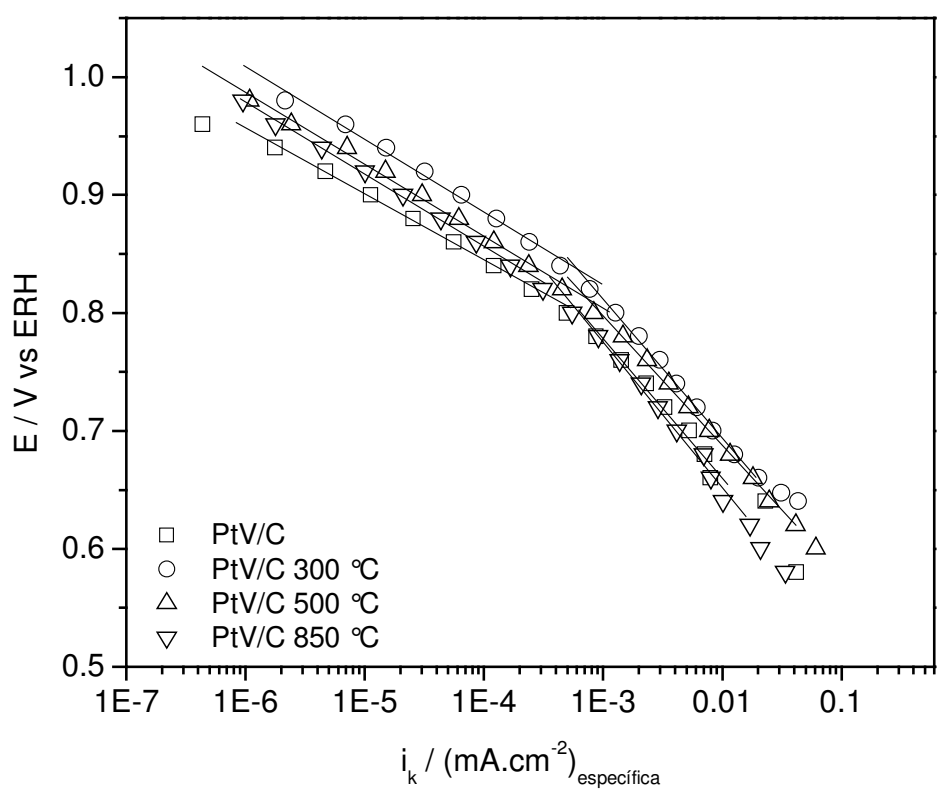

Figura 33: Diagramas de Tafel para RRO em diversos catalisadores de Pt-V/C em $\mathrm{H}_{2} \mathrm{SO}_{4}$ 0,5 mol.L ${ }^{-1}$ 
Analisando-se os resultados da Figura 32 nota-se que conforme se aumenta à temperatura do tratamento térmico a atividade catalítica específica do catalisador $\mathrm{Pt} / \mathrm{C}$ melhora, estando este resultado concordante com os da literatura. Este efeito resulta da menor interação de espécies oxigenadas com a superfície catalisadora (menor energia de adsorção), fato que reduz o grau de recobrimento da superfície por óxidos, conforme evidenciado pelas alterações na ocupação da banda 5d da Pt já mencionadas.

Conforme já mencionado, deslocamentos anódicos no pico de redução dos óxidos obtidos na voltametria cíclica podem ser atribuídos a diminuição da energia livre de adsorção $\left(\Delta \mathrm{G}_{\mathrm{ads}}\right)$ de Pt-OH, Pt-O ou Pt- $\mathrm{O}_{2}$, devido a presença do segundo metal na liga. Este resultado corrobora o resultado obtido por XANES onde para o catalisador de Pt há aumento da ocupação da banda 5d, diminuindo a força de interação entre Pt e espécies oxigenadas, fato este que facilita a redução das espécies oxigenadas.

No caso do material de $\mathrm{PtV} / \mathrm{C}$, os diagramas de Tafel indicam também que há maior atividade catalítica para os materiais tratados termicamente quando comparado ao $\mathrm{Pt}-\mathrm{V} / \mathrm{C}$ sem tratamento. Entretanto a maior atividade específica ocorre com o material tratado termicamente a $300{ }^{\circ} \mathrm{C}$, havendo um decréscimo do desempenho a partir desta temperatura. Os resultados de XANES mostraram que não houve alteração da ocupação da banda 5d da Pt com o aumento do tratamento térmico. Portanto, o efeito majoritário na RRO em meio ácido para $\mathrm{PtV} / \mathrm{C}$ tratado termicamente pode não estar relacionado somente com a ocupação da banda $5 \mathrm{~d}$ da Pt, tendo-se que levar em conta outros fatores, tais como; número de coordenação e distância Pt-Pt. Entretanto, como observado na Figura 25 o catalisador de PtV/C tem maior ocupação da banda $5 \mathrm{~d}$ da platina, levando a menor interação com espécies oxigenadas, portanto, este catalisador apresenta menor grau de recobrimento por óxidos superficiais, fato este que explicaria o melhor desempenho do catalisador Pt-V/C sem tratamento comparado a Pt/C. Em trabalho prévio realizado por Antolini e col. [29], variando-se a pressão de oxigênio 
na célula unitária foi verificado que a atividade das ligas Pt-V/C frente à RRO é inferior a da Pt/C a 1 atm, porém, em pressões superiores a atividade das ligas é superior. Lima e col. [62] estudaram a RRO em meio alcalino em catalisadores de Pt-V/C tratados termicamente e a melhora na atividade destes catalisadores foi relacionada com efeitos eletrônicos, pois foi verificado maior ocupação da banda $5 \mathrm{~d}$ da Pt com o aumento da temperatura do tratamento térmico, não tendo sido relacionados com a distância Pt-Pt, pois, não foi observada variação das distâncias inter-atômicas com o tratamento térmico. Desta forma, na base dos resultados obtidos neste trabalho não é possível apontar uma causa específica para explicar o efeito de temperatura de tratamento térmico sobre o comportamento eletroquímico do eletrocatalisador de Pt-V/C.

Os resultados obtidos para $\mathrm{n}$ e percentual de $\mathrm{H}_{2} \mathrm{O}_{2}$ estão incluídos na Tabela 5, onde estão representados os números de elétrons obtidos em 0,9 V que é a região de ativação da reação, portanto, de interesse para o estudo da atividade catalítica. Os valores do número de elétrons obtidos todos os materiais resultaram próximos de 4, independentemente do potencial. Já os valores do percentual de peróxido formado foram obtidos em $0,7 \mathrm{~V}$ que é a região próxima à qual o cátodo opera na prática e justifica-se também, pois a quantidade de peróxido formada acima de 0,8 V é negligenciável conforme evidenciado nas Figuras 30 e 31.

Tabela 5: Parâmetros cinéticas para a RRO em meio ácido em diversos catalisadores.

\begin{tabular}{c|c|c|c|c}
\hline Catalisador & $\mathrm{b}_{1} \mathrm{mVdec}^{-1}$ & $\mathrm{~b}_{2} \mathrm{mVdec}^{-1}$ & $\mathrm{n}_{0,9 \mathrm{~V}}$ & $\begin{array}{c}\mathrm{x}_{2} \mathrm{O}_{2}(\%) \\
0,7 \mathrm{~V}\end{array}$ \\
\hline $\mathrm{Pt} / \mathrm{C}$ & 64 & 140 & 4 & 0,10 \\
\hline $\mathrm{Pt} / \mathrm{C} 300{ }^{\circ} \mathrm{C}$ & 66 & 138 & 4 & 0,17 \\
\hline $\mathrm{Pt} / \mathrm{C} 500{ }^{\circ} \mathrm{C}$ & 59 & 136 & 4 & 0,80 \\
\hline $\mathrm{Pt} / \mathrm{C} 800{ }^{\circ} \mathrm{C}$ & 64 & 126 & 4 & 0,35 \\
\hline $\mathrm{PtV} / \mathrm{C}$ & 57 & 114 & 4 & 0,13 \\
\hline $\mathrm{PtV} / \mathrm{C} 300{ }^{\circ} \mathrm{C}$ & 66 & 120 & 4 & 0,28 \\
\hline $\mathrm{PtV} / \mathrm{C} 500{ }^{\circ} \mathrm{C}$ & 61 & 110 & 4 & 0,82 \\
\hline $\mathrm{PtV} / \mathrm{C} 800{ }^{\circ} \mathrm{C}$ & 62 & 123 & 4 & 0,32 \\
\hline
\end{tabular}




\subsection{Catalisadores preparados por refluxo em THF}

A Figura 34 apresenta os difratogramas de raio-X para $\mathrm{Pt} / \mathrm{C}$ comercial e o $\mathrm{Pt} / \mathrm{C}$ preparado no laboratório, utilizando o método de refluxo. Os padrões dos difratogramas são os esperados para platina e seus picos largos indicam a formação de nanocristalitos. Os tamanhos de cristalito para os eletrocatalisadores foram calculados através dos dados de difração de raio-X utilizando-se a equação de Scherrer, tendo-se obtido $2,7 \mathrm{~nm}$ para o catalisador comercial e 3,1 nm para o sintetizado no laboratório. O parâmetro de rede obtido para ambos resultou no valor esperado de 3,92 A. A Figura 35 apresenta a imagem de HRTEM para o catalisador de Pt/C preparado por refluxo. A análise dos resultados mostra que o método produz partículas homogeneamente distribuídas sobre carbono. O tamanho médio de partícula obtido por HRTEM foi de $3 \mathrm{~nm}$, o que concorda com o resultado obtido por DRX.

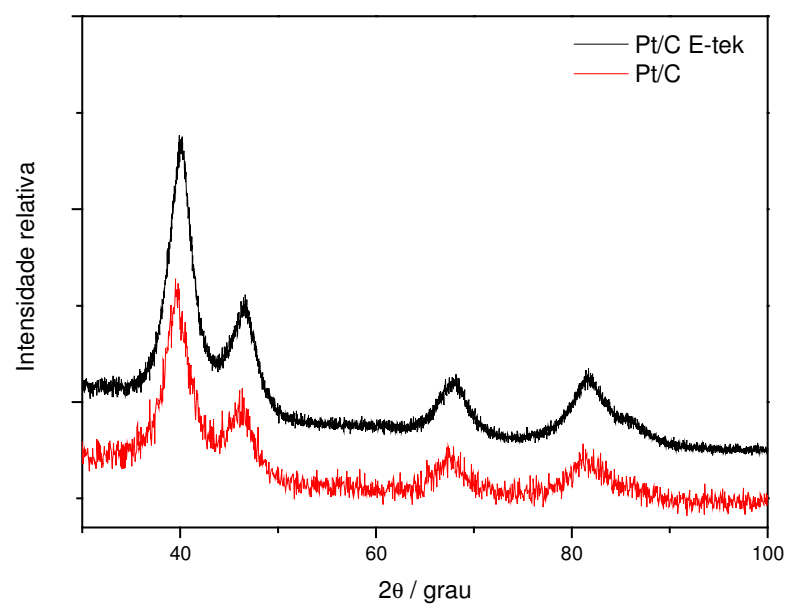

Figura 34: Difratograma de raio-X para os catalisadores de $\mathrm{Pt} / \mathrm{C}$ comercial e $\mathrm{Pt} / \mathrm{C}$ preparado pelo método de refluxo em THF. 


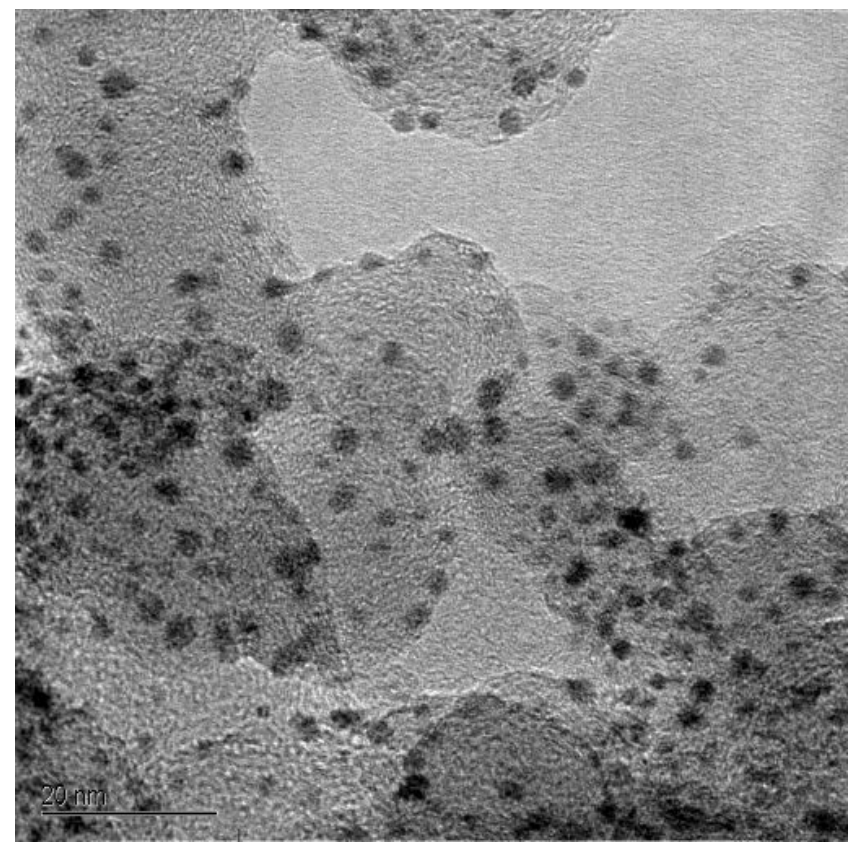

Figura 35: Imagem de HRTEM obtida para as nanopartículas de Pt/C preparadas pelo método de refluxo em THF.

A Figura 36 apresenta o espectro XANES para Pt/C E-tek a $600 \mathrm{mV}$ e para $\mathrm{Pt} / \mathrm{C}$ preparada pelo método de refluxo em diversos potenciais. No resultado para a $\mathrm{Pt} / \mathrm{C}$ preparada por refluxo à magnitude de absorção em $600 \mathrm{mV}$ é muito superior do que o Pt/C E-tek demonstrando claramente que o material apresenta maior vacância na banda $5 \mathrm{~d}$ da Pt, reflexo da presença de óxidos na superfície do catalisador que retira densidade eletrônica da banda $5 \mathrm{~d}$ da Pt. Para catalisadores de Pt/C E-tek há aumento da vacância da banda 5d da platina com aumento de potencial, como verificado na Figura 8, mas, para o material local tal efeito não foi verificado, provavelmente devido ao fato do material estar oxidado. Outra explicação seria um problema experimental, tal como uma falha no controle de potencial durante os experimentos, e deste modo o eletrodo de trabalho não recebeu a variação de potencial aplicada pelo potenciostato, porém esta hipótese é pouco provável pelas razões que serão discutidas mais adiante. 


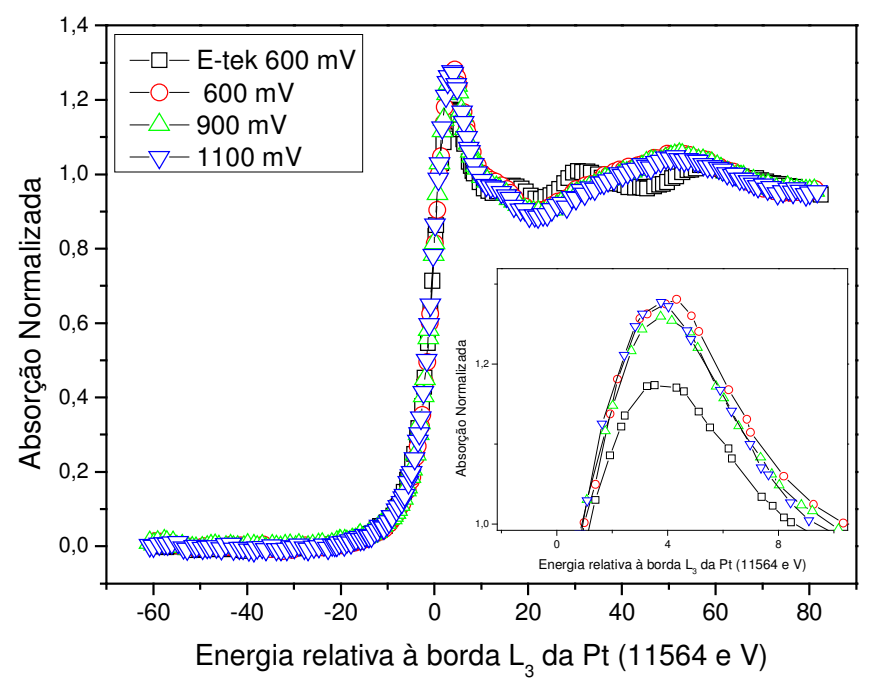

Figure 36: Espectro XANES para Pt/C preparado por refluxo em THF em diversos potenciais e Pt/C Etek a $600 \mathrm{mV}$ em $\mathrm{H}_{2} \mathrm{SO}_{4} 0,5 \mathrm{M}$.

A Figura 37 apresenta os voltamogramas cíclicos para os dois catalisadores de platina. O catalisador de $\mathrm{Pt} / \mathrm{C}$ preparado por refluxo apresenta perfil típico de platina, com comportamento semelhante ao Pt/C comercial tanto na região de adsorção/dessorção de hidrogênio como na região de óxidos. A comparação das curvas de polarização para a RRO no eletrodo de disco, obtidas a $900 \mathrm{rpm}$ para os catalisadores de $\mathrm{Pt} / \mathrm{C}$ E-tek e $\mathrm{Pt} / \mathrm{C}$ preparado por refluxo estão mostradas na Figura 38. As correntes no anel referentes à oxidação do peróxido de hidrogênio formado no disco $\left(E_{d}=1,2\right.$ V), também a 900 rpm, são mostradas na Figura 38b. Os diagramas de Tafel corrigidos pelo transporte de massa são apresentados na Figura 39. Por estes resultados nota-se que o catalisador comercial apresenta desempenho catalítico superior ao preparado no laboratório, com o início da reação ocorrendo praticamente no mesmo sobrepotencial para os dois catalisadores, porém, o catalisador comercial apresentando maiores valores de corrente a um determinado potencial na região de controle misto. 


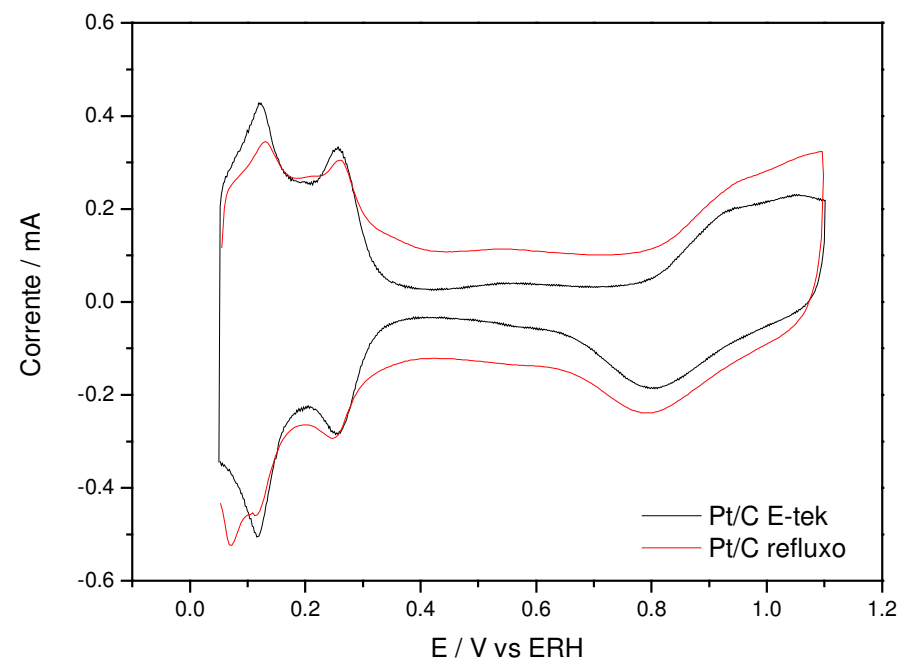

Figure 37: Voltametria cíclica para Pt/C E-tek e Pt/C preparada por refluxo em $\mathrm{H}_{2} \mathrm{SO}_{4}$ 0,5 M.

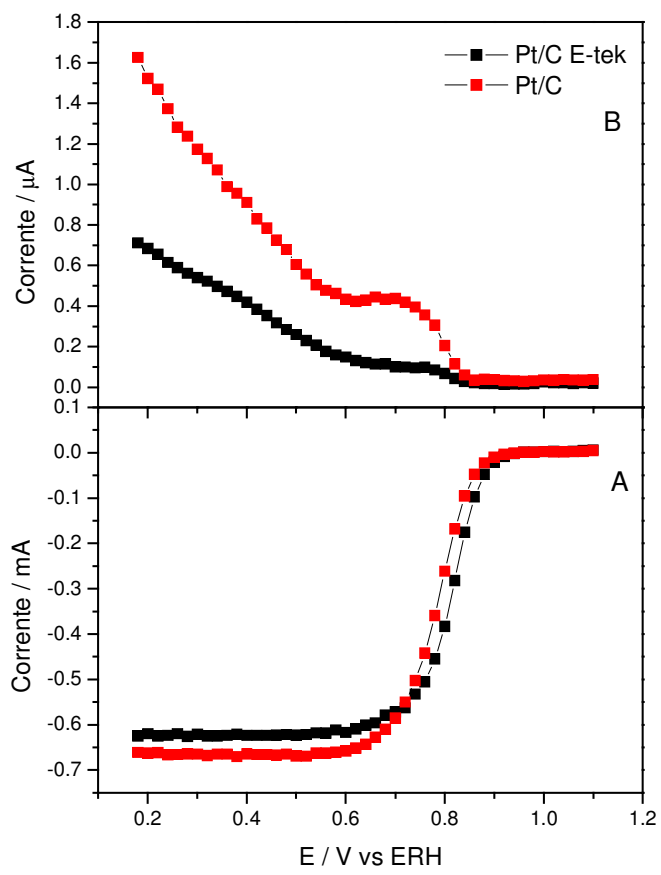

Figura 38: Curva de polarização de estado estacionário para a RRO em Pt/C E-tek e para Pt/C preparada por refluxo em THF em $\mathrm{H}_{2} \mathrm{SO}_{4}$ 0,5 M. (A) eletrodo de disco, (B) eletrodo de anel. $\omega=900 \mathrm{rpm}$. 


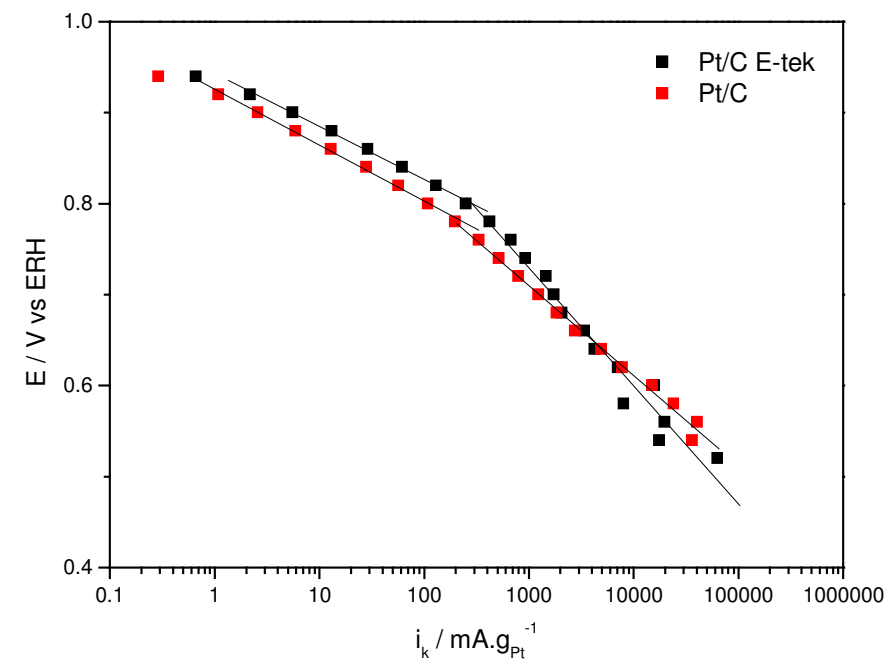

Figura 39: Diagramas de Tafel para RRO em catalisadores Pt/C E-tek e Pt/C preparados por refluxo; em $\mathrm{H}_{2} \mathrm{SO}_{4}$ 0,5 mol.L $\mathrm{L}^{-1}$.

O recobrimento das partículas por óxidos superficiais, como observado pelos dados de Xanes, pode explicar a diferença de atividade entre os dois catalisadores, pois, apesar de haver uma diferença no tamanho das partículas, esta não é muito pronunciada. Como observado acima, o catalisador de Pt/C preparado localmente apresenta-se oxidado, resultando em dois fatores prejudiciais para a RRO, que são: maior grau de recobrimento das partículas com óxidos proporcionando menor quantidade de sítios livres para que a reação ocorra, e maior interação (maior força de adsorção) dos sítios livres de platina com espécies oxigenadas intermediarias da reação, dificultando a remoção das mesmas sobre estes sítios após a sua formação. $\mathrm{O}$ valor do coeficiente de Tafel obtido para o catalisador de $\mathrm{Pt} / \mathrm{C}$ preparado pelo método de refluxo em THF é semelhate ao da Pt/C E-tek, ou seja, $60 \mathrm{mVdec}^{-1}$ para a região de baixa densidade de corrente, porém menor na região de alta densidade de corrente, apresentando o valor de $100 \mathrm{mVdec}^{-1}$. Este menor valor deve ser devido à maior dificuldade de redução dos óxidos, o que leva a um maior grau de recobrimento. Prabhuram et al. [63] analisando os dados de XPS para o catalisador de Pt/C preparado pelo mesmo método e Pt/C 
E-tek verificaram que o catalisador preparado por este método apresenta realmente maior quantidade de óxido. Segundo o autor, o catalisador preparado por refluxo em THF apresentou 60,30\% das espécies na forma $\operatorname{Pt}(0)$ e 39,70\% na forma $\mathrm{Pt}(\mathrm{II})$, enquanto o catalisador Pt E-tek apresentou 73,54\% na forma $\mathrm{Pt}(0)$ e 26,46\% na forma $\mathrm{Pt}(\mathrm{II})$.

Visando a obtenção de catalisadores melhores o método foi modificado. O tempo de refluxo foi diminuído de 6 para 2 horas, sendo que foi continuamente borbulhado gás nitrogênio no balão. O espectro Xanes comparando as propriedades eletrônicas dos catalisadores de $\mathrm{Pt} / \mathrm{C}$ comercial e o preparado pelo método de refluxo modificado (denominado Pt/C A) são apresentados na Figura 40. As curvas de polarização frente à RRO para estes catalisadores são apresentados na Figura 41, sendo o inserto os diagrama de Tafel obtidos para os mesmos.

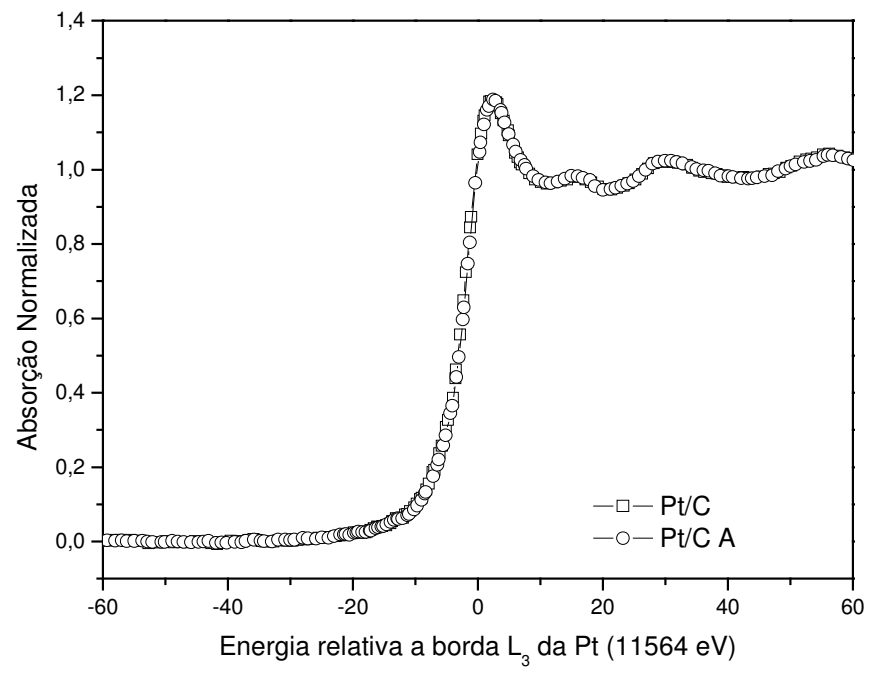

Figure 40: Espectro Xanes para Pt/C comercial e Pt/C preparado pelo método de refluxo modificado (Pt/C A) a $900 \mathrm{mV} \mathrm{em} \mathrm{H}_{2} \mathrm{SO}_{4} 0,5 \mathrm{M}$. 
Analisando o espectro Xanes da Figura 40 nota-se claramente que a intensidade da absorção é a mesma para os dois catalisadores indicando que a modificação no método foi eficaz para a produção de catalisadores com superfície livre de óxidos, e esta hipótese é confirmada também através dos resultados a curva de polarização e diagrama de Tafel, onde observa-se que os desempenhos eletrocatalíticos dos dois eletrodos são muito semelhantes.

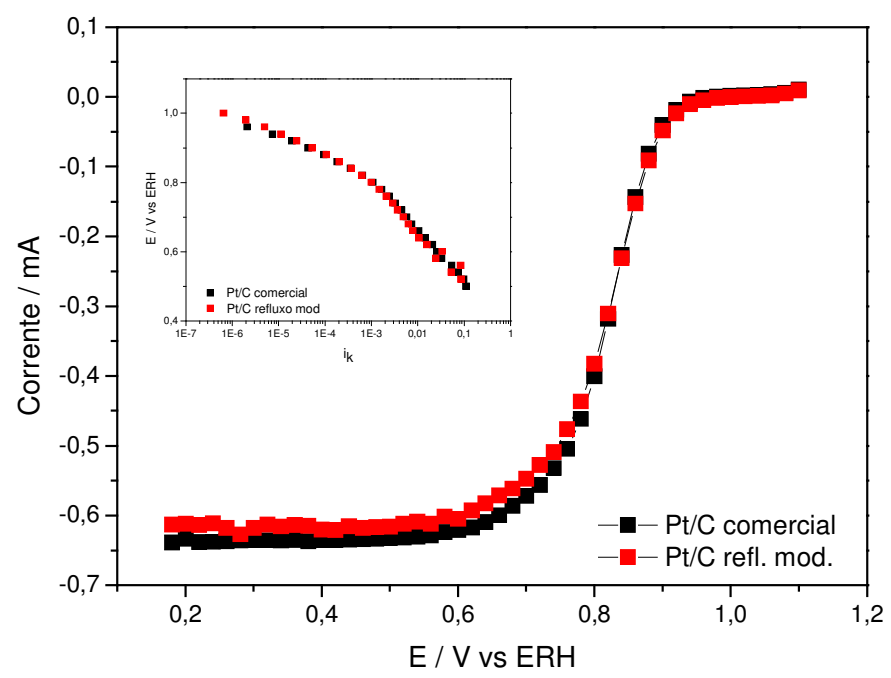

Figura 41: Curva de polarização de estado estacionário para a RRO em Pt/C E-tek e para Pt/C preparada por refluxo em THF em $\mathrm{H}_{2} \mathrm{SO}_{4} 0,5 \mathrm{M}$. (A) eletrodo de disco, (B) eletrodo de anel. $\omega=900 \mathrm{rpm}$.

Ligas baseadas em platina Pt-M foram preparadas utilizando-se o método de refluxo já modificado. Foram preparadas ligas de $\mathrm{PtV} / \mathrm{C}$ e PtFe/C na composição de 80:20. Inicialmente os catalisadores foram preparados sem a adição de um agente protetor, e posteriormente os mesmos catalisadores foram preparados novamente pelo método de refluxo, contudo, desta vez utilizando-se PVP (polyvinilpirrolidona) como agente estabilizante das partículas, a fim de se evitar que ocorresse crescimento das mesmas. A Figura 42 apresenta os difratogramas de raio-X para os catalisadores de $\mathrm{PtFe} / \mathrm{C}$, sem $(\mathrm{PtFe} \mathrm{A})$ e com o agente estabilizante $(\mathrm{PtFe}$ B). Os picos do difratrograma para o PtFe B (com agente estabilizante) estão menos estreitos, indicando que houve uma diminuição no tamanho de cristalitos deste material quando 
comparado ao PtFe A (sem a presença do agente estabilizante). Para os dois catalisadores de $\mathrm{PtFe} / \mathrm{C}$ os picos de difração estão ligeiramente deslocados para maiores valores de $2 \theta$ quando comparados com os da Pt/C. O tamanho de partícula e o parâmetro de rede destes materiais encontram-se na Tabela 6.

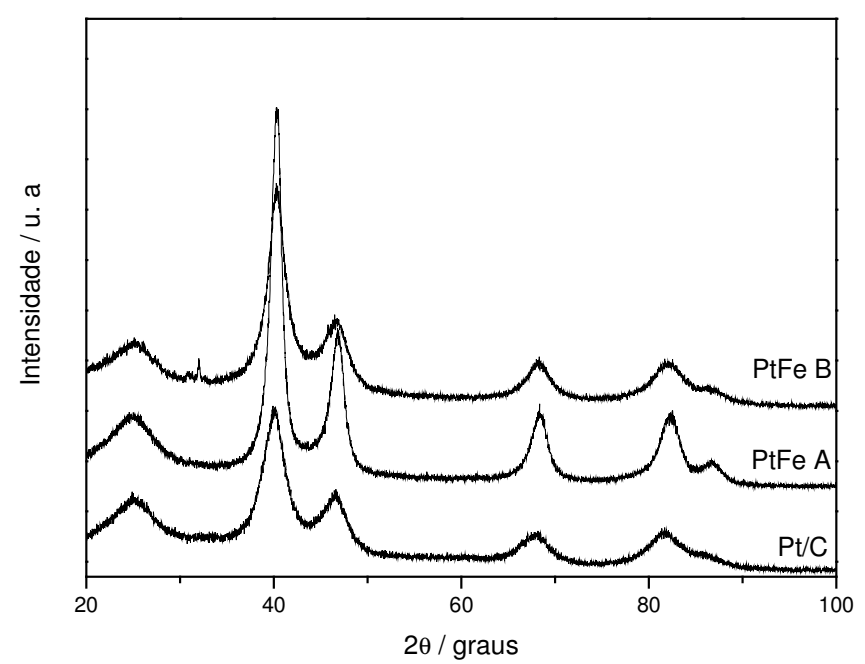

Figura 42: Difratograma para os catalisadores Pt/C, PtFe/C (PtFe A) e PtFe/C preparado na presença de PVP (PtFe B).

A Figura 43 apresenta os difratogramas de raio-X para os catalisadores de $\mathrm{PtV} / \mathrm{C}$, sem ( $\mathrm{PtV} \mathrm{A})$ e com o agente estabilizante (PtV B). Observa-se que o catalisador PtV A apresenta os picos cfc característicos da platina acrescidos de picos referentes ao óxido de vanádio $\left(\mathrm{V}_{2} \mathrm{O}_{3}\right)$, bem como elevado tamanho de cristalito, como evidenciado pelos picos estreitos. Partindo-se do pressuposto que se deveria utilizar um agente redutor mais forte na tentativa de reduzir todo o vanádio sem a formação de óxido, a solução foi alcalinizada, uma vez que o agente redutor tornar-se-ia mais forte em ambiente alcalino. Concomitantemente foi adicionado o agente estabilizante para que se obtivessem partículas menores. O resultado apresentado na Figura 43 como PtV B mostra claramente que houve diminuição do tamanho 
de cristalito, evidenciado pela diminuição da largura do pico de difração e não há a presença de picos observáveis de $\mathrm{V}_{2} \mathrm{O}_{3}$. Contudo, não se pode afirmar que o $\mathrm{V}_{2} \mathrm{O}_{3}$ não esta presente no catalisador, pois o mesmo pode estar na forma amorfa.

Tabela 6: Tamanho de partícula obtido para os catalisadores preparados por refluxo em THF.

\begin{tabular}{|c|c|c|}
\hline Catalisador & $\begin{array}{c}\text { Tamanho de Cristalito } \\
(\mathrm{DRX})\end{array}$ & $\begin{array}{c}\text { Tamanho de partícula } \\
(\mathrm{MET})\end{array}$ \\
\hline $\mathrm{PtFe} / \mathrm{C}$ sem PVP & $3,9 \mathrm{~nm}$ & $3,5 \mathrm{~nm}$ \\
\hline $\mathrm{PtFe} / \mathrm{C}$ com PVP & $2,9 \mathrm{~nm}$ & $10 \mathrm{~nm}$ \\
\hline $\mathrm{PtV} / \mathrm{C}$ sem PVP & $11 \mathrm{~nm}$ & $5,5 \mathrm{~nm}$ \\
\hline $\mathrm{PtV} / \mathrm{C}$ com PVP & $4 \mathrm{~nm}$ & \\
\hline
\end{tabular}

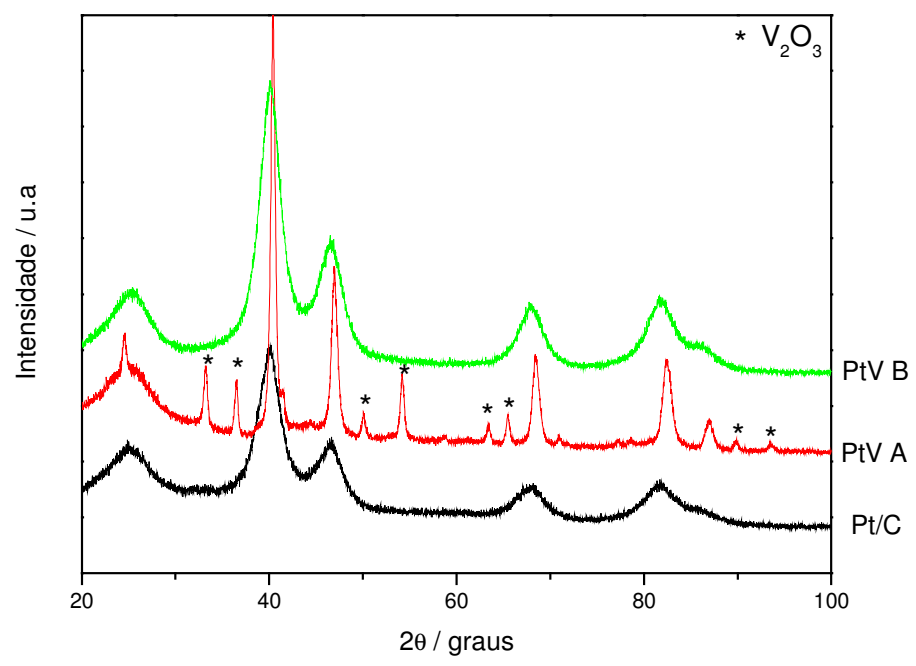

Figura 43: Difratograma para os catalisadores Pt/C, PtV/C (PtFe A) e PtV/C preparado na presença de PVP (PtV B). 
As Figuras 44 e 45 apresentam as imagens de microscopia de transmissão eletrônica (MET) para os catalisadores de $\mathrm{PtFe} / \mathrm{C}$ e as Figuras 46 e 47 para $\mathrm{PtV} / \mathrm{C}$ preparados pelo método de refluxo. Os valores para o tamanho de partícula obtido por MET encontram-se na Tabela 6 onde observa-se que não houve grande variação no tamanho de partícula para os catalisadores de PtFe. Para o catalisador de PtV observa-se que na ausência de PVP o catalisador encontra-se um pouco aglomerado enquanto na presença de PVP estão mais homogeneamente distribuídos.

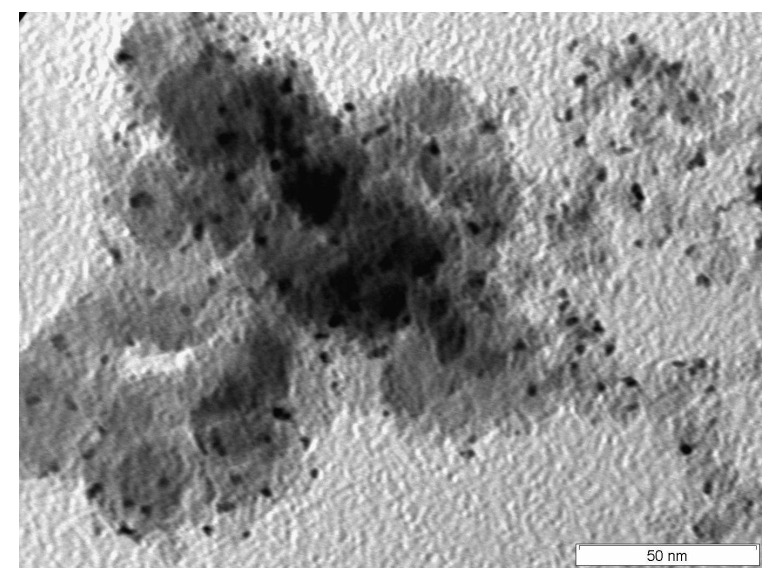

Figura 44: Imagens de MET para $\mathrm{PtFe} / \mathrm{C}$ preparada por refluxo em THF sem a presença de PVP.

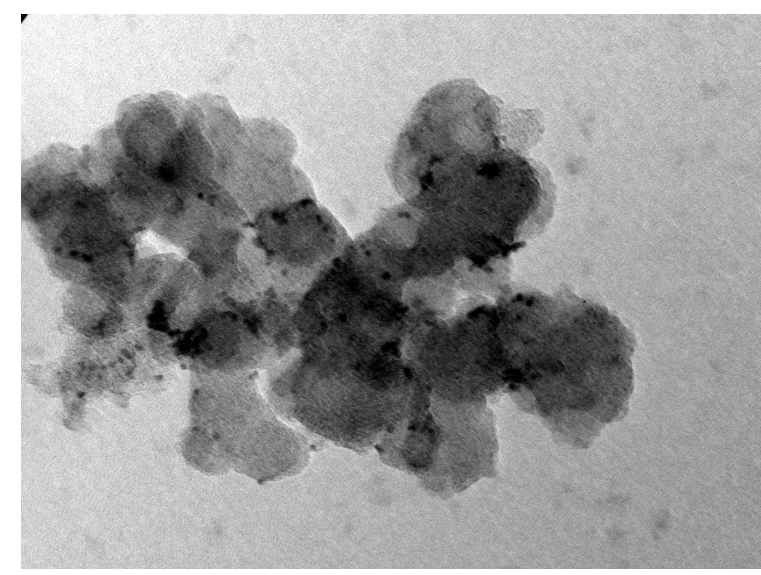

Figura 46: Imagens de MET para PtV/C preparada por refluxo em THF sem a presença de PVP.

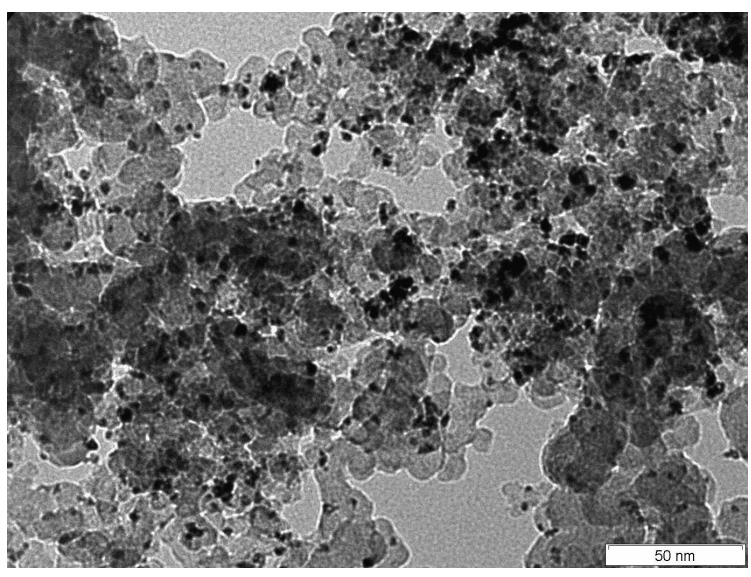

Figura 45: Imagens de MET para $\mathrm{PtFe} / \mathrm{C}$ preparada por refluxo em THF com a presença de PVP.

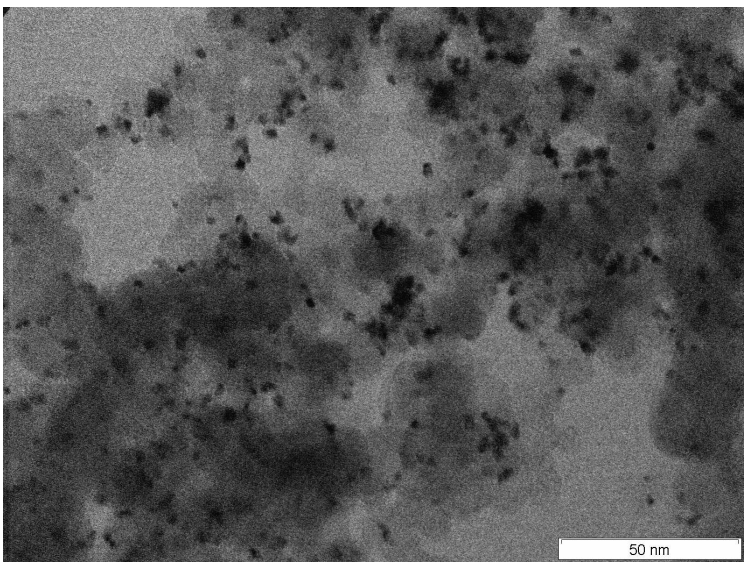

Figura 47: Imagens de MET para PtV/C preparada por refluxo em THF sem a presença de PVP. 
Nas Figuras 48 e 49 são apresentadas as curvas de polarização a 900 rpm para os catalisadores de $\mathrm{PtV} / \mathrm{C}$ e $\mathrm{PtFe} / \mathrm{C}$ preparados na ausência e na presença de PVP. Os catalisadores preparados na presença de PVP apresentaram atividade catalítica superior aos catalisadores preparados sem PVP. O baixo desempenho do catalisador PtV/C A, deve se a provavelmente aos óxidos presentes no catalisador bem como ao elevado tamanho das partículas (baixa área específica). A Figura 50 apresenta os diagramas de Tafel para os catalisadores preparados na presença de PVP, onde se observa que o catalisador $\mathrm{PtFe} / \mathrm{C}$ apresenta o melhor desempenho. Os valores de coeficiente de Tafel e número de elétrons da reação são os valores esperados, sendo os coeficientes de Tafel em torno de $60 \mathrm{mVdec}^{-1}$ para baixos sobrepotenciais e $120 \mathrm{mVdec}^{-1}$ a altos sobrepotenciais e o número de elétrons 4 .

A Figura 51 apresenta os espectros Xanes na borda $\mathrm{L}_{3}$ da Pt obtidos a $900 \mathrm{mV}$ para os catalisadores $\mathrm{PtFe} / \mathrm{C}$ e PtV/C preparados na presença de PVP. Assim como os resultados de Xanes para os catalisadores $\mathrm{PtFe} / \mathrm{C}$ e $\mathrm{PtV} / \mathrm{C}$ 75:25 preparados por impregnação, aqui observase também que a intensidade de absorção para as ligas é inferior a da Pt pura, indicando que há menor interação dos sítios de Pt com espécies oxigenadas, que leva a um menor grau de recobrimento do catalisador por óxidos e proporcionando sítios livres para que a reação ocorra.

Entretanto, quando se compara a diferença da linha branca entre o $\mathrm{Pt} / \mathrm{C}$ e o $\mathrm{PtV} / \mathrm{C}$ para o catalisador preparado por refluxo em THF com o $\mathrm{PtV} / \mathrm{C}$ preparado por impregnação nota-se que a diferença é menor, o que concorda com o fato de que a diferença entre a atividade da $\mathrm{Pt}$ pura e o do PtV/C é também menor. Neste caso, provavelmente o método de impregnação, devido a elevada temperatura provoque uma alteração maior da propriedade eletrônica da Pt, do que quando o PtV é preparado pelo método de refluxo. Cabe ressaltar ainda que o tamanho de partícula para o $\mathrm{PtV} / \mathrm{C}$ preparado por refluxo em THF é superior ao do catalisador 
preparado por refluxo e como observado na introdução, a magnitude da intensidade de absorção da borda $\mathrm{L}_{3}$ da $\mathrm{Pt}$ é dependente do tamanho de partícula.

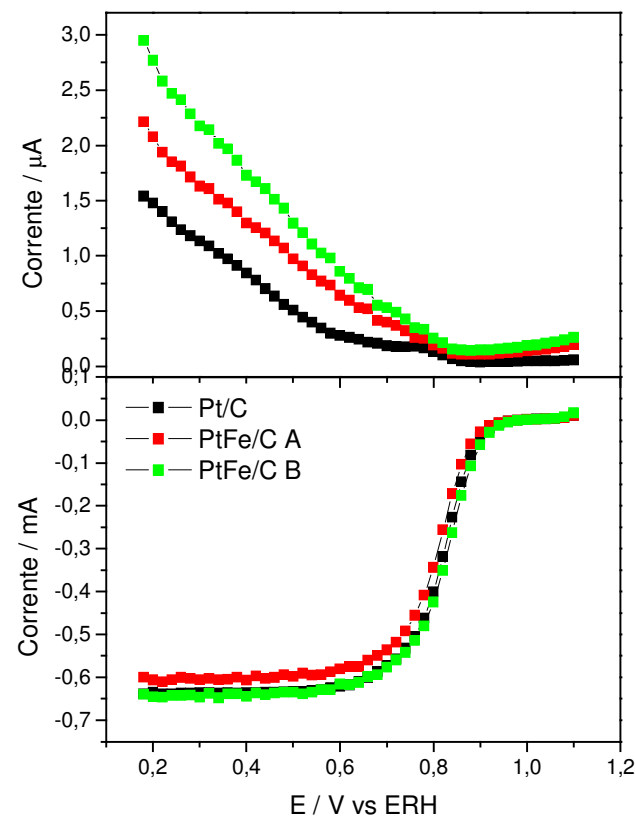

Figura 48: Curva de polarização em estado estacionário para RRO em catalisadores de $\mathrm{PtFe} / \mathrm{C}$ em $\mathrm{H}_{2} \mathrm{SO}_{4}$ 0,5 mol.L $\mathrm{L}^{-1}, \omega=900 \mathrm{rpm}$. (a) disco e (b) anel. $E_{a}=1,2$ V. PtFe $A=$ sem PVP; PtFe B = com PVP.

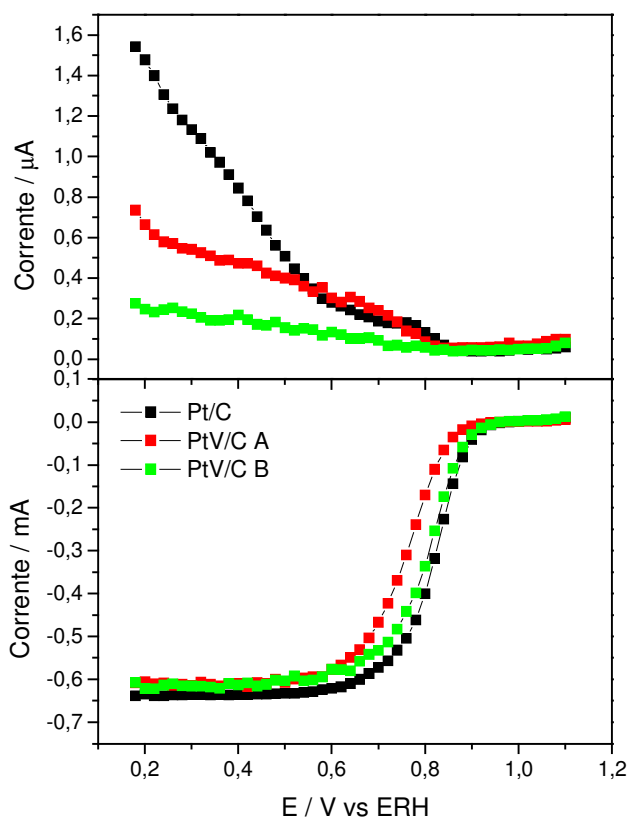

Figure 49: Curva de polarização em estado estacionário para RRO em catalisadores de $\mathrm{PtFe} / \mathrm{C} \mathrm{em} \mathrm{H}_{2} \mathrm{SO}_{4}$ 0,5 mol.L ${ }^{-1}, \omega=900 \mathrm{rpm}$. (a) disco e (b) anel. $E_{a}=1,2$ V. PtV $A=\operatorname{sem}$ PVP; PtV B = com PVP. 


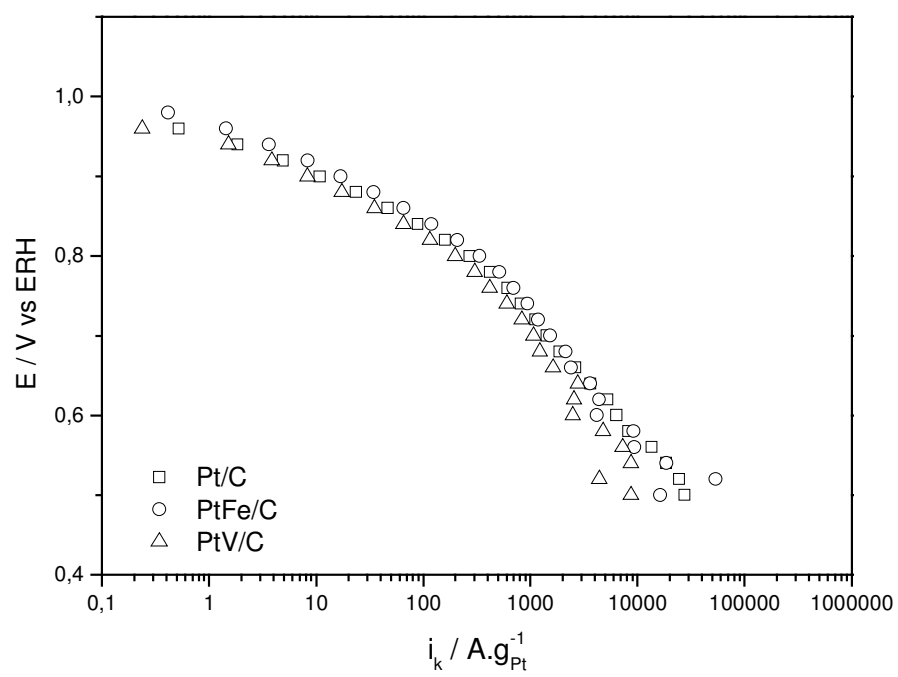

Figura 50: Diagramas de Tafel para RRO em catalisadores Pt/C E-tek, PtFe/C e PtV/C preparados por refluxo em THF na presença de PVP; em $\mathrm{H}_{2} \mathrm{SO}_{4} 0,5$ mol.L $\mathrm{L}^{-1}$.

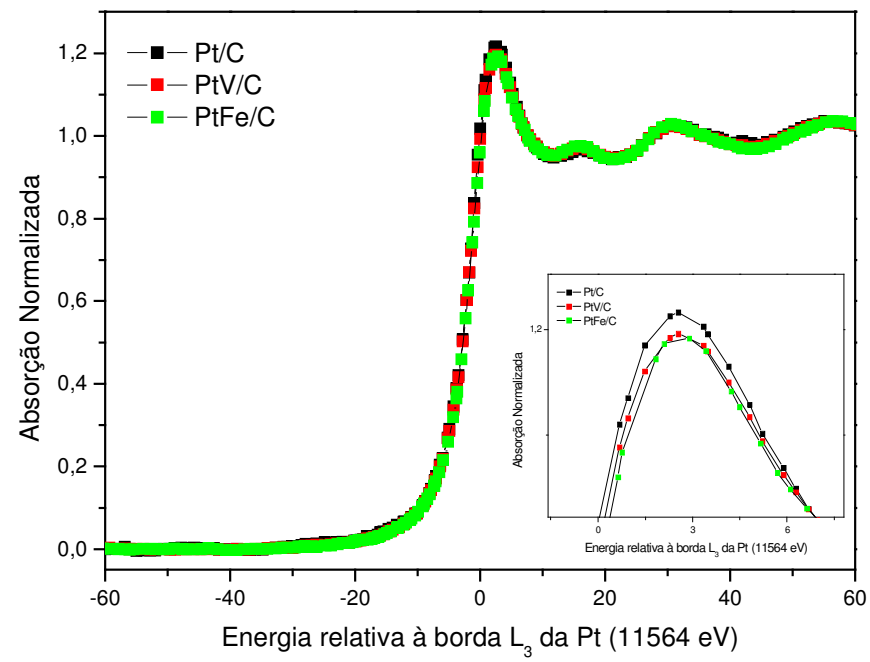

Figura 51: Espectro Xanes para Pt/C E-tek, PtFe/C e PtV/C, ambos preparados pelo método de refluxo em THF na presença de PVP, a $900 \mathrm{mV}$ em $\mathrm{H}_{2} \mathrm{SO}_{4} 0,5$ mol. $\mathrm{L}^{-1}$. 


\subsection{Catalisadores de PtNi/C preparados por microemulsão com surfactante não iônico}

Na Figura 52 são apresentadas as imagens de microscopia de transmissão eletrônica $(\mathrm{MET})$ e os histogramas para os catalisadores de PtNi/C (Pt:Ni = 90:10, 75:25 e 60:40) preparados pelo método de microemulsão utilizando um surfactante não-iônico (Brij ${ }^{\circledR} 30$ ). Como pode ser observado pelas imagens de MET, as partículas de PtNi aparecem como pequenos pontos, os quais estão bem dispersos no carbono Vulcan XC-72. Tamanhos médios de partículas de $3.8 \pm 0.8 \mathrm{~nm}, 3.6 \pm 0.8 \mathrm{~nm}, 4.7 \pm 0.9 \mathrm{~nm}$ foram obtidos para $\mathrm{Pt}_{90} \mathrm{Ni}_{10} / \mathrm{C}$, $\mathrm{Pt}_{75} \mathrm{Ni}_{25} / \mathrm{C}, \mathrm{Pt}_{60} \mathrm{Ni}_{40} / \mathrm{C}$, respectivamente. A análise das imagens mostra que as partículas metálicas estão homogeneamente distribuídas sobre o substrato de carbono, estando as partículas para o catalisador $\mathrm{PtNi} / \mathrm{C}$ 60:40 um pouco mais aglomeradas.

Foram obtidos os difratogramas de raios-X, apresentados na Figura 53 para as várias composições de $\mathrm{PtNi} / \mathrm{C}$ e para o catalisador de $\mathrm{Pt} / \mathrm{C}$ comercial. O perfil dos difratogramas para todos os eletrocatalisadores é similar ao da $\mathrm{Pt} / \mathrm{C}$, sem picos adicionais, indicando que como nos casos anteriores, os eletrocatalisadores apresentam estrutura cúbica de face centrada (cfc), assim como a Pt. De acordo com Xiong [28] a ausência de picos adicionais indica que a liga de $\mathrm{Pt}-\mathrm{Ni} / \mathrm{C}$ apresenta estrutura desordenada, com os átomos de $\mathrm{Ni}$ distribuídos aleatoriamente nas posições dos átomos de Pt na estrutura cfc. $\mathrm{O}$ autor verificou a presença de picos adicionais apenas para $\mathrm{PtFe} / \mathrm{C}$ e $\mathrm{PtCo} / \mathrm{C}$ preparado pelo método de microemulsão, quando submetidos a tratamento térmico em alta temperatura. Os picos de reflexão para todos os catalisadores de Pt-Ni/C estão levemente deslocados para maiores valores de $2 \theta$, indicando a contração da rede cristalina da Pt devido à substituição dos átomos de Pt por átomos de Ni que são menores. Os parâmetros de rede (a) obtidos para todos os catalisadores são apresentados na Tabela 7, juntamente com demais parâmetros estruturais, onde claramente é notado que os valores de a são menores do que aqueles da $\mathrm{Pt} / \mathrm{C}$ e que, 
considerando o erro experimental, os tamanhos de partícula obtidos por DRX são um pouco menores que os obtidos por MET. Este fato evidencia que as partículas observadas por MET (d 4,0 nm) na verdade correspondem a aglomerados de cristalitos de menor dimensão ( $\mathrm{d} \sim$ $2,5 \mathrm{~nm})$.
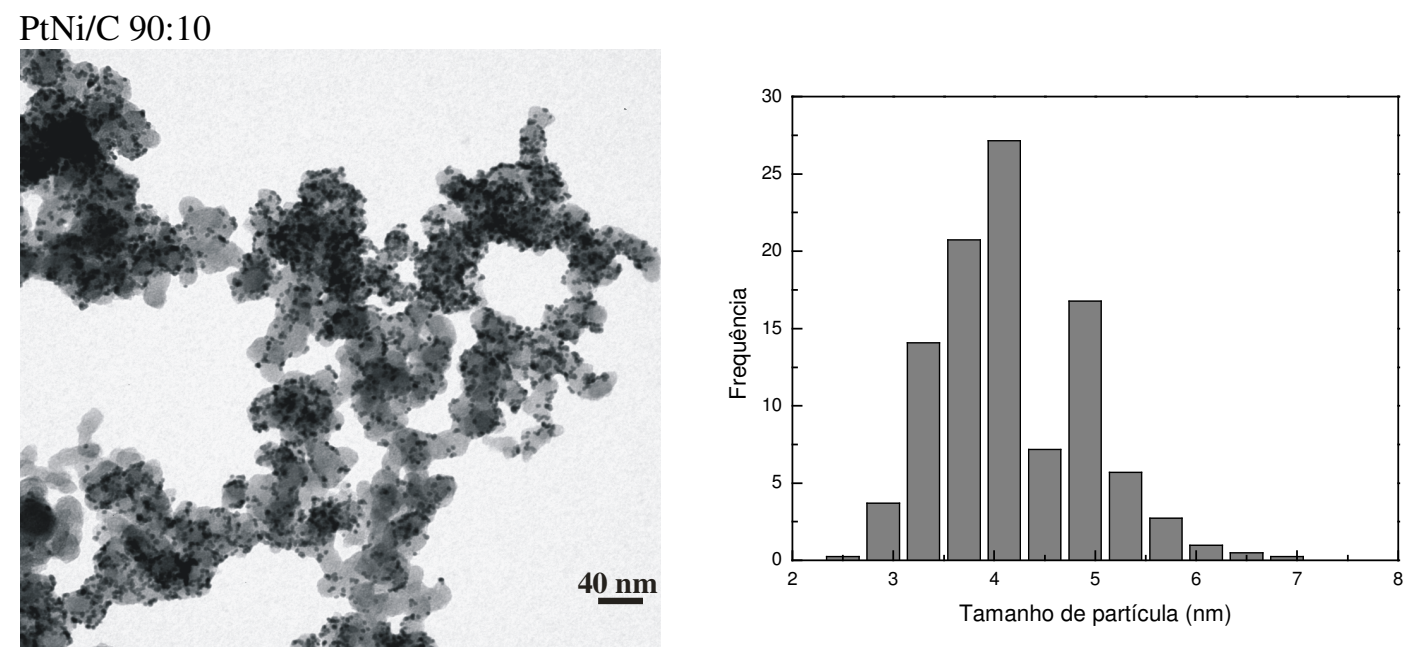

$\mathrm{PtNi} / \mathrm{C} 75: 25$
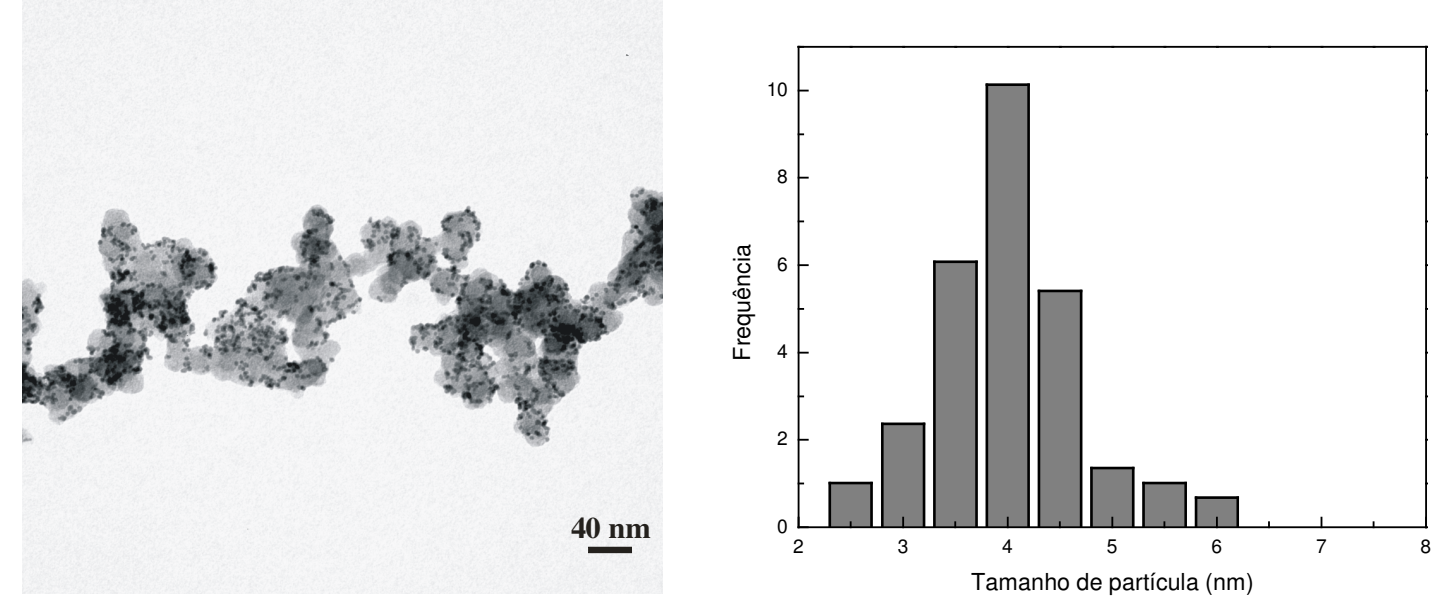

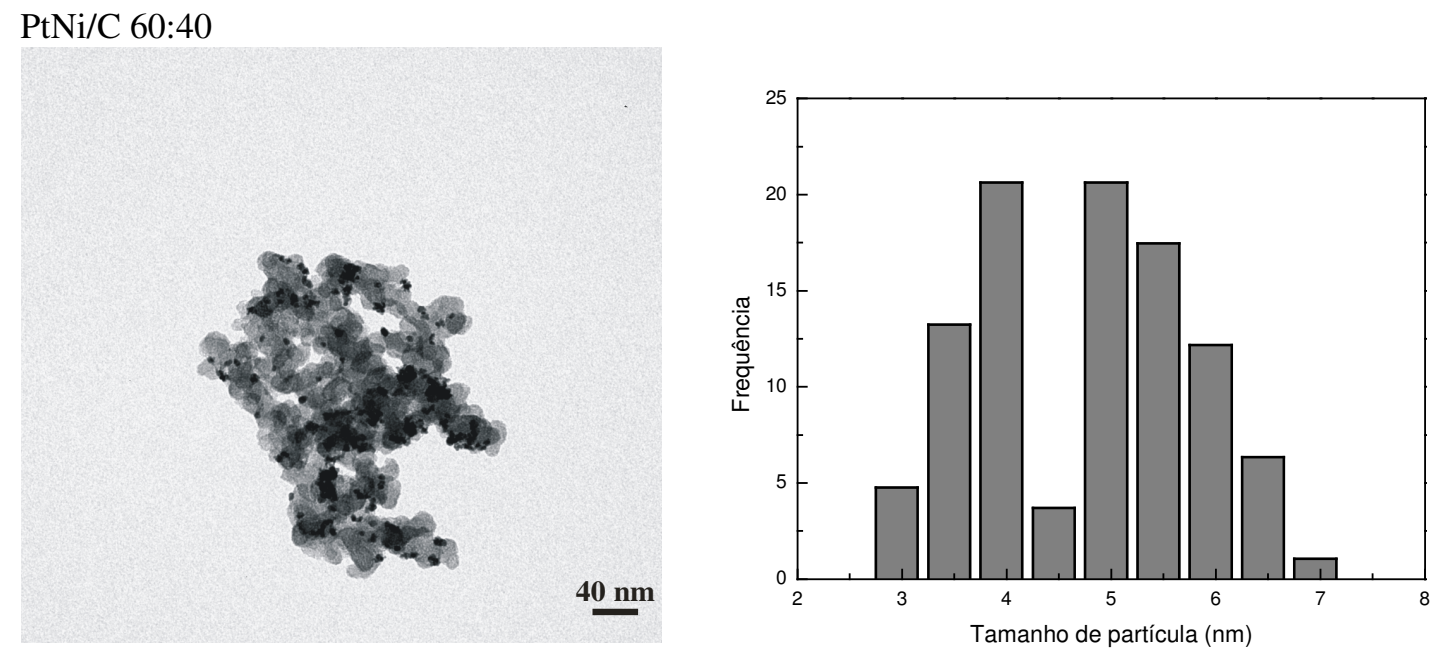

Figura 52: Imagens e histogramas para imagens de TEM para catalisadores Pt-Ni/C preparadas pelo método de microemulsão.

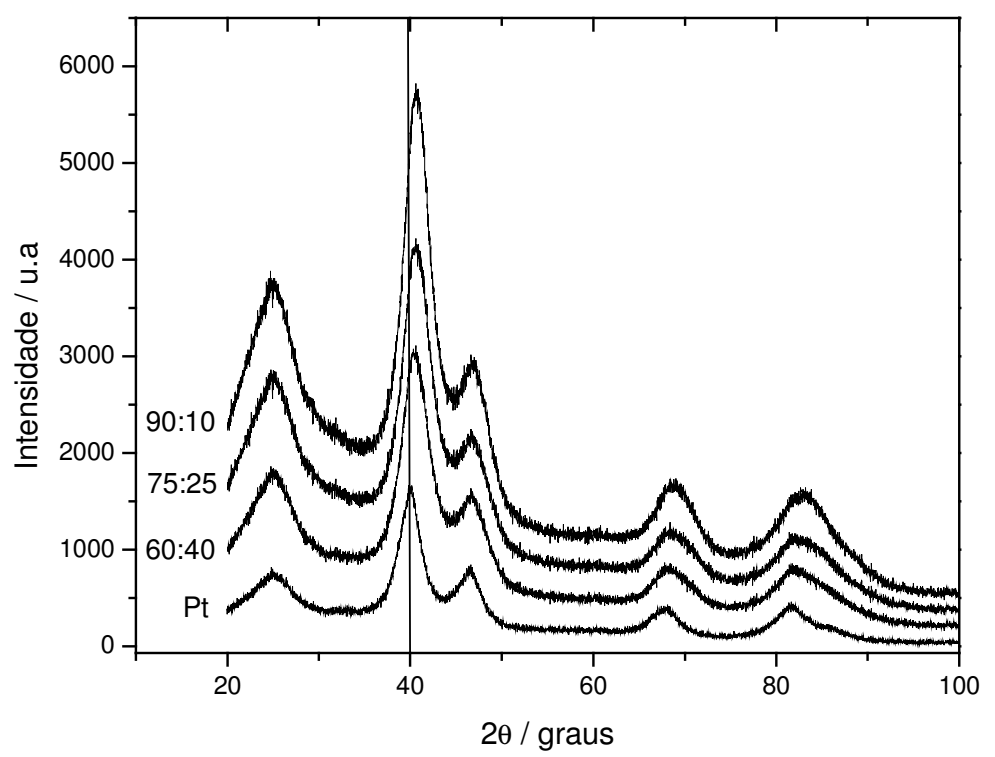

Figura 53: Difratogramas de raios-X para os catalisadores de Pt-Ni/C em diferentes proporções atômicas. 
Tabela 7: Parâmetros estruturais para catalisadores de $\mathrm{Pt}-\mathrm{Ni} / \mathrm{C} \mathrm{e} \mathrm{Pt/C}$.

\begin{tabular}{c|c|c|c|c}
\hline Catalisador & Tam. Part. (nm) & Tam. Part. (nm) & Parâmetro rede & Dist. Pt-Pt \\
& XRD & TEM & $(\AA)$ & $(\mathrm{nm})$ \\
\hline Pt/C & 2.6 & - & 3.9088 & 0.276 \\
\hline Pt-Ni/C 90:10 & 2.7 & $3.8 \pm 0.8$ & 3.8428 & 0.272 \\
\hline Pt-Ni/C 75:25 & 2.0 & $3.6 \pm 0.8$ & 3.8194 & 0.270 \\
\hline Pt-Ni/C 60:40 & 2.6 & $4.7 \pm 0.9$ & 3.8178 & 0.270 \\
\hline
\end{tabular}

Na Figura 54 são apresentados voltamogramas cíclicos para os diferentes catalisadores de Pt-Ni/C. Os resultados mostram o comportamento típico de Pt e suas ligas em meio ácido, relacionado com as regiões de adsorção/dessorção hidrogênio e formação de óxidos. Como esperado, as cargas associadas ao processo de adsorção/dessorção de hidrogênio decrescem com a diminuição da quantidade de platina, indicando um pequeno decréscimo da área ativa de Pt. Os picos na região de adsorção/dessorção de hidrogênio para Pt-Ni/C 90:10 e 75:25 estão bem resolvidos e são muito similares ao da $\mathrm{Pt} / \mathrm{C}$, enquanto os picos para $\mathrm{Pt}-\mathrm{Ni} / \mathrm{C}$ 60:40 não estão bem resolvidos, provavelmente devido à maior inserção de níquel no retículo cristalino da Pt. 


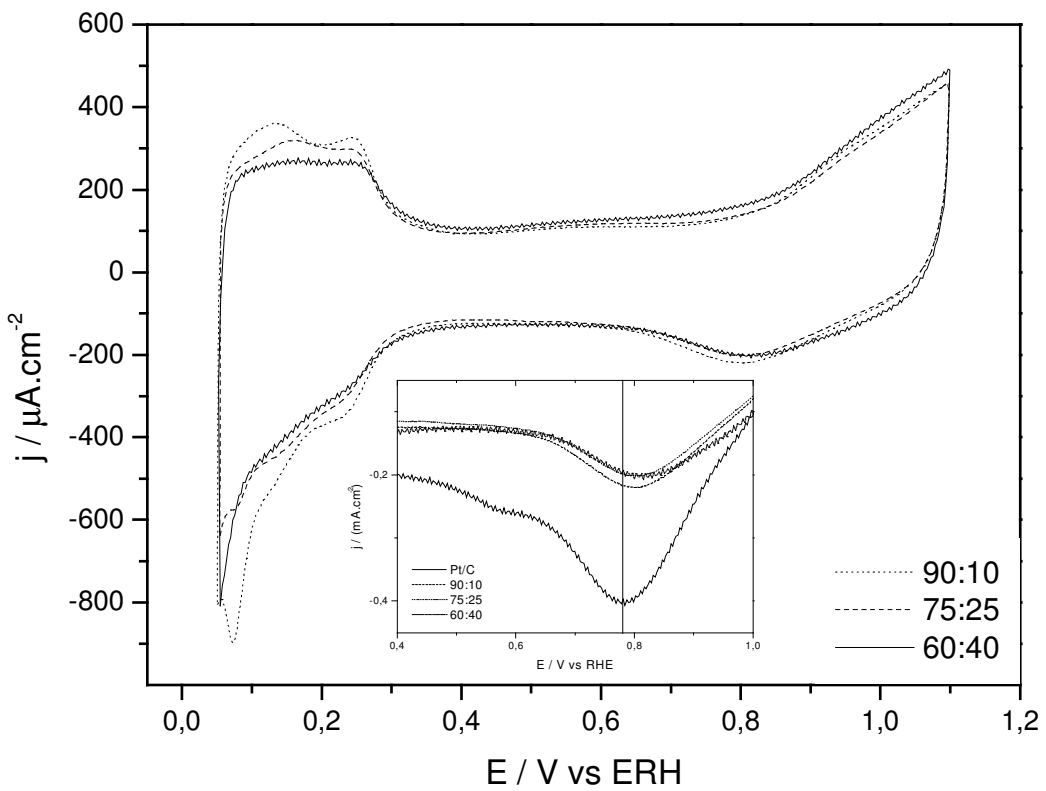

Figura 54: Voltamogramas cíclicos obtidos para os catalisadores de $\mathrm{Pt}-\mathrm{Ni} / \mathrm{C} \mathrm{em} \mathrm{H}_{2} \mathrm{SO}_{4} 0,5 \mathrm{molL}^{-1}$ a 50 $\mathrm{mVs}^{-1}$. Inset: Varredura catódica expandida na região de redução dos óxidos.

A comparação dos resultados mostrados no inserto da Figura 54 evidencia um pequeno deslocamento dos potenciais de pico de redução dos óxidos de Pt para potenciais mais elevados (anódicos) para todos os eletrocatalisadores de $\mathrm{PtNi} / \mathrm{C}$, comparados com $\mathrm{Pt}$. Conforme já mencionado, deslocamentos anódicos no pico de redução podem ser atribuídos a diminuição da energia livre de adsorção $\left(\Delta \mathrm{G}_{\mathrm{ads}}\right)$ de $\mathrm{Pt}-\mathrm{OH}$, Pt-O ou Pt- $\mathrm{O}_{2}$, devido a presença do segundo metal na liga, fato este que facilita a redução das espécies oxigenadas.

Na Figura 55 são apresentadas às curvas de polarização de estado estacionário a 900 rpm para a RRO no disco e a corrente de oxidação para $\mathrm{H}_{2} \mathrm{O}_{2}$ no anel, nos diferentes catalisadores de PtNi/C, onde nota-se uma melhora no desempenho catalítico dos catalisadores com aumento da quantidade de níquel, evidenciado por uma ligeira diminuição do sobrepotencial. Para melhor comparação das atividades catalíticas os resultados são apresentados na forma de diagramas de Tafel corrigidos por transporte de massa, na Figura 56. 


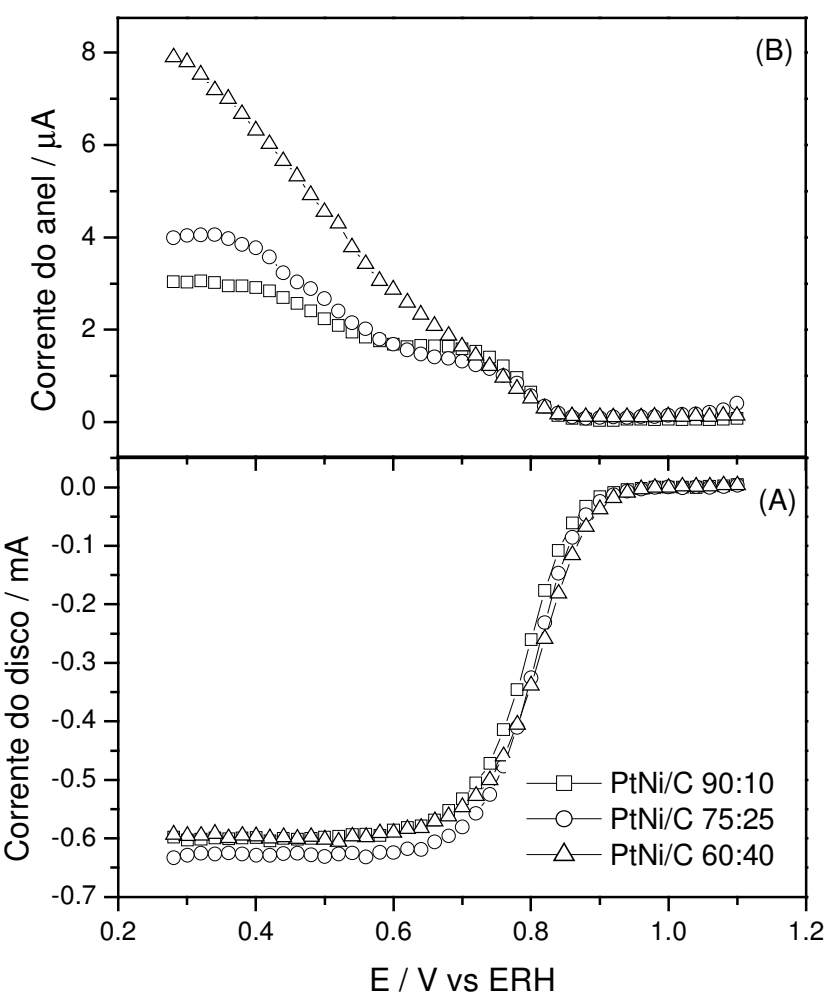

Figura 55: Curva de polarização em estado estacionário para RRO em catalisadores de Pt-Ni/C em $\mathrm{H}_{2} \mathrm{SO}_{4}$ 0,5 mol.L ${ }^{-1}, \omega=900 \mathrm{rpm}$. (a) disco e (b) anel. $\mathrm{E}_{\mathrm{a}}=1,2 \mathrm{~V}$

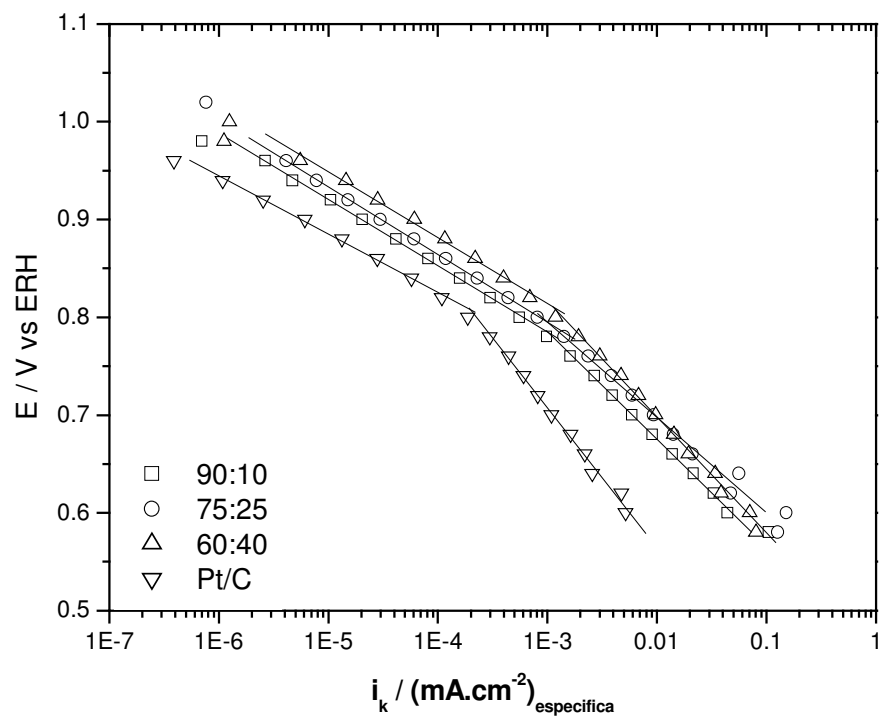

Figure 56: Diagramas de Tafel para RRO em catalisadores de Pt-Ni/C com diferentes razões atômicas em $\mathrm{H}_{2} \mathrm{SO}_{4}$ 0,5 mol.L ${ }^{-1}$. 
De acordo com a Figura 56 conclui-se que a atividade específica aumenta na seqüência PtNi/C 60:40 > PtNi/C 75:25 > PtNi/C 90:10 > Pt/C. Este aumento na cinética da RRO pode ser atribuído a efeitos eletrônicos ou geométricos dos átomos de $\mathrm{Ni}$ sobre os átomos de Pt nos catalisadores bimetálicos, sendo a melhora no desempenho catalítico proporcional ao aumento da quantidade de $\mathrm{Ni}$ no catalisador como pode ser observado na Figura 57.

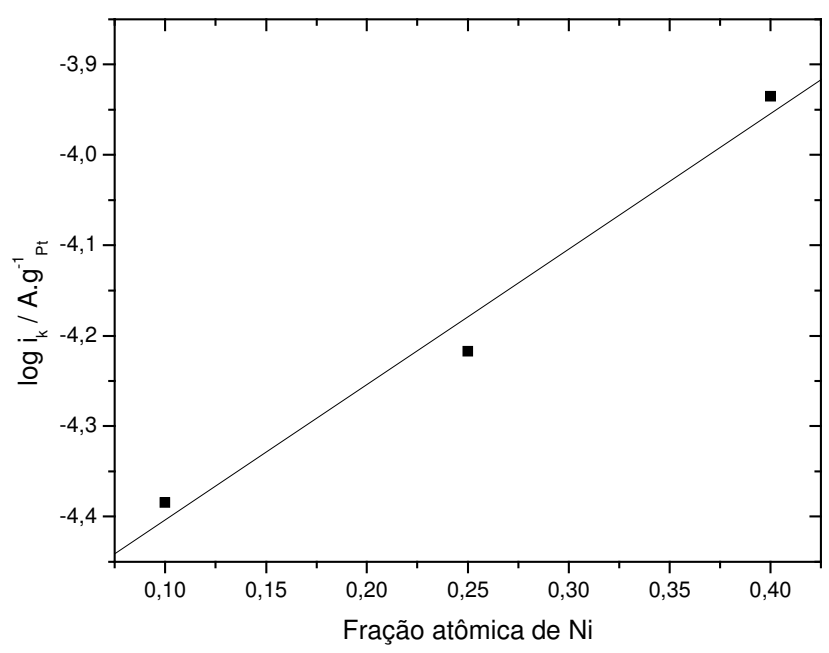

Figura 57: Correlação entre atividade e fração atômica de Ni do catalisador.

As Figuras 58 e 59 apresentam os resultados das medidas espectroscópicas (XANES) realizadas nos catalisadores de $\mathrm{PtNi} / \mathrm{C}$. Os dados mostraram considerável modificação na ocupação da banda 5d da Pt, notando-se que conforme aumenta-se o teor de níquel há menor vacância da banda $5 d$ da platina. Essa alteração de propriedade eletrônica, ocasionada pela maior ocupação na banda 5d, tem como conseqüência, menor interação dos sítios de platina com espécies oxigenadas, o que deixa mais sítios de platina livres para que ocorra a reação, além de enfraquecer a força de adsorção de espécies oxigenadas e facilitar a redução e dessorção das espécies oxigenadas intermediárias da reação. 
Como observado através dos voltamogramas da Figura 54 a redução dos óxidos superficiais para a liga Pt-Ni é facilitada, em comparação à Pt/C, o que deve levar ao aumento do número de sítios livres de Pt. Do ponto de vista microscópico estas modificações nas propriedades químicas da Pt no catalisador PtNi/C está associada ao efeito ligante e de tensão/ compressão no retículo cristalino da rede, conforme proposto por Nǿrskov. Os resultados aqui obtidos evidenciam a formação de liga, caracterizada pela diminuição do parâmetro de rede, havendo também o efeito ligante do níquel sobre a platina. De acordo com Nǿrskov, a diminuição do parâmetro de rede levaria a diminuição do centro de energia da banda d, conseqüentemente, a energia de adsorção das espécies oxigenadas diminuiria, fatos que foram confirmados pelos resultados de XANES e dos voltamogramas cíclicos. A hipótese de alteração do centro da banda d proposta por Nǿrskov vem sendo utilizada com muito sucesso por Adzic e colaboradores [13] para explicar a atividade catalítica frente a RRO em vários monocristais.

Neste contexto, fica evidenciado que o aumento da atividade catalítica decorrente do aumento do teor de níquel está associado com um efeito eletrônico do Ni sobre os átomos de Pt. Entretanto, os resultados de Xanes para os catalisadores de PtNi/C são contraditórios aos resultados da literatura em meio ácido e alcalino [64], os quais indicam que o efeito do níquel sobre a platina é de retirar densidade eletrônica da platina aumentando assim a intensidade de absorção, consequentemente a vacância. Assim, a explicação para a melhor atividade dos catalisadores de $\mathrm{PtNi} / \mathrm{C}$ é atribuída à maior facilidade para romper a ligação $\mathrm{O}-\mathrm{O}$. A consistência dos dados obtidos no presente trabalho em relação a todos os catalisadores estudados permite concluir que os dados obtidos nestes trabalhos são mais representativos dos sistemas em estudo. 


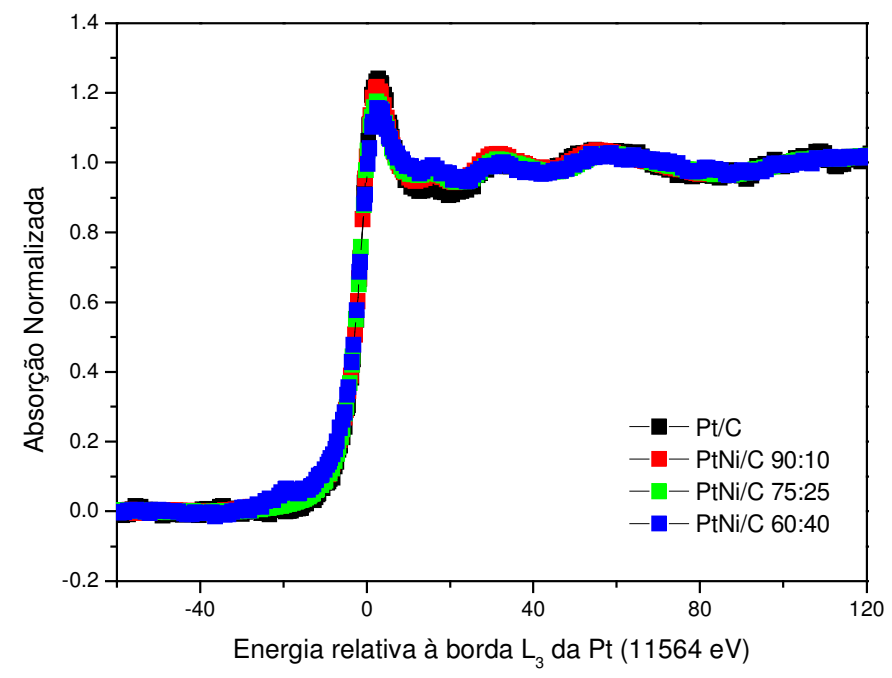

Figura 58: Espectro XANES para diversos catalisadores de PtNi/C a $900 \mathrm{mV}$ em $\mathrm{H}_{2} \mathrm{SO}_{4}$ 0,5 M.

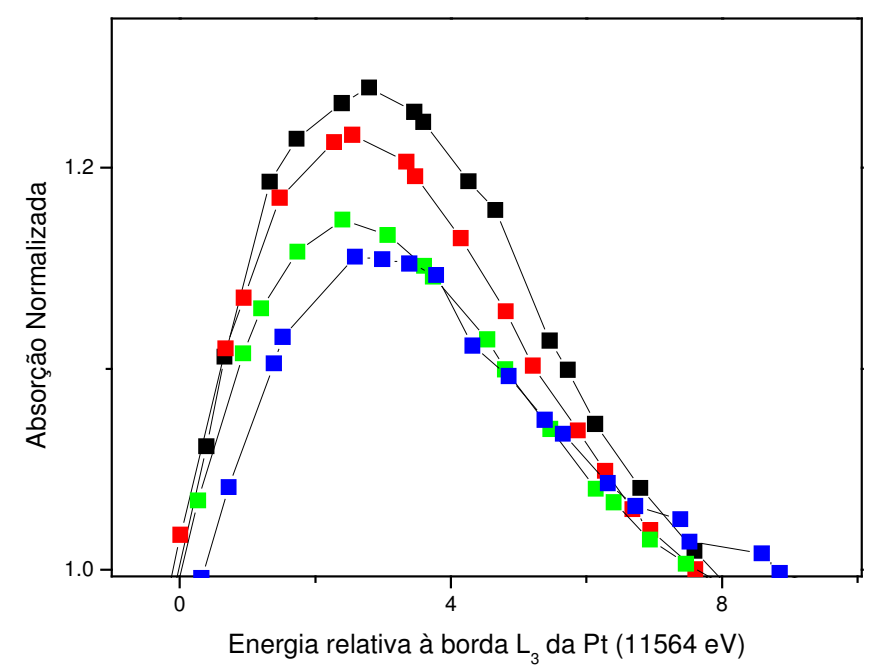

Figura 59: Ampliação do espectro XANES para diversos catalisadores de $\mathrm{PtNi} / \mathrm{C}$ a $900 \mathrm{mV}$ em $\mathrm{H}_{2} \mathrm{SO}_{4}$ $0,5 \mathrm{M}$.

Os valores dos coeficientes de Tafel, bem como os valores para o número de elétrons e percentual de peróxido formado são apresentados na Tabela 8 e estão dentro do valor esperado. Seus valores próximos indicam que o mecanismo reacional não é alterado. 
Tabela 8: Parâmetros cinéticos para RRO em catalisadores de Pt-Ni/C.

\begin{tabular}{c|c|c|c|c}
\hline Catalisador & $\mathrm{n}_{0,9 \mathrm{~V}}$ & $\mathrm{~b}_{1} \mathrm{mVdec}^{-1}$ & $\mathrm{~b}_{2} \mathrm{mVdec}^{-1}$ & $\% \mathrm{H}_{2} \mathrm{O}_{2}$ \\
\hline Pt/C & 4.0 & 60 & 111 & 0.11 \\
\hline Pt-Ni/C 90:10 & 3.8 & 62 & 109 & 1.5 \\
\hline Pt-Ni/C 75:25 & 3.8 & 67 & 110 & 1.4 \\
\hline Pt-Ni/C 60:40 & 3.9 & 60 & 111 & 0.86 \\
\hline
\end{tabular}

\subsection{Catalisadores de PtM/C preparados por microemulsão com surfactantes iônicos}

Utilizando o método de microemulsão com surfacante aniônico foram preparados catalisadores de PtFe/C na composição de 90:10, 75:25, e 60:40 e de PtCo/C e PtNi/C na composição de 80:20 e 60:40. A composição real dos catalisadores foi determinada por análises de EDX e os resultados coincidem com os nominais. Os difratogramas de raio-X para catalisadores preparados pelo método de microemulsão utilizando um surfactante aniônico (AOT), são apresentados na Figura 60 para as várias composições de $\mathrm{PtFe} / \mathrm{C}$ e para o catalisador de Pt/C comercial. O perfil dos difratogramas para todos os eletrocatalisadores é similar ao da $\mathrm{Pt} / \mathrm{C}$, sem picos adicionais, indicando que, como na maioria dos casos anteriores, os materiais apresentam estrutura cúbica de face centrada (cfc). Dados da literatura [28] são semelhantes aos encontrados neste trabalho, demonstrando que o catalisador preparado pelo método de microemulsão, apresenta estrutura desordenada, com os átomos de Fe distribuídos aleatoriamente nas posições dos átomos de Pt na estrutura cfc. Assim como nos casos dos catalisadores de $\mathrm{PtFe} / \mathrm{C}$ preparados por impregnação, os picos de reflexão para todos os catalisadores de $\mathrm{PtFe} / \mathrm{C}$ estão deslocados para maiores valores de $2 \theta$, indicando a 
contração da rede cristalina da Pt devido à substituição dos átomos de Pt por átomos de $\mathrm{Fe}$ que são menores. Os largos picos de reflexão para os catalisadores mostram que os materiais são nanoestruturados, com pequeno tamanho de cristalito. Os tamanhos de cristalito, juntamente com os parâmetros de rede obtidos para todos os catalisadores são apresentados na Tabela 9, onde claramente é notado que os valores são menores do que aqueles da Pt/C, e que a diminuição do parâmetro de rede aumenta com o aumento da quantidade de ferro no catalisador, indicando efetiva formação de liga de platina com ferro.

Na Figura 61 são apresentados voltamogramas cíclicos para os diferentes catalisadores de PtFe/C. Observa-se que os picos na região de adsorção/dessorção de hidrogênio estão bem resolvidos e são muito similares ao da Pt/C. Assim como no caso do catalisador de $\mathrm{PtNi} / \mathrm{C}$, a carga associada ao processo de adsorção/dessorção de hidrogênio decresce com a diminuição da quantidade de platina, indicando um pequeno decréscimo da área ativa de Pt.

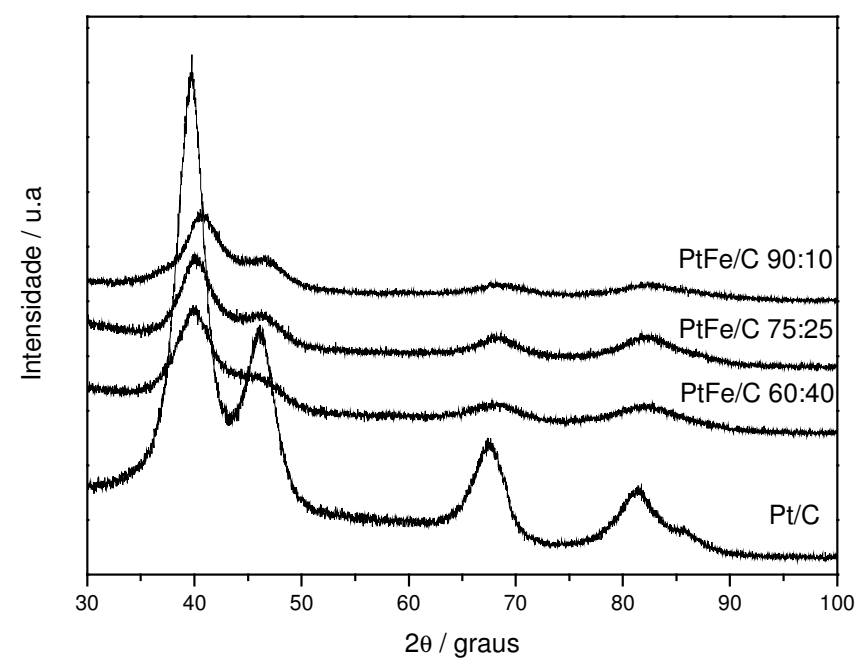

Figure 60: Difratograma de raios-X para os catalisadores $\mathrm{PtFe} / \mathrm{C}$ em diferentes composições e Pt/C. 
Tabela 9: Tamanho médio da partícula e parâmetro de rede (a) obtidos a partir dos padrões de raio-X dos catalisadores.

\begin{tabular}{|c|c|c|}
\hline Catalisador & diâmetro (nm) & a (nm) \\
\hline $\mathrm{Pt}(\mathrm{E}-\mathrm{Tek})$ & 2,7 & 0,3922 \\
\hline $\mathrm{PtFe} / \mathrm{C} \mathrm{90:10}$ & 3,0 & 0,3894 \\
\hline $\mathrm{PtFe} / \mathrm{C} \mathrm{75:25}$ & 2,9 & 0,3869 \\
\hline $\mathrm{PtFe} / \mathrm{C} \mathrm{60:40}$ & 3,7 & 0,3834 \\
\hline $\mathrm{PtNi} / \mathrm{C} \mathrm{80:20}$ & 3,3 & 0,3909 \\
\hline $\mathrm{PtNi} / \mathrm{C} \mathrm{60:40}$ & 3,1 & 0,3879 \\
\hline $\mathrm{PtCo} / \mathrm{C} \mathrm{80:20}$ & 2,9 & 0,3795 \\
\hline $\mathrm{PtCo} / \mathrm{C} \mathrm{60:40}$ & 3,4 & 0,3717 \\
\hline
\end{tabular}

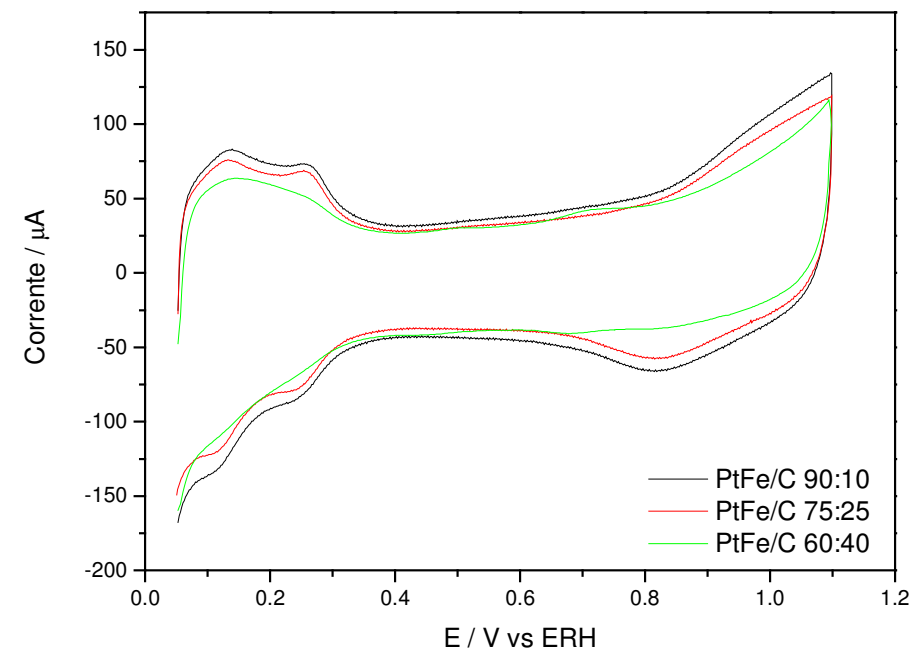

Figure 61: Voltamogramas cíclicos para $\mathrm{PtFe} / \mathrm{C}$ com diferentes composições em $\mathrm{H}_{2} \mathrm{SO}_{4} 0,5 \mathrm{M}$.

Na Figura 62 são apresentadas às curvas de polarização de estado estacionário a 900 rpm para a RRO no disco e a corrente de oxidação para $\mathrm{H}_{2} \mathrm{O}_{2}$ no anel, nos diferentes catalisadores de $\mathrm{PtFe} / \mathrm{C}$, preparados com surfactante aniônico. Os correspondentes diagramas de Tafel corrigidos por transporte de massa são mostrados na Figura 63. A exemplo do catalisador PtNi/C nota-se uma melhora no desempenho catalítico dos catalisadores com 
aumento da quantidade de ferro, evidenciado por uma ligeira diminuição do sobrepotencial da reação.

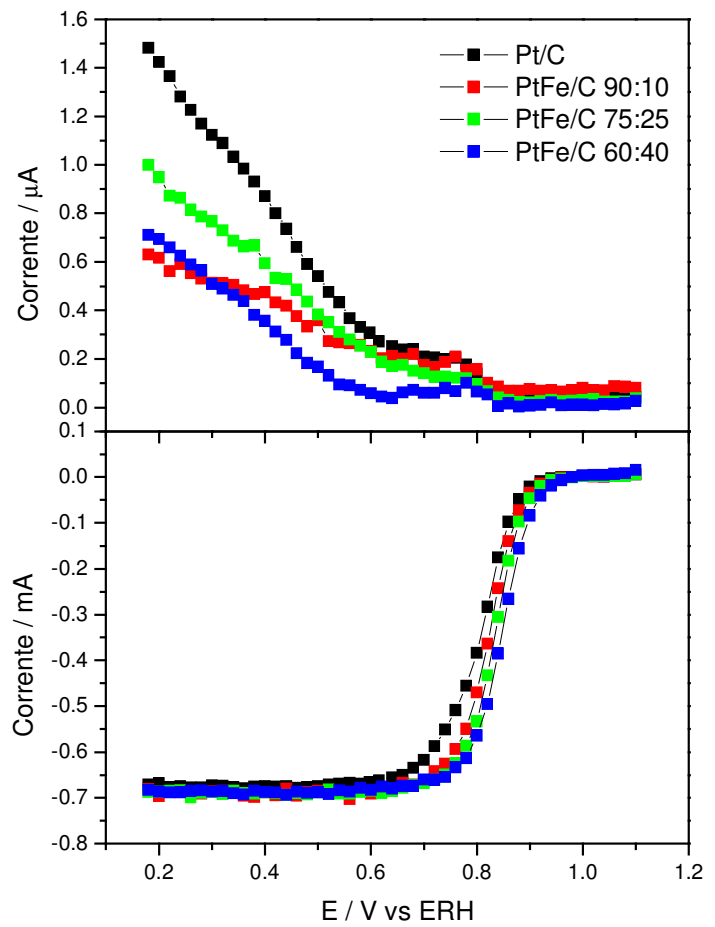

Figura 62: Curva de polarização de estado estacionário para a RRO em diversos catalisadores em $\mathrm{H}_{2} \mathrm{SO}_{4}$ 0,5 M. (A) eletrodo de disco, (B) eletrodo de anel. 


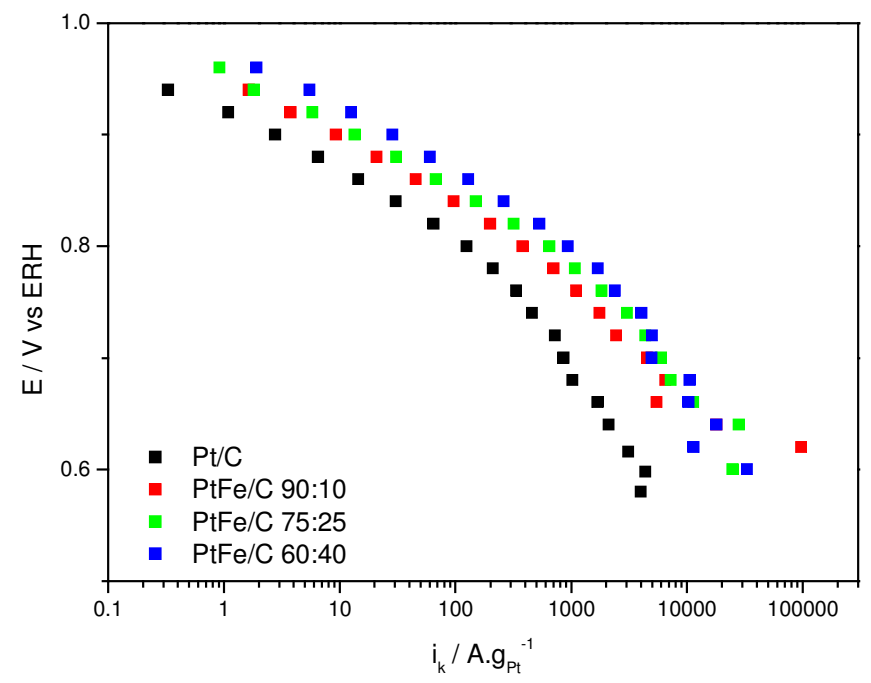

Figura 63: Diagramas de Tafel para RRO em catalisadores de PtFe/C preparados por microemulsão com surfactante aniônico com diferentes composições em $\mathrm{H}_{2} \mathrm{SO}_{4} 0,5$ mol.L ${ }^{-1}$.

Catalisadores de $\mathrm{PtFe} / \mathrm{C}$ e PtNi/C foram também preparados na composição (nominal) de 80:20 e 60:40, por microemulsão, utilizando-se surfactante catiônico em cujos casos as análises por EDX indicaram a composição 90:10 e 75:25, respectivamente. O perfil e a tendência dos DRX e dos voltamogramas cíclicos para estes materiais bem como para PtFe/C e $\mathrm{PtCo} / \mathrm{C}$ preparados com surfctante aniônico resultaram semelhantes aos casos anteriores e portanto não serão mostrados. Os parâmetros estruturais obtidos para estes catalisadores são apresentados na Tabela 9.

Na Figura 64 é apresentada a imagem representativa do padrão morfológico do catalisador PtFe/C 75:25 preparado pelo método de microemulsão utilizando-se surfactante catiônico. Foram adquiridas imagens de diferentes regiões das amostras e os histogramas de distribuição de diâmetros médios foram obtidos pela medida de ao menos 500 partículas. Observa-se na Figura 64 que o catalisador apresentou uma boa dispersão das partículas e uma distribuição estreita de tamanho médio de partículas. Apesar de terem sido observadas algumas partículas grandes, $6 \mathrm{~nm}$, as partículas acima de $5 \mathrm{~nm}$ somam juntas menos de $5 \%$ 
do número total. O tamanho médio calculado por HRTEM foi de 2,7 nm. Também se avaliou a composição de uma partícula individualmente, por EDS, onde foi obtida a composição média de $25 \%$ de $\mathrm{Fe}$, corroborando o resultado obtido por EDX.
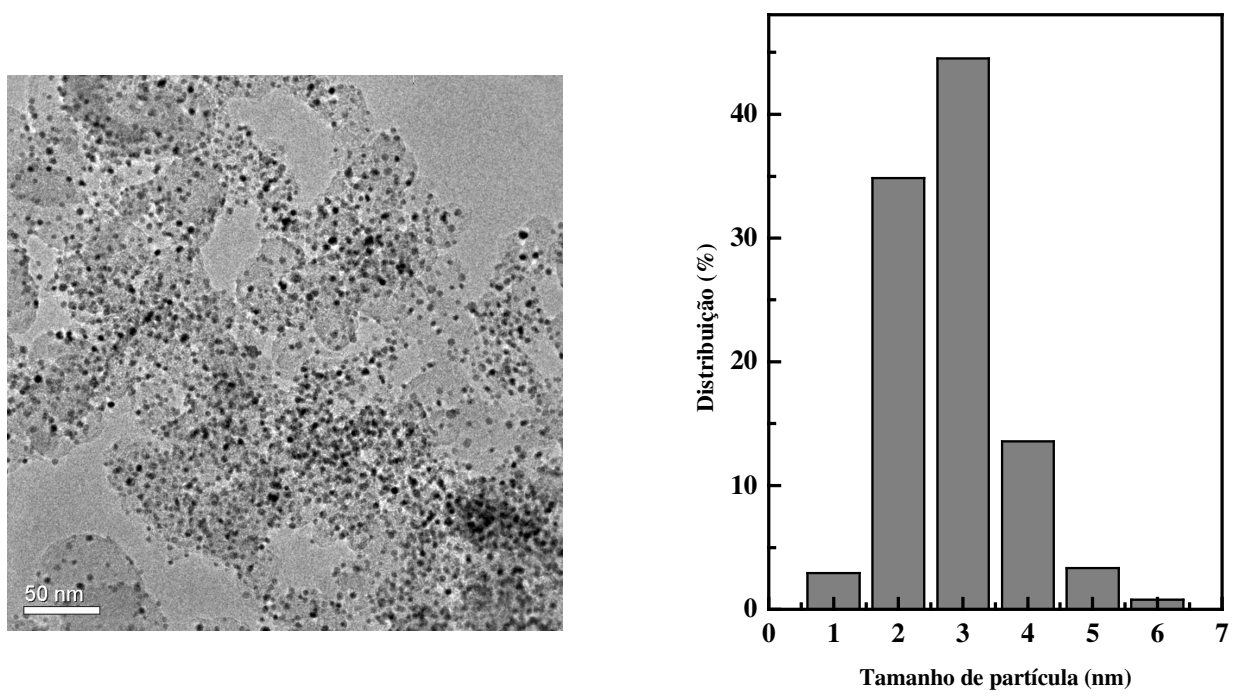

Figura 64: Imagens de microscopia eletrônica de transmissão de alta resolução (HRTEM) do catalisador PtFe/C preparado pelo método de microemulsão com surfactante catiônico. $O$ histograma mostra a distribuição numérica relativa de tamanho de partícula do catalisador.

$\mathrm{Na}$ Figura 65 é apresentada a imagem representativa do padrão morfológico do catalisador $\mathrm{PtFe} / \mathrm{C}$ preparado pelo método de microemulsão utilizando-se surfactante aniônico. Observa-se na Figura 65 que o catalisador apresentou uma boa dispersão de partículas, porém a distribuição do tamanho médio de partículas é maior do que quando o catalisador foi preparado com surfactante catiônico. Foram observadas algumas partículas muito grandes, $11 \mathrm{~nm}$, entretanto como no caso acima o percentual de partículas grandes é pequeno. O tamanho médio calculado por HRTEM foi de $4 \mathrm{~nm}$. Também se avaliou a composição de uma partícula individualmente, por EDS, onde foi obtida a composição média de $25 \%$ de Fe, corroborando o resultado obtido por EDX. Esses dados demonstram que o método de síntese é eficaz para se produzir catalisadores com a composição desejada, bem como para obter partículas pequenas, com bom controle do tamanho de partícula. 

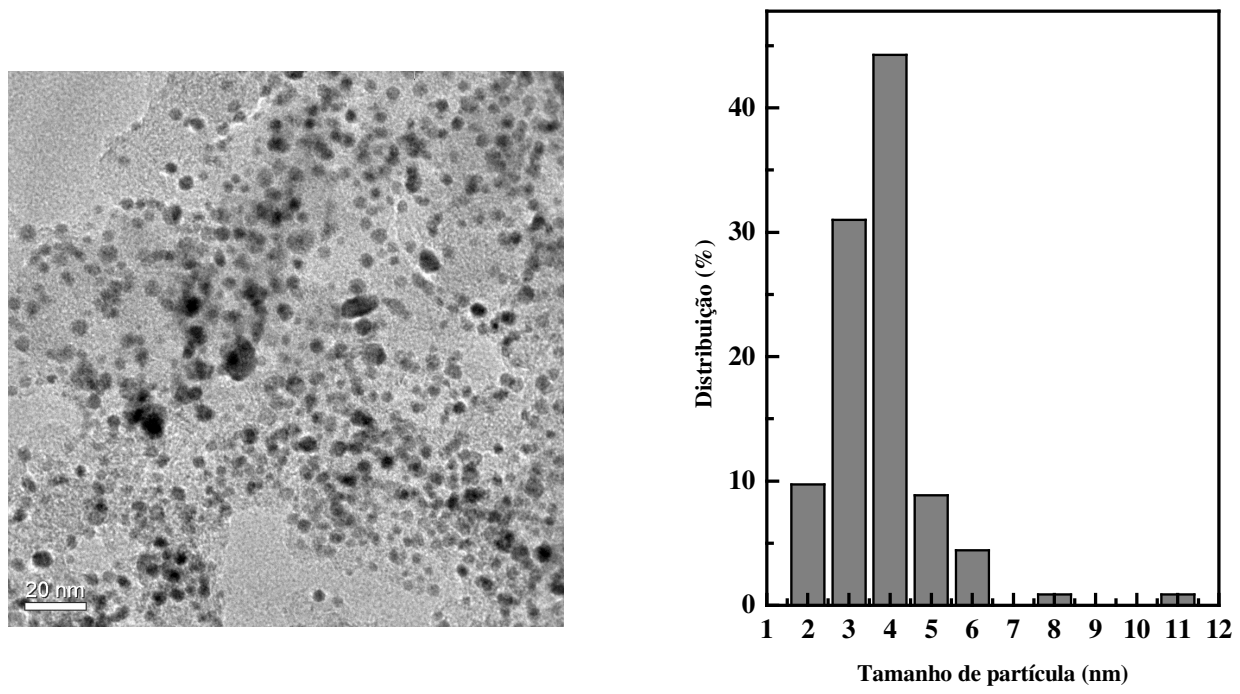

Figura 65: Imagens de microscopia eletrônica de transmissão de alta resolução (HRTEM) do catalisador $\mathrm{PtFe} / \mathrm{C}$ preparado pelo método de microemulsão com surfactante aniônico. $O$ histograma mostra a distribuição numérica relativa de tamanho de partícula do catalisador.

A Figura 66 apresenta às curvas de polarização de estado estacionário a 900 rpm para a RRO no disco e a corrente de oxidação para $\mathrm{H}_{2} \mathrm{O}_{2}$ no anel, nos diferentes catalisadores de $\mathrm{PtNi} / \mathrm{C}$ e $\mathrm{PtCo} / \mathrm{C}$ preparados com surfactante aniônico e a Figura 67 apresenta às curvas de polarização nos diferentes catalisadores de $\mathrm{PtNi} / \mathrm{C}$ e $\mathrm{PtFe} / \mathrm{C}$ preparados com surfactante catiônico, sendo que nas Figuras 68 e 69 são apresentados os correspondentes diagramas de Tafel corrigidos por transporte de massa. 


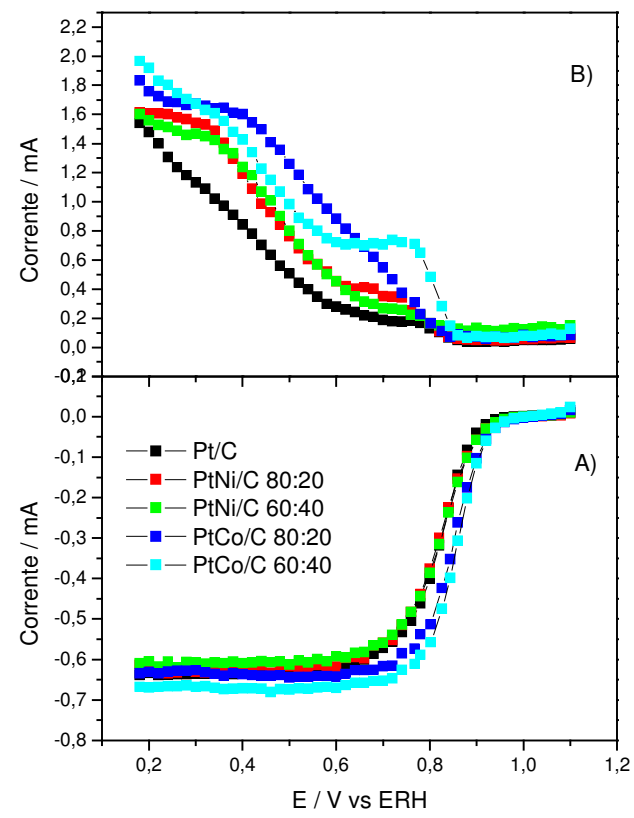

Figura 66: Curva de polarização de estado estacionário para a RRO em diversos catalisadores preparados com surfactante aniônico em $\mathrm{H}_{2} \mathrm{SO}_{4} 0,5$

M. (A) eletrodo de disco, (B) eletrodo de anel.

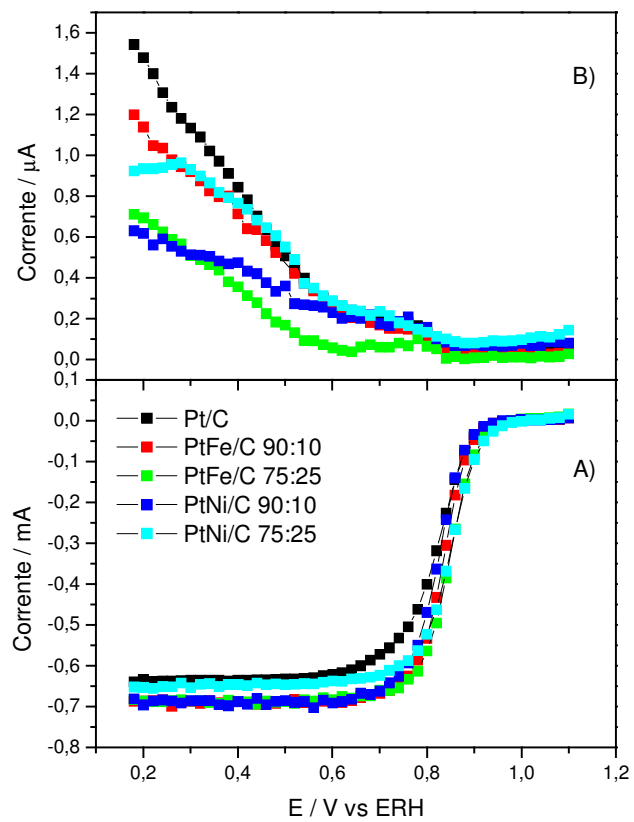

Figura 67: Curva de polarização de estado estacionário para a RRO em diversos catalisadores preparados com surfactante catiônico em $\mathrm{H}_{2} \mathrm{SO}_{4} 0,5$

M. (A) eletrodo de disco, (B) eletrodo de anel.

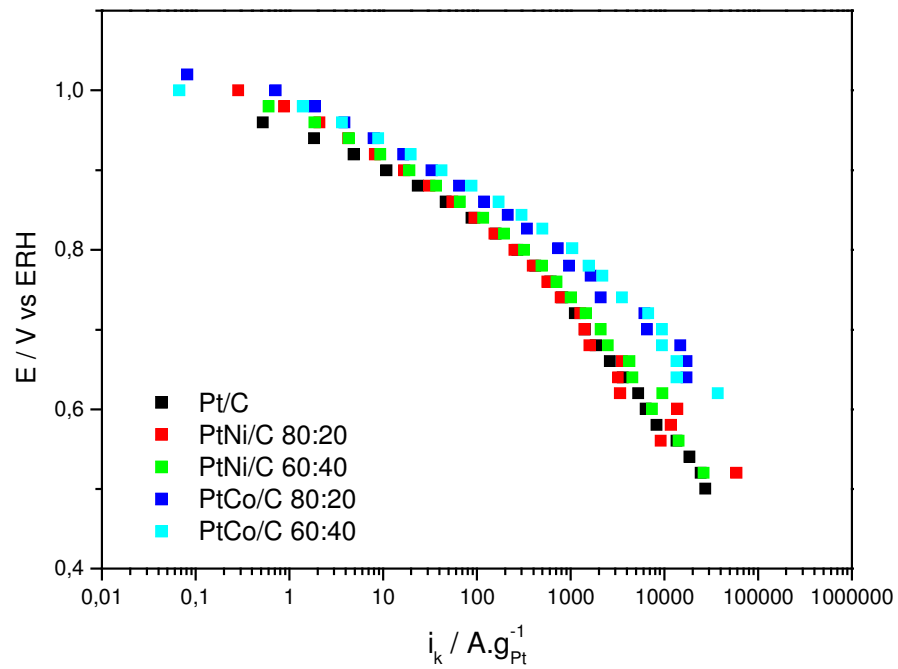

Figura 68: Diagramas de Tafel para RRO em catalisadores preparados por microemulsão com surfactante aniônico com diferentes composições em $\mathrm{H}_{2} \mathrm{SO}_{4} 0,5$ mol.L ${ }^{-1}$. 


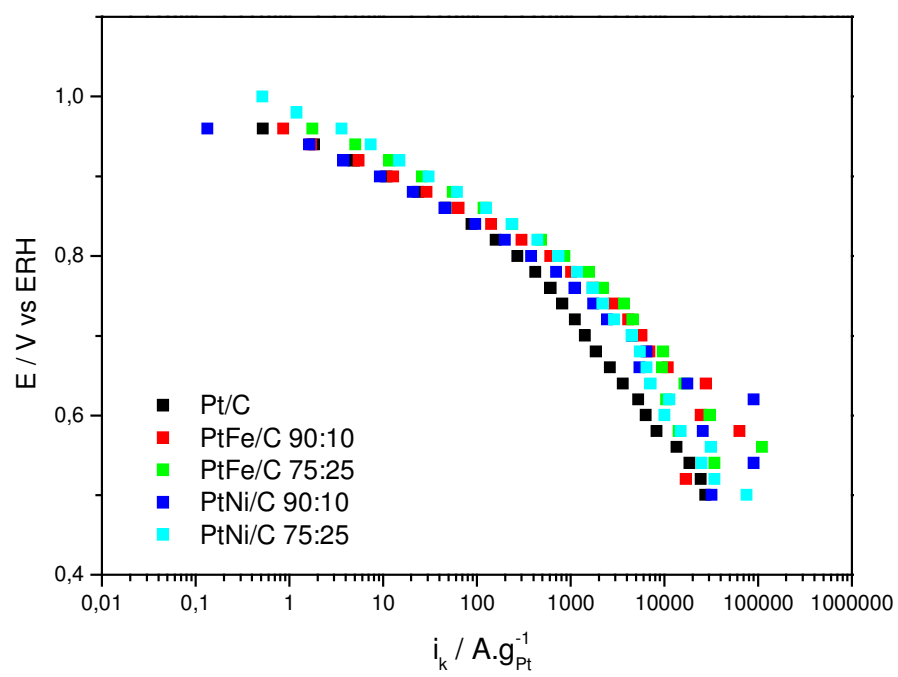

Figura 69: Diagramas de Tafel para RRO em catalisadores preparados por microemulsão com surfactante catiônico com diferentes composições em $\mathrm{H}_{2} \mathrm{SO}_{4} 0,5$ mol.L ${ }^{-1}$.

Nota-se que em todos os casos o número de elétrons da reação $(n=4)$ e os coeficientes de Tafel (em torno de $60 \mathrm{mVdec}^{-1}$ para baixos sobrepotenciais e $120 \mathrm{mVdec}^{-1} \mathrm{e}$ altos sobrepotenciais) resultaram também semelhantes aos casos anteriores. Na Figura 70 são comparados os diagramas de Tafel para diversos catalisadores de $\mathrm{PtFe} / \mathrm{C}$ preparados com os surfactantes aniônico e catiônico. Comparando-se os resultados para catalisadores de PtFe com a mesma composição nota-se um melhor desempenho catalítico quando se utiliza surfactante catiônico durante o processo de síntese. Os dados discutidos anteriormente indicam claramente que este efeito é decorrente do menor tamanho de partícula apresentado por este catalisador. 


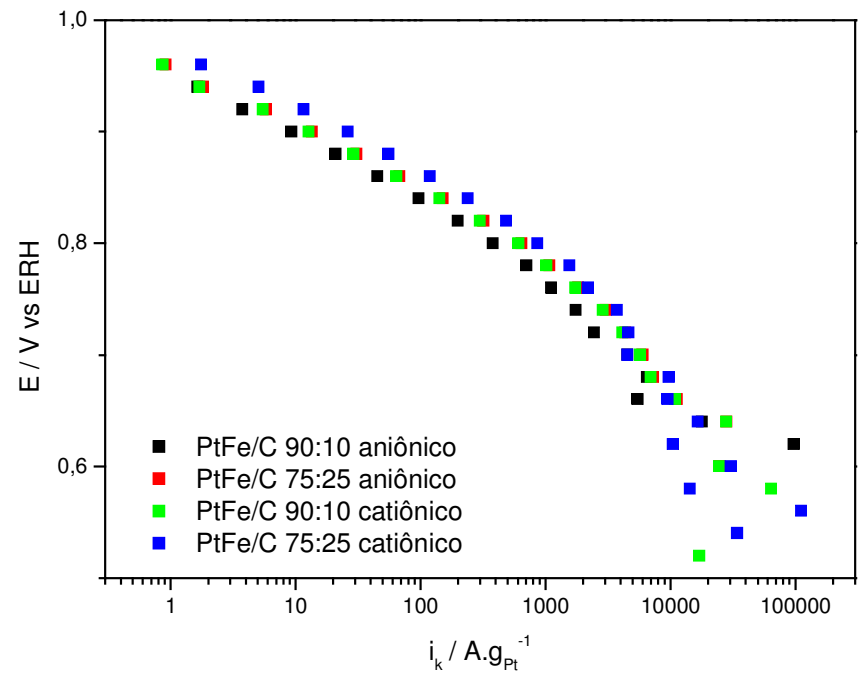

Figura 70: Diagramas de Tafel para RRO em catalisadores $\mathrm{PtFe} / \mathrm{C}$ preparados com diferentes surfactantes; em $\mathrm{H}_{2} \mathrm{SO}_{4} 0,5$ mol.L ${ }^{-1}$. 


\section{CAPÍTULO IV}

\section{CONSIDERAÇÕES GERAIS E CONCLUSÃO}

De forma geral nota-se que os catalisadores bimetálicos estudados neste trabalho mostram-se mais ativos frente à RRO do que platina pura, independentemente de qual metal não nobre foi adicionado à platina. Uma das dificuldades em determinar o efeito das ligas em catalisadores suportados é que a atividade de um catalisador suportado pode ter um largo intervalo de valores dependendo da sua microestrutura e/ou método de preparação. A atividade intrínseca de nanopartículas depende do tamanho de partícula, forma e composição real do mesmo, ou seja, pode não ser um mesmo quando normalizado pela área superficial de Pt. Como catalisadores formados por ligas de Pt podem não ter o mesmo tamanho de partícula ou forma do que os catalisadores de Pt com o qual são comparados, uma simples comparação da atividade normalizada por massa ou área superficial é insuficiente para identificar o verdadeiro efeito do metal ligante.

O número de elétrons da reação (4), a baixa produção de peróxido e o coeficiente de Tafel resultaram muito semelhantes para todos os materiais o que mostra que não há mudança no mecanismo reacional, estando a diferença de desempenho associada a propriedades intrínsecas de cada material. É difícil identificar os motivos pelos quais o desempenho catalítico de um determinado catalisador é aumentado. Entretanto, para as ligas de Pt a causa chave parece estar relacionada com a interação dos sítios de Pt com espécies oxigenadas provenientes da quebra da molécula de água ou de $\mathrm{O}_{2}$. 
Resultados presentes na literatura [65] para catalisadores à base de Pt apresentados na forma de gráficos de atividade específica a um dado potencial em função da energia do centro da banda 5d da Pt em catalisadores com composição bem definida mostram uma relação do tipo vulcão. A explicação geral para esta tendência é que para se obter melhor desempenho é necessário contrabalançar dois efeitos opostos, que são: a necessidade de ser ter forte energia de adsorção do $\mathrm{O}_{2}$ e seus intermediários reacionais $\left(\mathrm{O}_{2}^{-}, \mathrm{O}_{2}{ }^{2-}, \mathrm{H}_{2} \mathrm{O}_{2}\right.$, etc. $)$ e ao mesmo ter baixo grau de recobrimento pelas espécies oxigenadas e por ânions especificamente adsorvidos. Desta forma o resultado na forma de vulcão pode ser racionalizado aplicando-se o princípio de Sebatier: para catalisadores com forte ligação com espécies oxigenadas, a reação é limitada pela velocidade de remoção dos óxidos superfíciais; por outro lado, catalisadores que se ligam fracamente ao oxigênio a cinética é limitada pela velocidade de transferência de prótons e elétrons para o $\mathrm{O}_{2}$ adsorvido.

A Figura 71 apresenta um gráfico de atividade específica em função do centro de energia da banda d para diversos catalisadores com composição 75:25 preparados pelo método de impregnação e para catalisadores 75:25 preparados pelo método de microemulsão utilizando-se surfactante catiônico. O resultado indica uma relação aproximadamente linear da atividade catalítica versus a energia da banda d, não corroborando os resultados da literatura em cujo caso a atividade máxima é notada para o catalisador contendo cobalto. Entretanto, os resultados da literatura são para catalisadores não suportados, com composição superficial bem definida, enquanto que os resultados deste trabalho são para catalisadores suportados, onde há interação do metal com o suporte de carbono e ainda prováveis interações com óxidos do metal de transição (M). Assim é bastante provável que o centro de energia da banda $5 \mathrm{~d}$ de Pt dos materiais suportados não correspondam aos verdadeiramente valores calculados para as ligas metalúrgicas. 
Um outro aspecto relacionado com este fato é que o material nanoparticulado pode sofrer profundas modificações, em particular a sua superfície, quando submetido ao ambiente eletroquímico. Desta forma o uso dos cálculos de DFT enfrentam uma dificuldade adicional quando aplicada a situações práticas. Neste Trabalho, a ênfase principal para a análise das propriedades catalíticas foi dada aos resultados de XANES, os quais permitem investigar as propriedades eletrônicas da Pt nos diversos catalisadores em condições «in situ» e portanto nas suas condições operacionais.

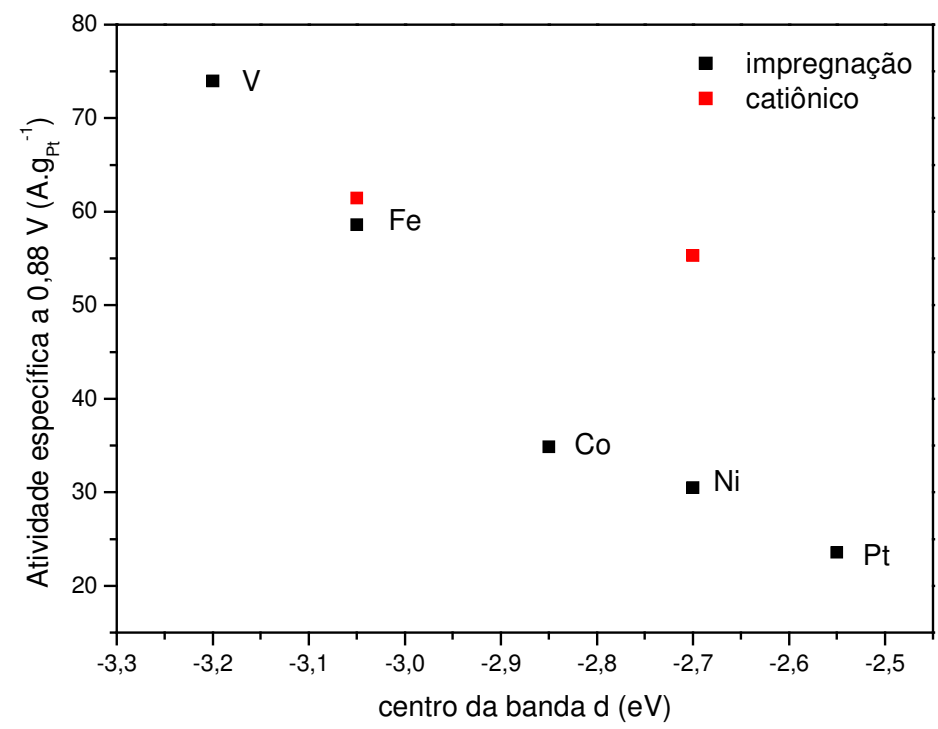

Figura 71: Variação da atividade específica em função da energia do centro da banda 5d da Pt para catalisadores Pt:M preparados por impregnação e para catalisadores de PtFe e PtNi 75:25 preparados por microemulsão utilizando surfcatante catiônico.

Os resultados de XANES obtidos a $600 \mathrm{mV}$ mostram que a ocupação da banda $5 \mathrm{~d}$ da platina nas ligas é a mesma da platina pura, evidenciado que não há efeito de doação ou retirada de elétrons por parte do metal não nobre. Entretanto, a ocupação da banda $5 \mathrm{~d}$ da platinanas ligas a $900 \mathrm{mV}$ é diferente da platina pura, estando à banda menos vacante, o que indica que há uma diminuição da energia livre de adsorção $\left(\Delta \mathrm{G}_{\mathrm{ads}}\right)$ de Pt-OH, Pt-O ou Pt-O2, que facilita a redução das espécies oxigenadas melhorando o desempenho catalítico. 
Analisando-se os resultados para os catalisadores preparados pelo método de impregnação nota-se que a melhora no desempenho catalítico segue a sequência de aumento da ocupação da banda $5 \mathrm{~d}$ da platina, sendo que a mairo variação no grau de ocupação da banda $5 \mathrm{~d}$ da platina ocorreu para o catalisador PtV/C, sendo este também o catalisador que apresentou o melhor desempenho catalítico.

Para catalisadores de platina tem sido observado que conforme se aumentaàq temperatura do tratamento térmico, aumenta-se ligeiramente à ocupação da banda $5 \mathrm{~d} d a \mathrm{Pt}$, pois o fenômeno é dependente do tamanho de partícula. Os resultados do trataemento térmico no catalisador $\mathrm{PtV} / \mathrm{C}$ comercial revelam que o mesmo exibe maior resistência a coalescência dos cristalitos do que os catalisadores contendo somente Pt. Como a ocupação da banda $5 \mathrm{~d}$ da Pt depende tamanho de partícula, a alteração na ocupação da mesma obersavada na Figura XX para Pt pura pode estar em parte associada à grande variação no tamanho de partícula observada para este catalisador com o aumento da temperatura. Já no caso do material PtV/C, os resultados indicam também que há maior atividade catalítica para os materiais tratados termicamente, quando comparados ao $\mathrm{PtV} / \mathrm{C}$ sem tratamento. Etretanto a maior atividade específica ocorre com o material tratado termicamente a $300^{\circ} \mathrm{C}$, havendo um decréscimo do desempenho a partir desta temperatura. Os resultados de XANES mostram que não houve alteração da ocupação da banda 5d da Pt com o aumento do tratamento térmico. Portanto, o efeito majoritário na RRO em meio ácido para $\mathrm{PtV} / \mathrm{C}$ tratado termicamente deve estar relacioinado a outros fatores, tais como; número de coordenação, distância Pt-Pt e a pureza da superfície.

Independentemente do método utilizado para se preparar os catalisadores de PtV notase que a variação dos valores de $2 \theta$ não é tão pronunciada quanto nos demais catalisadores, evidenciando dificuldade na formação de uma liga PtV, devendo o vanádio estar na forma de óxidosnão identificados no DRX. 
Para os catalisadores preparados por refluxo, nota-se que a tendência é a mesma dos catalisadores preparados por impregnação, sendo a atividade das ligas superior a da platina pura e as mesmas apresentando-se menos vacante do que a platina pura. Porém, a diferença na atividade e na intensidade de absorção no espectro XANES são menos pronunciadas para estes casos do que nos catalisadores preparados pelo métodode impregnação, provavelmentedevido à menor temperatura utilizada durante a síntese a qual não proporcionaria condições para total redução dos íons ou óxidos metálicos.

A atividade eletrocatalítica frente à $\mathrm{RRO}$ nas ligas de PtFe e PtNi preparadas pelo método de microemulsão mostrou-se proporcional a quantidade de metal não nobre que forma liga com a Pt. Os métodos de preparação de catalisadores por microemulsão e refluxo mostraram-se eficientes produzindo catalisadores com partícula pequenas homogeneamente distribuída sobre o carbono. O desempenho catalítico dos materiais sofre influência da natureza do surfactante utilizado na síntese. Ainda é incerto os motivos que fazemos catalisadores preparados por microemulsão utilizando surfactante catiônico apresentarem melhor desempenho, porém, os resultados neste trabalho indicam que as partículas apresentam-se melhor distribuídas. 


\section{REFERÊNCIAS BIBLIOGRÁFICAS}

[1] GONZALEZ, E. R. Eletrocatálise e Poluição Ambiental. Química Nova, v. 23, n. 2, p. 262-266, 2000.

[2] VIELSTICH W.; GASTEIGER H. A.; LAMM A. Handbook of fuel cells : fundamentals, technology and applications. Weinheim: Willey, 2003.

[3] PAGANIN, V. A.; TICIANELli, E. A.; GONZALEZ, E. R. Development and electrochemical studies of gas diffusion electrodes for polymer electrolyte fuel cells. J. Applied Electrochem., v. 26, n. 3, p. 297-304, 1996.

[4] PAGANIN, V. A.; TICIANELLI, E. A.; GONZALEZ, E. R. Development of small polymer electrolyte fuel cell stacks. J. Power Sources, v. 70, n. 1, p. 55-58, 1998.

[5] PAGANIN, V. A.; OLIVEIRA, C. L. F.; TICIANELLI, E. A.; SPRINGER, T. E.; GONZALEZ, E. R. Modelistic interpretation of the impedance response of a polymer electrolyte fuel cell. Electrochim. Acta, v. 43, n. 24, p. 3761-3766, 1998.

[6] ADZIC, R. R. Recent advances in the kinetics of oxygen reduction. In: LIPKOWSKI J., ROSS P. N. Electrocatalysis. New York: Wiley-VCH, 1998. p. 197-242.

[7] YEAGER E. Electrocatalysts for $\mathrm{O}_{2}$ reduction. Electrochim. Acta, , v. 29, n. 11 p. 1527-1537, 1984.

[8] In: Conway B. E.; BOCKRIS J. O’M.; YEAGER E.; KHAN S. U. M.; WHITE R. E. Comprehensive treatise of electrochemistry. New York: Plenum Press, 1983, v. 7, p. 301.

[9] MUKERJEE S.; SRINIVASAN S.; SORIAGA M. P.; MCBREEN J. Role of structural and electronic properties of Pt and Pt alloys on electrocatalysis of oxygen reduction - An In Situ XANES and EXAFS Investigation. J. Electrochem. Soc., v. 142, p. 1409-1422, 1995. 
[10] SALGADO, J. R. C.; ANTOLINI, E.; GONZALEZ, E. Structure and Activity of Carbon-Supported Pt-Co Electrocatalysts for Oxygen Reduction. J. Phys. Chem. B., v. 108, p. 17767-17774, 2004.

[11] KOFFI, R. C.; COUTANCEAU, C.; GARNIER, E.; LÉGER, J.-M.; LAMY, C. Synthesis, characterization and electrocatalytic behaviour on non-alloyed PtCr methanol tolerant nanoelectrocatalysts for oxygen reduction reaction (ORR). Electrochim. Acta., v. 50, p. $4117-4127,2005$.

[12] ZHANG J.; VUKMIROVIC M. B.; XU Y.; MAVRIKAKIS M.; ADZIC R. R. Controlling the catalytic activity of platinum-monolayer electrocatalysts for oxygen reduction with different substrates. Angew. Chem., v. 117, p. 2170-2173, 2005.

[13] ZHANG J.; LIMA F. H. B.; SHAO M. H.; SASAKI K.; WANG J.X.; ADZIC R. R. Platinum monolayer on nonnoble metal-noble metal core-shell nanoparticle electrocatalysts for $\mathrm{O}_{2}$ reduction. J. Phys. Chem. B., v. 109, p. 22701-22704, 2005.

[14] MENG, H.; SHEN, P. K. Novel Pt-free catalysts for oxygen electroreduction. Electrochem. Comm., v. 8, p. 588-594, 2006.

[15] BAKER, W. S.; PIETRON, J. J.; TELISKA, M. E.; BOUWMAN, P. J.; RAMAKER, D. E.; SWIDER-LYONS, K. E. Enhanced Oxygen Reduction Activity in Acid by Tin-Oxide Supported Au Nanoparticles Catalyst. J. Electrochem. Soc., v. 153, n. 9, p. 1702-1707, 2006.

[16] RAGHUVEER, V.; FERREIRA, P. J.; MANTHIRAM, A. Comparison of Pd-Co-Au electrocatalysts prepared by conventional borohydride and microemulsion methods for oxygen reduction in fuel cells. Electrochem. Comm., v. 8, p. 807-814, 2006.

[17] SODE, A.; LI, W.; YANG, Y.; WONG, P. C.; GYENGE, E.; MITCHELL, K. A. R.; BIZZOTTO, D. Electrochemical Formation of a Pt/Zn Alloy and Its Use as a Catalysts for Oxygen Reduction Reaction in Fuel Cells. J. Phys. Chem. B., v. 110, p. 8715-8722, 2006.

[18] STAMENKOVICS, V. R.; FOWLER, B.; MUN, B. S.; WANG, G.; ROSS, P. N.; LUCAS, C. A.; MARKOVIC, N. M. Improved Oxygen Reduction Activity on Pt3Ni(111) via Increased Surface Site Availability. Science, v. 315, p. 493-497, 2007. 
[19] LUO, J.; KARIUKI, N.; HAN, L.; WANG, L.; ZHONG, C.-J.; HE, T. Preparation and characterization of carbon-supported PtVFe electrocatalysts. Electrochim. Acta, v. 51, p. 4821-4827, 2006.

[20] LIMA, F. H. B.; LIZCANO-VALBUENA, W. H.; TEIXEIRA-NETO, E.; NART, F. C.; GONZALEZ, E. R.; TICIANELLI, E. A. Pt-Co/C nanoparticles as electrocatalysts for oxygen reduction in $\mathrm{H} 2 \mathrm{SO} 4$ and $\mathrm{H} 2 \mathrm{SO} 4 / \mathrm{CH} 3 \mathrm{OH}$ electrolytes. Electrochim. Acta, v. 52 , p. 385-393, 2006.

[21] SANTOS, L. G. R. A.; OLIVEIRA, C. H. F, MORAES, I. R.; TICIANELLI, E. A. Oxygen reduction reaction in acid médium on $\mathrm{Pt}-\mathrm{Ni} / \mathrm{C}$ prepared by a microemulsion method. J. Electroanal. Chem., v. 596, p. 141-148, 2006.

[22] TELISKA, M.; MURTHI, V. S.; MUKERJEE, S.; RAMAKER, D. E. J. Electrochem. Soc., v. 152, n. 11, p. 2159-2169, 2005.

[23] YANO, H.; KATAOKA, M.; YAMASHITA, H.; UCHIDA, H.; WATANABE, M. Oxygen Reduction Activity of Carbon-Supported Pt-M (M = V, Ni, Cr, Co and Fe) Alloys Prepared by Nanocapsule Method. Langmuir, v. 23, p. 6438-6445, 2007.

[24] TODA, T.; IGARASHI, H.; WATANABE, M. Enhancement of the electrocatalytic $\mathrm{O}_{2}$ reduction on Pt-Fe alloys. J. Electroanal. Chem. , v. 460, p. 258-162, 1999.

[25] MIN, M. K.; CHO, J. H.; CHO, K.; KIM, H. Particle size and alloying effects of Ptbased alloy catalysts for fuel cell applications. Electrochim. Acta., v. 45, p. 4211-4217, 2000.

[26] PAULUS, U. A.; WOKAUN, A.; SHERER, G. G.; SCHMIDT, T. J.;

STAMENKOVIC, V.; MARKOVIC, N. M.; ROSS, P. N. Oxygen reduction on high surface area Pt-based alloy catalysts in comparison to well defined smooth bulk alloy electrodes. Electrochim. Acta., v. 47, p. 3787-3798, 2002.

[27] STAMENKOVIC, V.; SCHIMDT, T. J.; ROSS, P. N.; MARKOVIC, N. M. Surface composition effects in electrocatalysis: Kinetics of oxygen reduction on well-defined $\mathrm{Pt}_{3} \mathrm{Ni}$ and $\mathrm{Pt}_{3} \mathrm{Co}$ alloy surfaces. J. Phys. Chem. B., v. 106, p. 11970-11979, 2002. 
[28] XIONG, L.; KANNAN, A. M.; MANTHIRAM, A. Pt-M (M = Fe, Co, Ni and Cu) electrocatalysts synthesized by an aqueous route for proton exchange membrane fuel cells. Electrochem. Comm., v. 4, p. 898-903, 2002.

[29] ANTOLINI, E.; PASSOS, R. R.; TICIANELLI, E. A. Electrocatalysis of oxygen reduction on a carbon supported platinum-vanadium alloy in polymer electrolyte fuel cells. Electrochim. Acta., v. 48, p. 263-270, 2002.

[30] MURTHI, V. S.; URIAN, R. C.; MUKERJEE, S. Oxygen Reduction Kinetics in Low and Medium Temperature Acid Envivronment: Correlation of Water Activation and Surface Properties in Supported Pt and Pt Alloys Electrocatalysts. J. Phys. Chem B., v. 108, p. 11011-11023, 2004.

[31] DAMJANOVIC, A.; BRUSIC, V.; BOCKRIS, J. O`M. Mechanism of oxygen reduction related to electronic structure of gold-palladium alloy. J. Phys. Chem., v. 71, p. 2471, 1967.

[32] CLOUSER, S. J.; HUANG, J. C.; YEAGER, E. Temperature-dependence of the Tafel slope for oxygen reduction on platinum in concentrated phosphoric-acid. J. Appl. Electrochem., v. 23, p. 597-605, 1993.

[33] RAO, M. L. B.; DAMJANOVIC, A.; BOCKRIS, J. O’M. Oxygen reduction adsorption related to unpaired d-electrons in transition metals. J. Phys. Chem., v. 67, p. 2508-2509, 1963.

[34] BOCKRIS, J. O’M.; DAMJANOVIC, A.; McHARDY, J. In: Third International Symposium on Fuel Cells (Troisiemes Journees Internationales D'etudes des Piles a Combustible), 1969, Brussels. Proceedings of a conference held under joint sponsorship of SERAI and COMASCI. Brussels, Presses Academiques Europeennes, June 16-20, 1969, p. 15-16.

[35] APPLEBY, A. J. Electrocatalysts and fuel cells. Catal. Rev., v. 4, p. 221 - 222, 1970.

[36] JALAN, V.; TAYLOR, J. Importance of interatomic spacing in catalytic reduction of oxygen in phosphoric-acid. J. Electrochem. Soc., v. 130, p. 2299-2301, 1983. 
[37] MUKERJEE, S.; SRINIVASAN, S. Enhanced electrocatalysis of oxygen reduction on platinum alloys in proton-exchange membrane fuel cells. J. Electroanal. Chem., v. 357, p. 201-224, 1993.

[38] GLASS, J. T.; CAHEN, G. L.; STONER, G. E. TAYLOR, E. J. The effect of metallurgical variables on the electrocatalytic properties of $\mathrm{PtCr}$ alloys. J. Electrochem. Soc., v. 134, p. 58-65, 1987.

[39] ARICO, A. S.; SHUKLA, A. K.; KIM, H.; PARK, S.; MIN, M.; ANTONUCCI, V. An XPS study on oxidation states of $\mathrm{Pt}$ and its alloys with $\mathrm{Co}$ and $\mathrm{Cr}$ and its relevance to electroreduction of oxygen. Appl. Surf. Sci., v. 172, p. 33-40, 2001.

[40] XIONG, L.; MANTHIRAM, A. Influence of atomic ordering on the electrocatalytic activity of Pt-Co alloys in alkaline electrolyte and proton exchange membrane fuel cells. J. Mater. Chem., v. 14, n. 9, p. 1454-1460, 2004.

[41] WATANABE, M.; TSURUMI, K.; MIZUKAMI, T.; NAKAMURA, T.; STONEHART, P. Activity and stability of ordered and disordered Pt-Co Alloys for phosphoric-acid fuel cells. J. Electrochem. Soc., v. 141, n.10, p. 2659-2668, 1994.

[42] WEI, Z.; GUO, H.; TANG, Z. Heat treatment of carbon-based powders carrying platinum alloy catalysts for oxygen reduction: influence on corrosion resistance and particle size. J. Power Sources, v. 62, p. 233-236, 1996.

[43] HAMMER, B.; NØRSKOV, J. K. Theoretical surface science and catalysis Calculations and concepts. Adv. Catal., v. 45 p. 71-129, 2000.

[44] GREELEY, J.; NØRSKOV, J. K.; MAVRIKAKIS, M. Electronic structure and catalysis on metal surfaces. Annu. Rev. Phys. Chem., v. 53, p. 319-348, 2002.

[45] MAVRIKAKIS, M.; HAMMER, B.; NØRSKOV, J. K. Effect of strain on the reactivity of metal surfaces. Phys. Rev. Lett., v. 81, p. 2819-2822, 1998.

[46] HAMMER, B.; NØRSKOV, J. K. Theoretical surface science and catalysis Calculations and concepts. Adv. Catal., v. 45 p. 71-129, 2000. 
[47] KITCHIN, J. R.; NØRSKOV, J. K.; BARTEAU, M. A.; CHEN, G. Modification of the surface electronic and chemical properties of $\mathrm{Pt}(111)$ by subsurface $3 \mathrm{~d}$ transition metals. J. Chem Phys., v. 120, p. 10240-10246, 2004.

[48] ZHANG J.; MO Y.; VUKIMIROVIC M. B.; KLIE R.; SASAKI K.; ADZIC R. R. Platinum monolayer electrocatalysts for O-2 reduction: Pt monolayer on $\mathrm{Pd}(111)$ and on carbon-supported Pd nanoparticles. J. Phys. Chem. B., v. 108, p. 10955-10964, 2004.

[49] WEST, A. R. Solid state chemistry and its applications. New York: Wiley, 1984.

[50] TOLENTINO, H.; CEZAR, J. C.; CRUZ, D. Z.; COMPAGNON-CAILLOL, V.; TAMURA, E; ALVES, M. C. J. Commissioning and first results of the LNLS XAFS beamline. J. Synchrotron Radiat., v. 5, p. 521-523, 1998).

[51] RESSLER, T. WinXAS: A New software package not only for the analysis of energy-dispersive XAS data. Part 1. J. Phys. IV., v. 7, p. 269-270, 1997.

[52] PANDYA, K. I.; ROFFMAN, R. W.; MCBREEN, J.; GRADY, W. E. O’. In situ Xray absorption spectroscopic studies of nickel-oxide electrodes. J. Electrochem. Soc., v. 137, p. 383-388, 1990.

[53] ZON, J. B. A. D. VAN; KONINGSBERGER, D. C.; VAN'T BLIK, H. F. J.;

SAYERS, D. E. An EXAFS study of the structure of the metal-support interface in highly dispersed $\mathrm{Rh} / \mathrm{Al}_{2} \mathrm{O}_{3}$ catalysts. J. Chem. Phys., v. 82, p. 5742-5754, 1985.

[54] HAMANN, C. H.; HAMNETT, A.; VIELSTICH, W. Methods for the Study of the Electrode/Electrolyte Interface. In: Electrochemistry. New York: Wiley-VCH, 1998. p. 218-219.

[55] PINHEIRO, A. L. N.; NETO, A. O.; SOUZA, E. C.; PEREZ, J.; PAGANIN, V. A.; TICIANELLI, E. A.; GONZALEZ, E. R. Electrocatalysis on noble metal and noble metal alloys dispersed on high surface area carbon. J. New Mat. Electrochem. Systems, v. 6, p. 1-8, 2003.

[56] PAULUS, U. A.; SCHIMIDT, T. J.; GASTEIGER, H. A.; BEHM, R. J. Oxygen reduction on a high-surface area Pt/Vulcan carbon catalyst: a thin-film rotating ring-disk electrode study. J. Electroanal. Chem., v.495, p.134-145, 2001. 
[57] BARD, A.; FAULKINER, L. Kinetics of electrode reactions. In: Electrochemical Methods Fundamentals and Applications. New York: John Wiley, 2001. p.100-105.

[58] DURÓN, S.; RIVERA-NORIEGA, R.; NKENG, P.; POILLERAT, G.; SOLORZAFERIA, O. Kinetic study of oxygen reduction on nanoparticles of ruthenium synthesized by pyrolysis of $\mathrm{Ru}_{3}(\mathrm{CO})_{12}$. J. Electroanal. Chem., v. 566, p. 281-289, 2004.

[59] ANTOINE, O.; DURAND, R. RRDE study os oxygen reduction on Pt nanoparticles inside Nafion ${ }^{\circledR}: \mathrm{H}_{2} \mathrm{O}_{2}$ production in PEMFC cathode conditions. J. Appl. Electrochem., v. 30, p. 839-845, 2000.

[60] INABA, M.; YAMADA H.; TOKUNAGA, J.; TASAKA, A. Electrochemical and Solid State Letters, 2004, v. 7, p.474.

[61] MCBREEN, J.; MUKERJEE, S. In situ x-ray absorption studies of a Pt-Ru Electrocatalyst. J. Electrochem. Soc., v. 142, p. 3399-3404, 1995.

[62] LIMA, F. H. B; GIZ, M. J; TICIANELLI, E. A. Electrochemical Performance of Dispersed Pt-M ( $\mathrm{M}=\mathrm{V}, \mathrm{Cr}$ and $\mathrm{Co})$ Nanoparticles for the Oxygen Reduction Electrocatalysis. J. Braz. Chem. Soc., v. 16, n. 3A, p. 328-336, 2005.

[63] PRABHURAM, J.; ZHAO, T. S.; WONG, C. W.; GUO, J. W. Synthesis and physical/electrochemical characterization of $\mathrm{Pt} / \mathrm{C}$ nanocatalyst for polymer electrolyte fuel cells. J. Power Sources, v. 134, p. 1-6, 2004.

[64] LIMA, F. H. B.; SALGADO, J. R. C.; GONZALEZ, E. R.; TICIANELLI, E. A. Electrocatalytic properties of $\mathrm{PtCo} / \mathrm{C}$ and $\mathrm{PtNi} / \mathrm{C}$ alloys for the oxygen reduction reaction in alkaline solution. J. Electrochem. Soc., v. 154, p. 369-375, 2007.

[65] STAMENKOVIC, V. R.; MUN, B. S.; ARENZ, M.; MAYRHOFER, K. J. J.; LUCAS, C. A.; WANG, G.; ROSS, P. N.; MARKOVIC, N. M. Trends in electrocatalysis on extended and nanoscale Pt-bimetallic alloy surfaces. Nature Materials., v. 6, p. 241247, 2007. 